\author{
This electronic thesis or dissertation has been \\ downloaded from the King's Research Portal at \\ https://kclpure.kcl.ac.uk/portal/
}

\title{
Targeting DNA damage and repair mechanism in FLT3-ITD acute myeloid leukemia - a mechanistic and therapeutic study
}

$\mathrm{Ng}, \mathrm{Ka} \mathrm{Lam}$

Awarding institution:

King's College London

The copyright of this thesis rests with the author and no quotation from it or information derived from it may be published without proper acknowledgement.

\section{END USER LICENCE AGREEMENT}

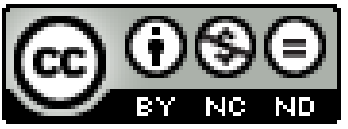

Unless another licence is stated on the immediately following page this work is licensed

under a Creative Commons Attribution-NonCommercial-NoDerivatives 4.0 International

licence. https://creativecommons.org/licenses/by-nc-nd/4.0/

You are free to copy, distribute and transmit the work

Under the following conditions:

- $\quad$ Attribution: You must attribute the work in the manner specified by the author (but not in any way that suggests that they endorse you or your use of the work).

- $\quad$ Non Commercial: You may not use this work for commercial purposes.

- $\quad$ No Derivative Works - You may not alter, transform, or build upon this work.

Any of these conditions can be waived if you receive permission from the author. Your fair dealings and other rights are in no way affected by the above.

Take down policy

If you believe that this document breaches copyright please contact librarypure@kcl.ac.uk providing details, and we will remove access to the work immediately and investigate your claim. 


\title{
TARGETING DNA DAMAGE AND REPAIR MECHANISM IN FLT3-ITD ACUTE MYELOID LEUKEMIA - A MECHANISTIC AND THERAPEUTIC STUDY
}

\author{
NG, KA LAM
}

Ph.D. THESIS

KING'S COLLEGE LONDON

DECEMBER 2018 


\author{
Abstract of thesis entitled \\ Targeting DNA damage and repair mechanism in FLT3-ITD acute myeloid \\ leukemia - a mechanistic and therapeutic study \\ Submitted by \\ NG, Ka Lam \\ for the Degree of Doctor of Philosophy \\ at King's College London
}

December 2018

Internal tandem duplication (ITD) of fms-like tyrosine kinase 3 (FLT3) is one of the most common mutations in acute myeloid leukemia (AML), occurring in nearly $30 \%$ of cases. FLT3-ITD involves in-frame duplication of 3-400 base-pairs at the juxtamembrane, resulting in ligand-independent activation of FLT3 signaling. Downstream effectors include activation of STAT5 via SRC kinase, phosphorylation of FOXO3A, down-regulation of the equilibrative nucleoside transporter 1 (ENT1) for cytarabine, and induction of reactive oxygen species (ROS) production. These aberrant signals result in increased DNA damage and defective repair, increased cellular proliferation and resistance to apoptosis.

Induction of ROS and DNA damage in FLT3-ITD AML has led to investigation of their mechanistic link and exploration of potential therapeutic targets. By examining gene expression associated with DNA repair in primary AML samples, BRCA2 expression was shown to be down-regulated in FLT3-ITD AML when compared with AML with wild-type FLT3 as well as normal hematopoietic cells. BRCA2 is an important protein in mediating homologous recombination (HR), providing a possible explanation for defective DNA damage response (DDR) in this AML subtype. A 
double-stranded break (DSB) DNA repair assay was used to measure the fidelity of DSB repair, either via error-free HR or error-prone non-homologous end joining (NHEJ). The results showed that $\mathrm{HR}$ was down-regulated in murine $\mathrm{Ba} / \mathrm{F} 3$ cells transduced with FLT3-ITD while NHEJ remained active.

DDR pathway as a target for therapeutic intervention in human cancers is exemplified by the use of poly (ADP-ribose) polymerase (PARP) inhibitor (PARPi) in $B R C A$ mutant breast and ovarian cancers. In Ba/F3 FLT3-ITD cells and knockin Flt3 ${ }^{\text {ITD/+ }}$ $N p m 1^{c /+}$ mouse leukemic cells, PARPi Olaparib suppressed leukemia growth in vitro. Combination of chemotherapy and Olaparib worked synergistically to eradicate leukemic cells in MOLM-13 murine xenograft model. Biochemically, Olaparib inhibited base excision repair and increased the DSB damage. Olaparib also increased intracellular ROS, resulting in positive feedback that accentuated DNA damage. To identify potential therapeutic targets that may be exploited in combination treatment with Olaparib, a DDR $\operatorname{shNA}$ library screening was performed. Potential candidate genes included those associated with checkpoint factors and DNA replication factors, for instance, Atr kinase and members of the Family B DNA Polymerase.

In summary, FLT3-ITD AML showed defective HR and higher levels of intracellular ROS and DSB, and Olaparib induced genomic instability and apoptosis. Targeting defective DNA repair in FLT3-ITD AML using PARPi might be considered as a novel therapeutic strategy. 


\section{Declaration}

I declare that this thesis represents my own work, except where due acknowledgement is made, and that has not been previously included in a thesis, dissertation or report submitted to this University or to any other institution for a degree, diploma or other qualifications.

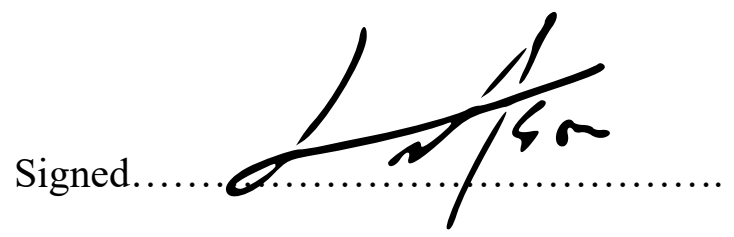

NG, Ka Lam 


\section{Acknowledgements}

I would like to express my sincerest gratitude to my supervisors, Prof. Anskar Y. H. Leung and Prof. Eric C. W. So. It has been a value experience to learn the perspectives and importance of leukemia research from clinical and basic science studies.

I would like to thank my dearest friends and labmates in HKU: Dr. Alvin Ma, Dr. Himm Man, Dr. Alex He, Dr. Yuhan Guo, Dr. Xiangguo Shi, Dr. Christa Ho, Dr. Eric Ho, Dr. Stephen Lam, Dr. Qingyun Wu, Dr. Ning Yang, Dr. Wan Liu, Miss Chae yin Cher, Mr. Harry Wong, Miss Toni Man, Miss Bowie Cheng, Mr. Leo Kan, Mr. Siyang Wang, Miss Lulu Wang, and friends and labmates in KCL: Dr. Bernd Zeisig, Miss Amanda Wilson, Dr. Michael Cheung, Dr. Tsz Kan Fung, Dr. Priscilla Lau, Dr. Rick Kong, Dr. Jackie Chen, Dr. Marco Saia, Dr. Lu Zhao, Dr. Jennifer Lynch, Dr. Haoli Li, Dr. Yongrang Kim, Dr. Bohan Stanojevic, Mr. Ray Tsai, Miss Siyi Zhang, Miss Claire Lynn and Mr. Mickey Wong for their continuous support and inspiration. In particular, my sincere thanks to Miss Claire Lynn for her help with bioinformatics analysis of the $\operatorname{sh} R N A$ screening.

I would like to thank Dr. Jerome Tamburini (Institut Cochin, Université Paris Descartes, Paris, France) for providing the Ba/F3 FLT3-ITD cell line, Dr. Johannes Zuber's group (Research Institute of Molecular Pathology, Vienna) for sharing their latest protocol on shRNA library screening and Dr. George S Vassiliou (Sanger Institute, UK) for providing the Flt3 ${ }^{I T D /+} x \mathrm{Npm}^{c /+}$ leukemic cells.

Last but not least, I would like to express my deepest gratitude to my family and friends for their continuous support and encouragement. 


\section{List of Publications and Award}

Publications with my contribution during the $\mathrm{PhD}$ study:

1. Man, C. H., Fung, T. K., Wan, H., Cher, C. Y., Fan, A., Ng, N., Ho, C., Wan, T. S., Tanaka, T., So, C. W., Kwong, Y. L. \& Leung, A. Y. Suppression of SOX7 by DNA methylation and its tumor suppressor function in acute myeloid leukemia. Blood 125, 3928-3936, doi:10.1182/blood-2014-06-580993 (2015).

2. Hou, J., Luo, T., Ng, K. L., Liang, R., Leung, A. Y. \& Sun, D. Characterization of drug effect on leukemia cells through single cell assay with optical tweezers and dielectrophoresis. IEEE Trans Nanobioscience, doi:10.1109/TNB.2016.2616160 (2016).

3. Lam, S. S., Ho, E. S., He, B. L., Wong, W. W., Cher, C. Y., Ng, N. K., Man, C. H., Gill, H., Cheung, A. M., Ip, H. W., So, C. C., Tamburini, J., So, C. W., Ho, D. N., Au, C. H., Chan, T. L., Ma, E. S., Liang, R., Kwong, Y. L. \& Leung, A. Y. Homoharringtonine (omacetaxine mepesuccinate) as an adjunct for FLT3-ITD acute myeloid leukemia. Sci Transl Med 8, 359ra129, doi:10.1126/scitranslmed.aaf3735 (2016).

Awards:

1. Poster presentation award, Cancer Studies PhD symposium 2017, Kings College London 


\section{List of Figures}

Figure 1.1 Examples of DNA damage response pathways in mammalian cells. ..................................

Figure 1.2. DSB repair pathways in mammalian cells. ................................................................. 4

Figure 1.3 A schematic diagram of the human FLT3 receptor tyrosine kinase. .................................. 9

Figure 1.4 A schematic diagram showing downstream signaling that occurred upon activation of

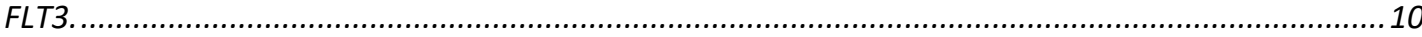

Figure 1.5 A schematic diagram showing the reported mechanism of elevated intracellular ROS via

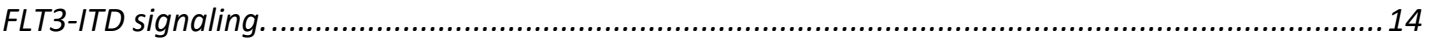

Figure 4.1 Gene expression profile of DNA repair genes in primary AML patients. ...........................229

Figure 4.2 BRCA2 expression profile from GSE15434......................................................................3 30

Figure 4.3 BRCA2 expression of human $A M L$ cell lines. .................................................................. 31

Figure 4.4 Gene expression profile of DNA repair genes in human AML cell lines after treatment of

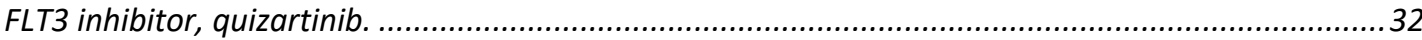

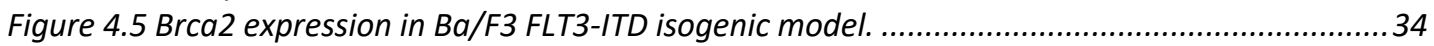

Figure 4.6 Principle of the Traffic Light Reporter (TLR) assay. .........................................................36

Figure 4.7 Representative flow plot of the TLR reporter assay. .......................................................37

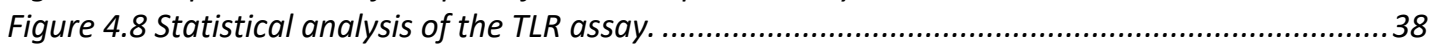

Figure 5.1 Cell proliferation assay of inhibitors targeting DNA repair proteins. ................................ 40

Figure 5.2 Analysis of $\gamma-H 2 A X$ level in Ba/F3 FLT3-ITD cells treated with Olaparib by immunoblot

analysis and immunofluorescence microscopy.........................................................................4 43

Figure 5.3 Diagrammatic illustration of neutral comet assay analysis using OpenComet Software. .. 44

Figure 5.4 Neutral comet assay in Ba/F3 FLT3-ITD cells treated with Olaparib................................45

Figure 5.5 Intracellular ROS measurement of Ba/F3 FLT3-ITD cells treated with Olaparib. ................47

Figure 5.6 In vivo drug treatment of Olaparib and chemotherapy in MOLM-13 xenograft model...... 48

Figure 6.1 Construction of mouse DDR shRNA library..................................................................50

Figure 6.2 Immunophenotype analysis of leukemic mice transplanted with spleen cells recovered

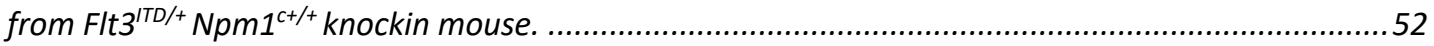

Figure 6.3 Immunophenotype analysis of primary murine Flt3 ${ }^{I T D /+} \mathrm{Npm} 1^{c /+}$ cell line.........................53

Figure 6.4 Colony formation assay of leukemic cells of MLL-AF9 or Flt3 ${ }^{\text {ITD/+ }} \mathrm{Npm} 1^{\text {c/+ }}$ treated with

Olaparib for 5 days in methyl cellulose. .......................................................................................5

Figure 6.5 Experimental scheme of in vivo shRNA library screening .................................................55

Figure 6.6 Information of DNA sample for Miseq. ........................................................................5 57

Figure 6.7 FASTQC plot of the Miseq sequencing run. .....................................................................58

Figure 6.8 Alignment result of Miseq run to unique hairpin sequences. .........................................59

Figure 6.9 Overall distribution of probability of gene dropout in the shRNA screen.........................61

Figure 6.10 Distribution of unique hairpin dropouts. .................................................................6 62

Figure 6.11 Pie chart of overall distribution of dropout genes categorized by their role in DNA

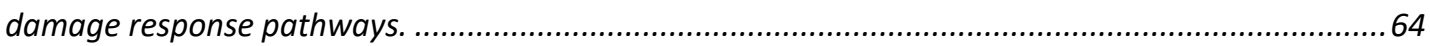

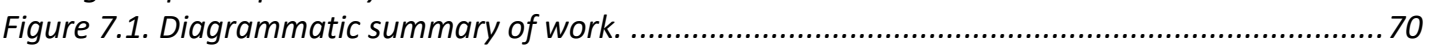




\section{Appendix}

Appendix 1 Culture conditions of human AML cell lines. ............................................................. 71

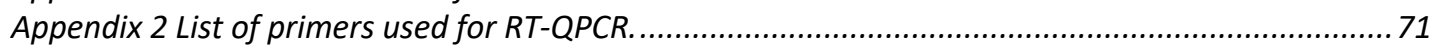

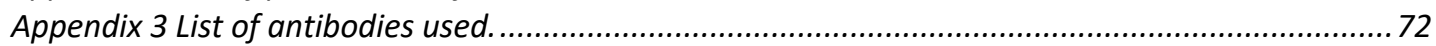

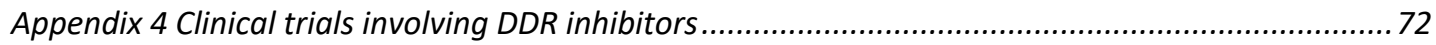

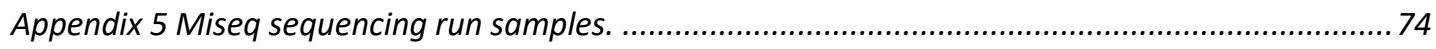

Appendix 6 Candidate dropout gene list specific to Olaparib treatment.......................................... 75

Appendix 7 Dropout probability of important DDR genes in the screening ....................................... 76 


\section{List of abbreviations}

\begin{tabular}{|c|c|}
\hline Abbreviation & Full name \\
\hline $2 \mathrm{HG}$ & D-2-hydroxyglutarate \\
\hline 8-OHdG & 8-hydroxy-2'-deoxyguanosine \\
\hline 8-oxoG & 8-hydroxyguanine \\
\hline $\mathrm{a}-\mathrm{KG}$ & alpha-ketoglutarate \\
\hline Alt-NHEJ & alternative nonhomologous end-joining \\
\hline AML & acute myeloid leukemia \\
\hline APL & acute promyelocytic leukemia \\
\hline ATM & ataxia telangiectasia mutated \\
\hline Atr & ATM and rad3-related \\
\hline BER & base excision repair \\
\hline $\mathrm{BM}$ & bone marrow \\
\hline cDNA & complementary DNA \\
\hline $\mathrm{CG}$ & cytogenetic \\
\hline ChIP & chromatin immunoprecipitation \\
\hline CML & chronic myelogenous leukemia \\
\hline CMML & chronic myelomonocytic leukemia \\
\hline D2HG & D-2-hydroxyglutarate \\
\hline DDR & DNA damage response \\
\hline dGFP & defective GFP \\
\hline Diff. & difference \\
\hline DMSO & dimethylsulfoxide \\
\hline DNA-PKcs & DNA-dependent protein kinase catalytic subunit \\
\hline $\mathrm{DR}$ & DNA repair \\
\hline DSB & double-stranded break \\
\hline DSBR & double stranded breaks repair \\
\hline ENT1 & equilibrative nucleoside transporter 1 \\
\hline FA & fanconi anemia \\
\hline FapyG & formamidopyrimidines \\
\hline FBS & fetal bovine serum \\
\hline FLT3 & fms-like tyrosine kinase 3 \\
\hline$\gamma-\mathrm{H} 2 \mathrm{AX}$ & gamma-H2AX \\
\hline H2DCFDA & 2'7'-dichlorodihydro-fluorecein diacetate \\
\hline HBSS & Hanks’ Balanced Salt Solution \\
\hline HR & homologous recombination \\
\hline HSCT & haematopoietic stem cell transplantation \\
\hline HSPC & hematopoietic stem and progenitor cells \\
\hline IDH1 & isocitrate dehydrogenase 1 \\
\hline$I D H 2$ & isocitrate dehydrogenase 2 \\
\hline ITD & Internal tandem duplication \\
\hline LIG3 & DNA ligase III $\alpha$ \\
\hline
\end{tabular}




\begin{tabular}{|c|c|}
\hline LSC & leukemia stem cell \\
\hline MDS & myelodysplastic syndrome \\
\hline MMEJ & microhomology-mediated end joining \\
\hline MMR & mismatch repair \\
\hline $\mathrm{MNC}$ & mononuclear cell \\
\hline MRE11 & meiotic recombination 11 homolog A \\
\hline MRN & MRE11/RAD50/NSB1 \\
\hline NAC & $\mathrm{N}$-acetyl cysteine \\
\hline NAPDH & nicotinamide adenine dinucleotide phosphate-oxidases \\
\hline NER & nucleotide excision repair \\
\hline NHEJ & non-homologous end joining \\
\hline NOX4 & NAPDH oxidase 4 \\
\hline NSG & NOD/SCID/IL2Rg ${ }^{-/-}$ \\
\hline Ola. & Olaparib \\
\hline ORF & open reading frame \\
\hline PARP & poly (ADP-ribose) polymerase \\
\hline PARPi & PARP inhibitor \\
\hline $\mathrm{PB}$ & peripheral blood \\
\hline PBSC & peripheral blood stem cell \\
\hline Pdrop & probability of hairpin dropout \\
\hline Pdrop of $\mathrm{O}-\mathrm{V}$ & $\begin{array}{l}\text { probability of hairpin dropout of Olaparib-treated } \\
\text { minus vehicle }\end{array}$ \\
\hline $\mathrm{pHi}$ & intracellular $\mathrm{pH}$ \\
\hline phox & phagocytic oxidase \\
\hline ROS & reactive oxygen species \\
\hline RTK & receptor tyrosine kinase \\
\hline SDS-PAGE & $\begin{array}{l}\text { sodium dodecyl sulfate polyacrylamide gel } \\
\text { electrophoresis }\end{array}$ \\
\hline SOP & standard operating procedure \\
\hline SSB & single-stranded break \\
\hline TKD & tyrosine kinase domain \\
\hline TLR & Traffic Light Reporter \\
\hline TLS & translesion repair \\
\hline TP53BP1 & p53-binding protein 1 \\
\hline Veh. & vehicle \\
\hline WB & Whole Blood \\
\hline WHO & World Health Organization \\
\hline
\end{tabular}




\section{Table of Contents}

Declaration ....................................................................................................... iv

Acknowledgements..............................................................................................

List of Publications and Award ....................................................................... vi

List of Figures.................................................................................................... vii

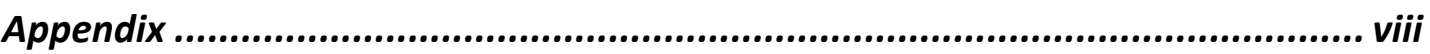

List of abbreviations ....................................................................................... ix

Chapter 1. Introduction .............................................................................. 1

1.1 Background of acute myeloid leukemia ................................................................. 1

1.2 Aberrant DNA damage repair mechanism in myeloid malignancies ........................ 2

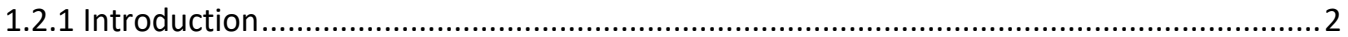

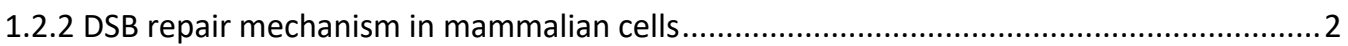

1.2.3 DNA repair defect in chronic myelogenous leukemia .......................................................

1.2.4 RAS are responsible for elevated ROS and DNA damage in myeloid malignancies..............6

1.2.5 IDH1/2 mutation impairs homologous recombination .....................................................

1.2.6 HR deregulation in translocations involving transcription factors ...................................

1.3 The role of internal tandem duplication of Fms-Like Tyrosine kinase 3 in AML ....... 8

1.3.1 Introduction to Fms-Like Tyrosine kinase 3 .................................................................. 8

1.3.2 Internal tandem duplication of Fms-Like Tyrosine kinase 3 ........................................ 11

1.3.3 Clinical strategies to prolong remission are lacking ...................................................11

1.4 Aberrant DNA damage response signaling in FLT3-ITD AML................................ 12

1.4.1 Elevated intracellular ROS is the cause of genomic instability in FLT3-ITD AML ...............12

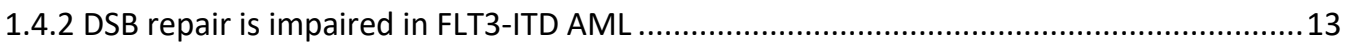

1.4.3 Targeting DNA repair defect in FLT3-ITD AML........................................................ 15

Chapter 2. Study Objectives ............................................................................ 16

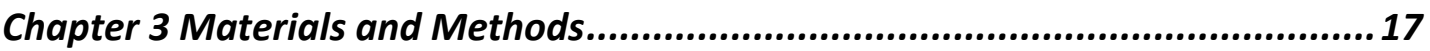

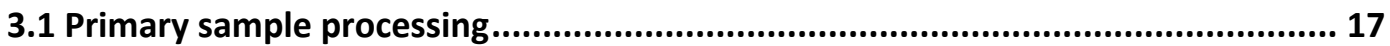

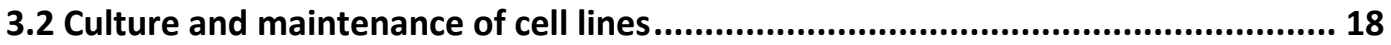

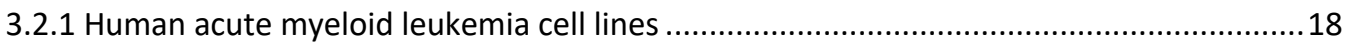

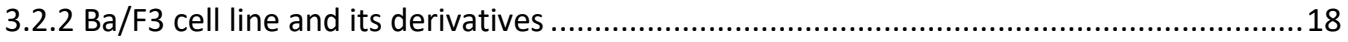

3.3 In vitro drug treatment...................................................................... 18

3.4 RNA extraction and reverse transcription polymerase chain reaction................. 19

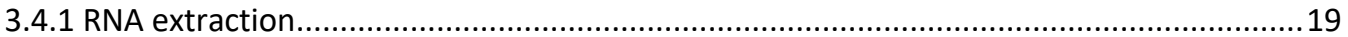

3.4.2 Reverse transcription polymerase chain reaction ...................................................20

3.5 Real-time quantitative PCR (RT-QPCR) .................................................... 20

3.6 Western Blot ............................................................................................. 20

3.7 Immunofluorescence Microscopy................................................................. 21

3.8 Neutral comet assay........................................................................... 21

3.9 General flow cytometry experiments .................................................. 22

3.9.1 Intracellular reactive oxidative species (ROS) level measurement..................................22

3.9.2 Immunophenotypic analysis of primary murine cells................................................22

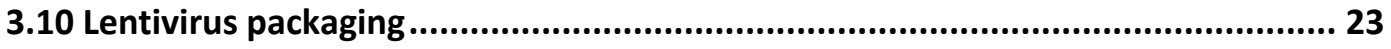


3.12 DNA damage response (DDR) shRNA library screening ......................................... 24

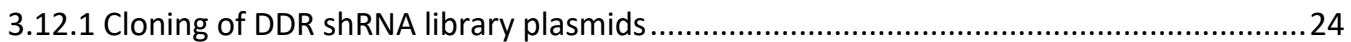

3.12.2 Experimental Scheme of DDR shRNA library screening...............................................2

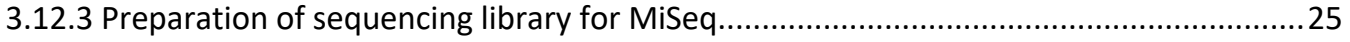

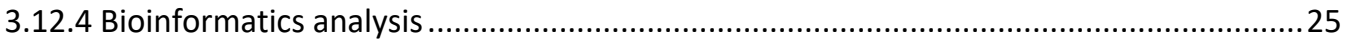

3.13 In vivo drug treatment of Olaparib and chemotherapy drugs in MOLM-13

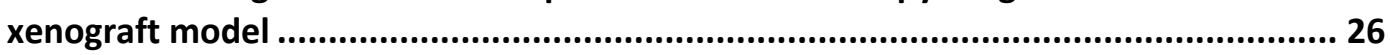

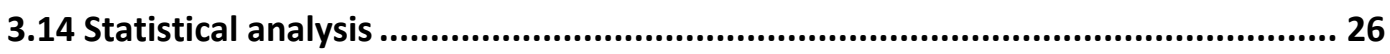

Chapter 4. Homologous recombination in FLT3-ITD AML was affected with possible mechanistic linkage to down-regulation of BRCA2 .............................27

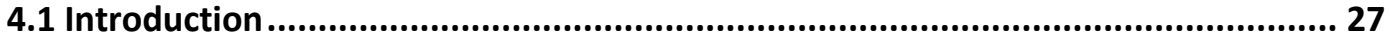

4.2 Down-regulation of BRCA2 in FLT3-ITD primary AML samples ........................... 27

4.3 FLT3-ITD signaling was responsible for the suppression of BRCA2 expression ........ 28

4.4 Homologous recombination activity was decreased in FLT3-ITD cells .................... 33

Chapter 5. Targeting FLT3-ITD AML with PARP inhibitor.................................39

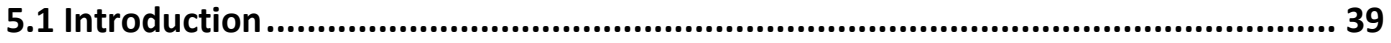

5.2 PARP inhibitors selectively targeted FLT3-ITD AML in vitro by cell proliferation assay.

5.3 FLT3-ITD cells showed higher basal level of double-stranded DNA breaks that was accentuated by Olaparib.................................................................................................. 41

5.4 Elevated ROS level modulated sensitivity of FLT3-ITD to PARP inhibitor ................ 46

5.5 Combination of PARP inhibitors and chemotherapy .............................................. 46

Chapter 6 Screening of synthetic lethal candidate of DDR genes with PARP inhibitors by shRNA library screen ............................................................49

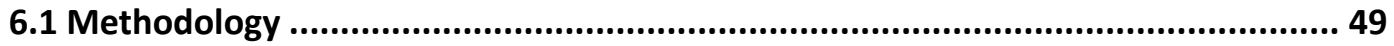

6.2 Characterization and generation of Flt3 $3^{I T D} \mathrm{Npm}^{1^{c+}}$ cell line ................................... 49

6.3 Experimental scheme of DDR shRNA screening in vivo ....................................... 51

6.4 Basic bioinformatics filtering of the MiSeq run ...................................................... 56

6.5 Dropout analysis of shRNA library screening .......................................................6 60

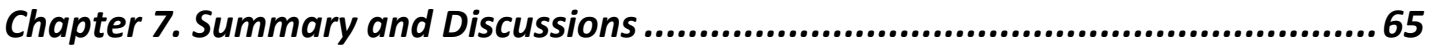

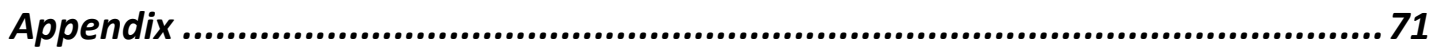

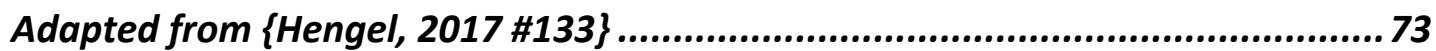

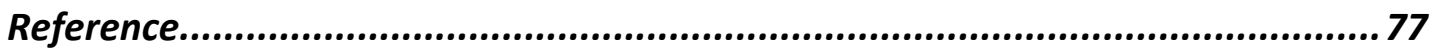




\section{Chapter 1. Introduction}

\subsection{Background of acute myeloid leukemia}

Acute myeloid leukemia (AML) is a heterogeneous group of diseases with diverse clinicopathologic features, cytogenetic (CG) abnormalities and genetic mutations, sharing in common an abnormal increase in myeloblasts in peripheral blood (PB) and bone marrow (BM) ${ }^{1}$. According to the World Health Organization (WHO) classification, diagnosis of AML is defined by the presence of more than $20 \%$ myeloblasts either in the $\mathrm{BM}$ or $\mathrm{PB}$, with the exception of $\mathrm{t}(8 ; 21)$, inv(16) and $\mathrm{t}(15 ; 17)$ in which the presence of specific CG abnormalities are sufficient for diagnosis ${ }^{2}$.

Despite the heterogeneity, treatment of AML has been uniform and unchanged in the past 4 decades ${ }^{3-6}$. Induction chemotherapy, known as the " $7+3$ " regimen, comprises concurrent treatment with cytarabine (day 1-7) and daunorubicin or equivalence (day 1-3). Following an initial remission (blasts $\leq 5 \%$ ), patients receive either consolidation chemotherapy (high dose cytarabine) or allogeneic haematopoietic stem cell transplantation (HSCT). However, disease relapse is a major cause of treatment failure and only $30-40 \%$ can survive long-term. For elderly patients unfit for conventional treatment, the outcome is dismal ${ }^{7}$. There is an urgent need to improve treatment outcome. 


\subsection{Aberrant DNA damage repair mechanism in mveloid}

\section{malignancies}

\subsubsection{Introduction}

Our genomic DNA is constantly exposed to genotoxic stress such as replication errors, reactive oxidative species (ROS) and ultraviolet radiation (Fig 1.1) ${ }^{8}$. Single-strand DNA breaks (SSB) are repaired by base excision repair (BER), nucleotide excision repair (NER) and mismatch repair (MMR) ${ }^{9}$. If unrepaired, SSB or crosslinks can induce replication fork collapse and result in double-stranded break (DSB) during DNA replication ${ }^{10-12}$. Cancer therapies such as ionization radiation, alkylating agents, topoisomerase II inhibitors or excessive ROS may also induce DSB ${ }^{13,14}$. DNA damage response (DDR) is strictly regulated to maintain genomic integrity and protect cells from genomic stress ${ }^{15}$. When DNA damage occurs, cells respond by an orchestrated network of signals that sense and repair the damage. At the same time, cell-cycle checkpoints are activated to allow time for DDR and avoid inadvertent replication of damaged DNA. If the damage is not repaired, these checkpoints can trigger cellular senescence or apoptosis ${ }^{16,17}$.

\subsubsection{DSB repair mechanism in mammalian cells}

Three major repair pathways of DSB have been described in mammals, viz. BRCAmediated error-free homologous recombination (HR), DNA-dependent protein kinase (DNA-PK)-mediated error-prone non-homologous end joining (NHEJ) and a less

characterized microhomology-mediated end joining (MMEJ) (Fig. 1.2) ${ }^{8,14,18}$. HR uses 
DNA Damaging agents

DNA lesions

Double strand breaks

lonizing radiation

X-ray

Chemotherapy

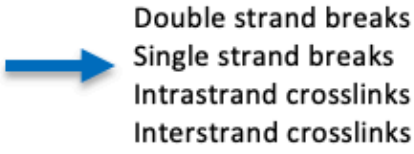

Bulky adducts

UV light

Oxygen radicals Alkylating agents

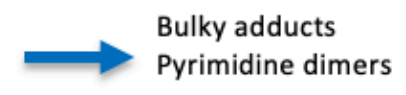

Single strand breaks

Abasic sites

8-oxoguanine lesions

Replication errors

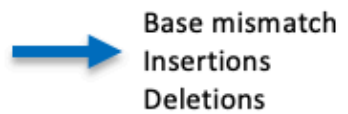
Deletions
DNA repair pathways

Fidelity

$\longrightarrow \begin{aligned} & \text { Non-homologous } \\ & \text { end-joining } \\ & \begin{array}{l}\text { Homologous } \\ \text { recombination }\end{array}\end{aligned}$

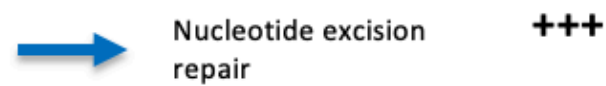

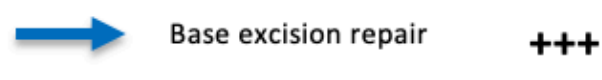

$\longrightarrow$ Mismatch repair

$+++$

Figure 1.1 Examples of DNA damage response pathways in mammalian cells.

DNA damage agents induce a spectrum of DNA lesions, which can be repaired by distinct and specific DNA repair pathways with various degrees of fidelity. The diagram is adapted from ${ }^{19}$. 


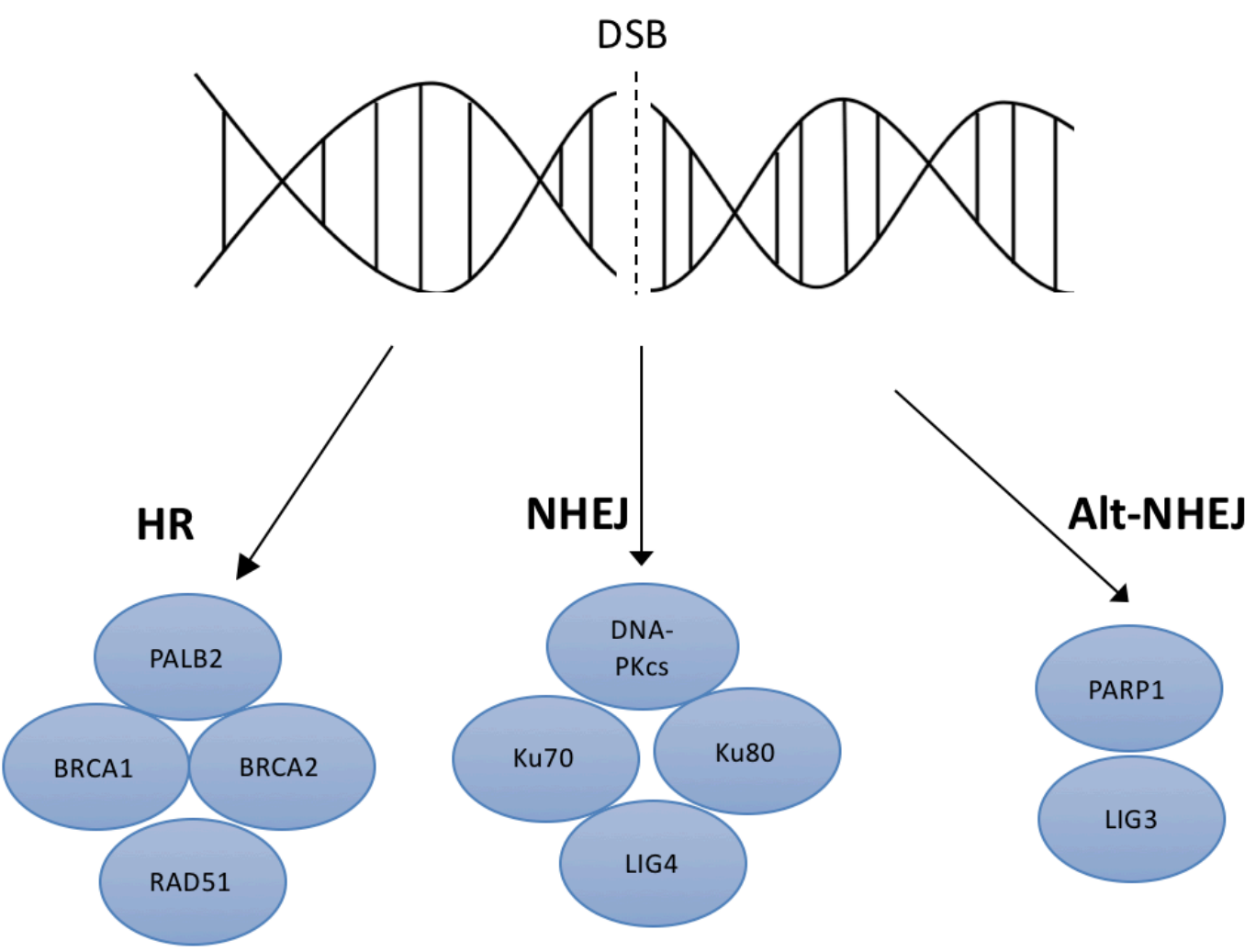

Figure 1.2. DSB repair pathways in mammalian cells.

DNA double-stranded breaks can be repaired by 3 major pathways, including homologous recombination (HR), non-homologous end joining (NHEJ) and alternative non-homologous end joining (Alt-NHEJ). Key components of these pathways are illustrated in the diagram. The diagram is adapted from ${ }^{20}$. 
sister chromatid as template for accurate DSB repair and is only active in proliferating cells during late S and G2 phases of cell cycle. NHEJ occurs throughout cell cycle but mostly during G1 in both proliferating and quiescent cells ${ }^{21}$. Emerging evidences demonstrate a PARP1-dependent and microhomology-mediated end joining (MMEJ), also known as alternative nonhomologous end joining (Alt-NHEJ) ${ }^{22}$. Mechanistically, MMEJ and HR share the same MRE11-dependent initial end resection step and both repair pathways occur during $\mathrm{S} / \mathrm{G} 2$ phase of cycle ${ }^{23}$.

DSBs are rapidly detected by the MRE11/RAD50/NSB1 (MRN) complex or the Ku70/80 complex, followed by phosphorylation and activation of the apical sensor kinases ataxia telangiectasia mutated (ATM) and DNA-dependent protein kinase catalytic subunit (DNA-PKc) respectively ${ }^{24}$. Activated apical sensor kinases phosphorylate the serine139 residue of histone variant gamma-H2AX $(\gamma-\mathrm{H} 2 \mathrm{AX})$ at the DSB site. Subsequently, DNA damage mediators are recruited, for instance, TP53binding protein 1 (TP53BP1) in NHEJ and BRCA1 in HR ${ }^{25,26}$. Defective DDR has been shown to play an important role in the pathogenesis of myeloid malignancies

driven by $B C R-A B L$ fusion and $N R A S$ activating mutations ${ }^{18,27-39}$ and more recently in AML carrying $I D H 1 / 2$ mutations and specific gene function arising from translocation $40-42$.

\subsubsection{DNA repair defect in chronic myelogenous leukemia}

Defective DDR has been reported in chronic myelogenous leukemia (CML) ${ }^{31,35,36}$. CML is caused by a balanced translocation between chromosome 9 and 22, resulting in the formation of oncogenic fusion protein $\mathrm{BCR}-\mathrm{ABL}^{36}$. The latter is a constitutively active tyrosine kinase that activates cell proliferation and protects them from apoptosis 
35. Recent reports showed that it also induced ROS production and caused DSB and genomic instability ${ }^{31-34}$. On the other hand, DDR by HR was defective in CML cells $27,28,33$. Mutation analysis of HR related proteins showed that half of them belonged to $\mathrm{G} / \mathrm{C} \rightarrow \mathrm{A} / \mathrm{T}$ transitions, suggesting oxidative DNA damage due to ROS ${ }^{43}$.

\subsubsection{RAS are responsible for elevated ROS and DNA damage in myeloid malignancies}

Activating NRAS and $K R A S$ mutations at codons 12, 13 and 61 have been shown to compromise its GTPase activity, leading to a constitutively active and GTP-bound state $^{38} . N-\& K-R A S$ mutations, mostly at codons 12 and 13 occur in $66 \%$ of chronic myelomonocytic leukemia (CMML) ${ }^{39}$ whereas $30 \%$ of AML carry NRAS mutations 38. Overexpression of $N R A S-G 12 D$ and $B C L 2$ driven by MRP8 promoter in a double transgenic mouse model led to increase in DNA damage and NHEJ repair errors ${ }^{37}$. RAC1, an essential component of the NADPH oxidase complex, was required for ROS production in the $N R A S / B C L 2$ mice. Mechanistically, RAC1 was a downstream target of RAS activation ${ }^{44}$. DSB and NHEJ repair error could be ameliorated by feeding the mice with anti-oxidant $\mathrm{N}$-acetyl cysteine (NAC), a scavenger of ROS, suggesting that the RAS/RAC1 pathways and ROS could be a therapeutic target for RAS mutated myeloid malignancies.

\subsubsection{IDH1/2 mutation impairs homologous recombination}

Isocitrate dehydrogenase 1 and $2(I D H 1 / 2)$ are frequently mutated in AML and myelodysplastic syndrome (MDS). Wild-type IDHs catalyze oxidative decarboxylation of isocitrate to alpha-ketoglutarate $(\alpha-K G)$ in citric acid cycle. Mutations of IDH1 at codon 132 and IDH2 at codon 140 and 172 conferred new 
substrate specificity and enzyme activity and the mutant enzymes converted $\alpha-K G$ to the oncometabolite D-2-hydroxyglutarate $(2 \mathrm{HG})^{45,46}$. The latter inhibited TET family proteins, thereby impeding DNA methylation ${ }^{45}$. In idh1-R132Q knockin mouse model, the mutant idh1 down-regulated Atm by altering histone methylation, impairing DNA repair via a TET2-independent pathway ${ }^{42}$. Recently, IDH1 R132H and $I D H 2 R 172 K$ knockin cell lines showed defective HR and increased sensitivity to PARP inhibitor (PARPi), reminiscent of synthetic lethality in $B R C A 1 / 2$ mutant breast and ovarian cancers ${ }^{40}$. The phenotype could be restored by inhibitors against mutant IDH1, proving the pathogenetic role of mutant IDH1/2 in defective DDR.

\subsubsection{HR deregulation in translocations involving transcription factors}

Chromosomal translocation resulting in fusion genes with aberrant transcription factor function is a common feature in AML ${ }^{1}$. RUNX1-RUNX1T1 and PML-RAR $\alpha$ fusion proteins have been shown to suppress expression of key HR-associated genes and hence defective $\mathrm{HR}^{41}$. Mouse leukemic cells carrying these fusions were sensitive to PARPi, in contrast to those carrying $M L L-A F 9$ fusion. Mechanistically, Hoxa9 that was downstream to MLL-AF9, activated expression of HR-associated genes. Pharmacological inhibition or genetic knockout of Hoxa9 gene impaired DDR and resensitized MLL-AF9 leukemic cells to PARPi. Moreover, combination of PARPi with DNMT inhibitors or chemotherapies showed significant anti-leukemic effects in both mouse and human leukemia cells carrying $M L L-A F 9$, providing important leads for clinical trials ${ }^{47}$. 


\subsection{The role of internal tandem duplication of Fms-Like Tyrosine}

\section{$\underline{\text { kinase } 3 \text { in AML }}$}

\subsubsection{Introduction to Fms-Like Tyrosine kinase 3}

Fms-like tyrosine kinase 3 (FLT3) encodes a 933-amino-acids class III receptor tyrosine kinase (RTK) and is located on chromosome 13q12, consisting of 24 exons 48,49. FLT3 is preferentially expressed in human CD34+ hematopoietic stem and progenitor cells (HSPC) where it provides signals for survival, proliferation and differentiation. The FLT3 receptor comprises i) five extracellular immunoglobulinlike domain for ligand binding and receptor dimerization in the N-terminus; ii) a transmembrane domain; iii) a juxtamembrane domain; and iv) two intracellular tyrosine kinase domains (TKD1 and TKD2) at the C-terminus (Fig. 1.3) ${ }^{50,51}$. FLT3 protein undergoes glycosylation in endoplasmic reticulum and Golgi apparatus to promote its translocation to the cell membrane ${ }^{52,53}$. Upon binding to its ligand, FLT3 undergoes dimerization, auto-phosphorylation and activation of the downstream effectors including PI3K (phosphoinositide-3-kinase), JAK-STAT and RAS pathways (Fig. 1.4) ${ }^{54-56}$. 


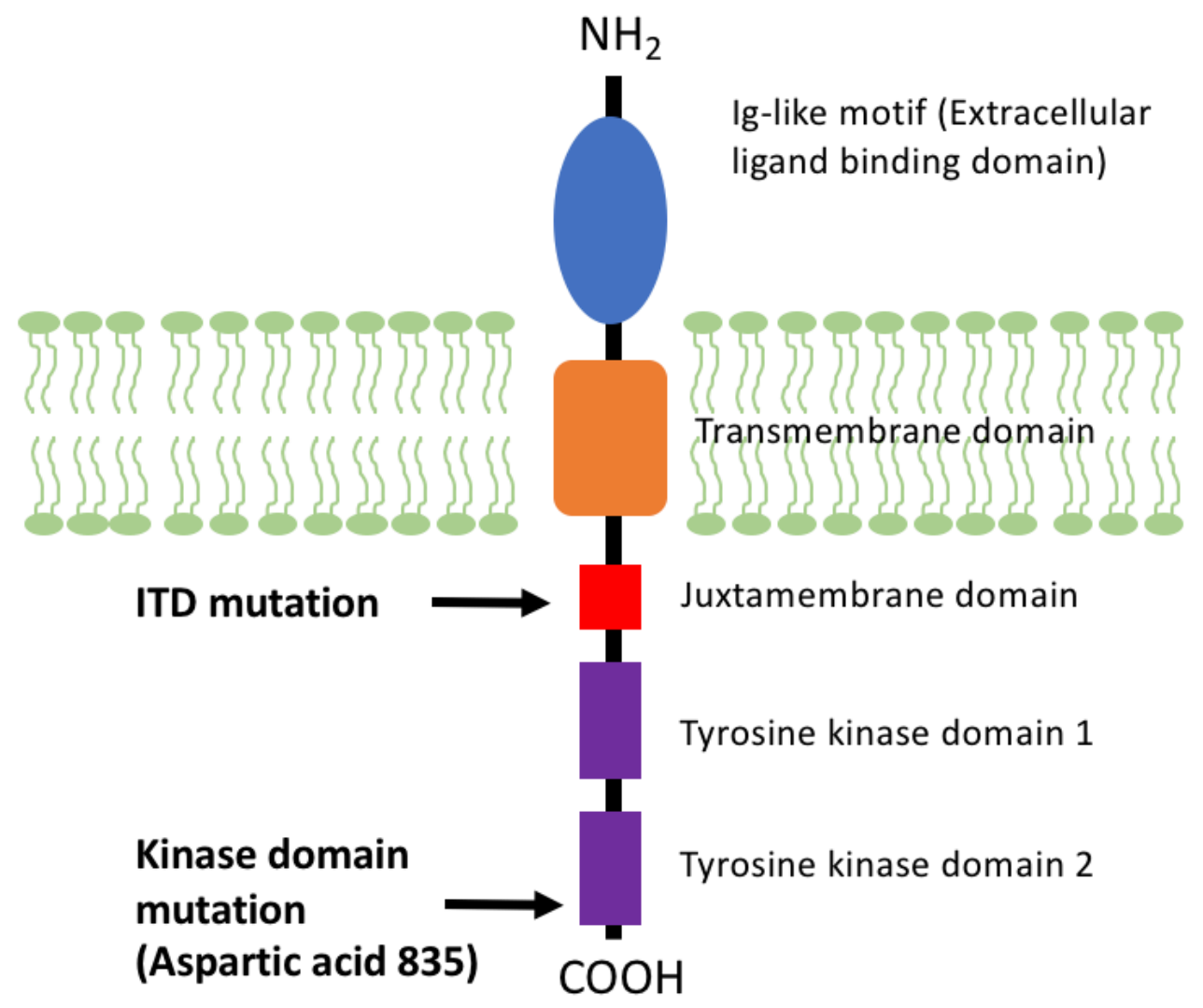

Figure 1.3 A schematic diagram of the human FLT3 receptor tyrosine kinase.

The positions of internal tandem duplication (ITD) mutation and tyrosine kinase domain (TKD) mutations are as indicated. 


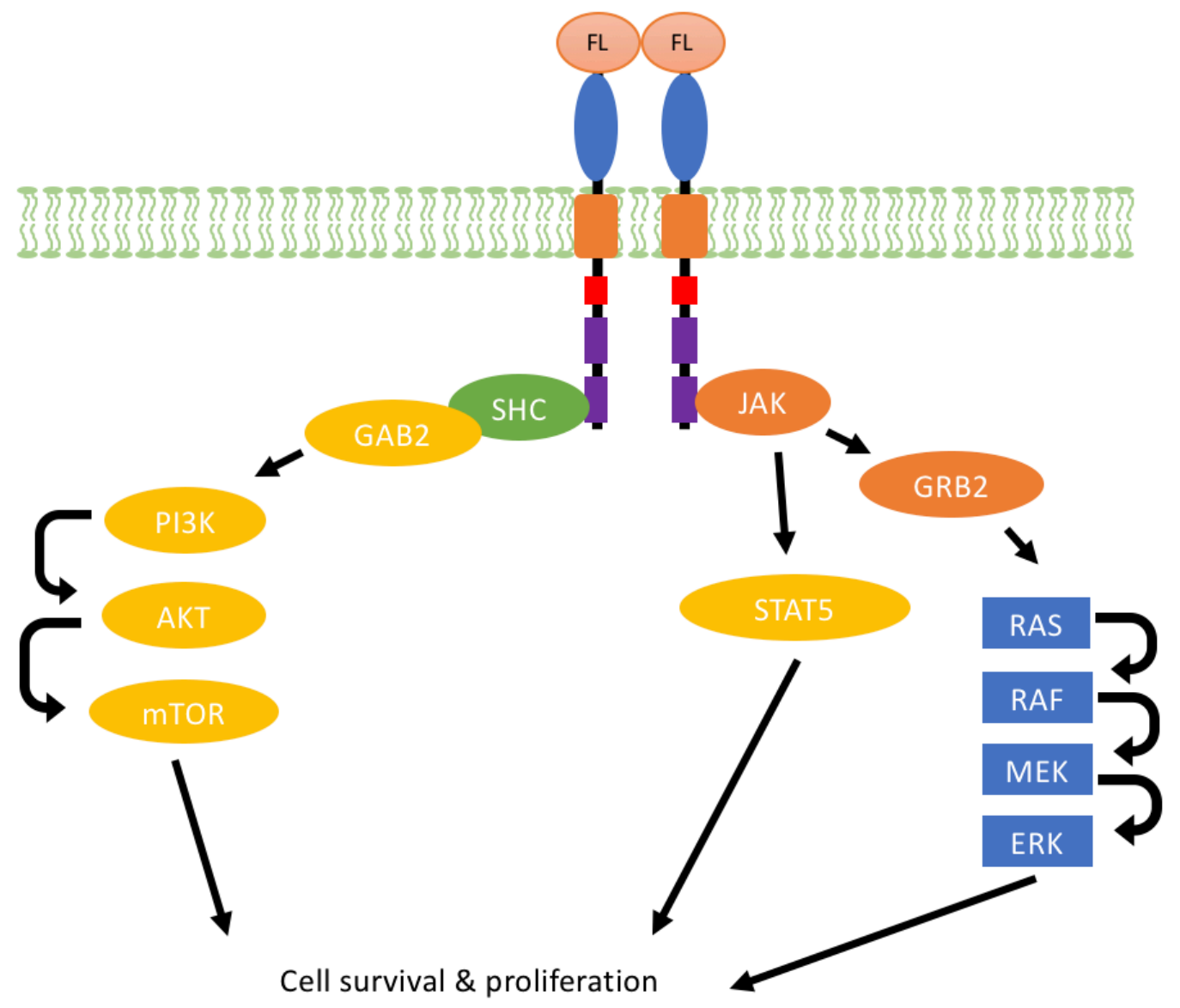

Figure 1.4 A schematic diagram showing downstream signaling that occurred upon activation of FLT3.

The binding of the FLT3 ligand (FL) to the receptor triggered the formation of FLT3 homodimer. The activation of FLT3 induced signal transduction via PI3K (phospatidylinositol-3-kinase), JAK-STAT and RAS pathways, resulting in enhanced cell survival and proliferation. 


\subsubsection{Internal tandem duplication of Fms-Like Tyrosine kinase 3}

Internal tandem duplication (ITD) of FLT3 is one of the most common mutations in AML, particularly in AML with normal cytogenetics, $t(6 ; 9)$ translocation and acute promyelocytic leukemia (APL) ${ }^{57}$. FLT3-ITD involves in-frame duplication of 3-400 base-pairs at the juxta-membrane or TKD1 domains, resulting in constitutive activation of FLT3 signaling independent of its ligand. Downstream effectors of FLT3 include activation of STAT5 via SRC kinase, phosphorylation of FOXO3A, downregulation of the equilibrative nucleoside transporter 1 (ENT1) for cytarabine, and induction of ROS production. These aberrant signals result in increased cellular proliferation, resistance to apoptosis and defective DDR. FLT3-ITD AML showed higher relapse risk after conventional treatment and hence inferior outcome. Larger size of ITD, higher allelic burden and multiple ITD mutations also indicated worse prognosis ${ }^{58-60}$.

\subsubsection{Clinical strategies to prolong remission are lacking}

Clinical trials using multi-kinase or specific FLT3 inhibitors including sorafenib and quizartinib (formerly AC220) have been effective in clearing myeloblasts from $\mathrm{PB}$ and BM but responses are typically transient. Proposed mechanisms of drug resistance include emergence of TKD mutations $(F L T 3 / I T D / T K D){ }^{61,62}$, over-expression of FLT3 signaling proteins ${ }^{63}$, protection of leukemia stem cells (LSC) in niche ${ }^{64}$ and an increase in intracellular $\mathrm{pH}(\mathrm{pHi}){ }^{65}$. Effective means to overcome drug resistance is presently lacking. 


\subsection{Aberrant DNA damage response signaling in FLT3-ITD AML}

1.4.1 Elevated intracellular ROS is the cause of genomic instability in FLT3-ITD AML

FLT3-ITD has been shown to induce ROS production. The latter induced DNA damages, including oxidization of DNA bases and abasic sites as well as single and double-stranded DNA breaks ${ }^{66}$. In particular, guanine was most sensitive to oxidation by ROS due to its low redox potential ${ }^{67}$, forming 8-hydroxyguanine (8-oxoG) which was a highly mutagenic ${ }^{68}$. Increase in ROS was closely related to the NOX family of nicotinamide adenine dinucleotide phosphate-oxidases (NAPDH oxidases, NOXs). There were 7 isoforms designated as NOX1-5 and dual oxidase 1-2 (DUOX1-2), whereas $N O X 2$ and $N O X 4$ are expressed in leukemia ${ }^{44,69}$. Each NOX enzymatic complex comprised 6 subunits, including a GTPase, usually RAC1 or RAC2 and 5 phox units (phagocytic oxidase) including gp91 phox $, \mathrm{p} 22^{\text {phox }}, \mathrm{p} 40^{\text {phox }}, \mathrm{p} 47^{\text {phox }}$ and p6 $7^{\text {phox70 }}$. Mechanistically, a direct association of phosphorylated STAT5 (P-STAT5) to RAC1-GDP has been shown to keep the GTPase in its active state, providing a possible mechanism for increased ROS generation. In addition, FLT3-ITD signaling stabilized $\mathrm{p} 22^{\text {phox }}$ protein via AKT signaling and P-STAT5 can activate transcription of NOX4 ${ }^{71,72}$. The resulting increase in NOX4 protein generates ROS that caused damage to genomic DNA. The myeloblast-like 32D cell line expressing FLT3-ITD had a higher level of oxidized DNA 8-hydroxy-2'-deoxyguanosine (8-OHdG) and DSBs than its wild-type counterparts. Mechanistically, FLT3-ITD increased both NOX and $2_{2} 2^{\text {phox }}$ protein expression level. Most importantly, NOX4, p22 $2^{\text {phox }}$ and FLT3-ITD protein had been shown to co-localize in the nuclear membrane and were essential for the generation of $\mathrm{H}_{2} \mathrm{O}_{2}$ that diffused into the nucleus to damage genomic $\mathrm{DNA}^{72}$. The reported mechanism of ROS generation via FLT3-ITD signaling is illustrated in Figure 1.5. 
Furthermore, increased ROS might oxidase and hence inactivate a tumour suppressor protein-tyrosine phosphatase PTP/DEP-1 which was a negative regulator of FLT3 signaling. Therefore, ROS may feed forward to FLT3-ITD signaling by inactivating its negative regulator. In this context, $N O X 4$ has been shown to be particularly relevant 73. NOX4 knockdown by shRNA reduced ROS, restored PTP/DEP-1 activity and attenuated FLT3-ITD cells proliferation in vitro. A NOX4 inhibitor GKT137831 also delayed leukemic progression in FLT3-ITD xenograft mouse model. The FLT3-ITDSTAT5-NOX4-ROS-PTP/DEP1 axis may provide multiple targets for therapeutic inactivation in FLT3-ITD AML.

\subsubsection{DSB repair is impaired in FLT3-ITD AML}

In addition to an increase in DNA damage due to increased ROS level, FLT3-ITD might impair DDR directly. It has been reported that $\mathrm{Ku} 70$ and $\mathrm{Ku} 86$, key components of the classical NHEJ pathway, were decreased in FLT3-ITD AML ${ }^{74}$. On the other hand, DNA ligase III $\alpha$ (LIG3), a component of the MMEJ pathway, was increased. Therefore, FLT3-ITD signaling may affect the choice of DSB repair and skewed it from classical to alternative microhomology-based NHEJ. DSB repair via MMEJ resulted in larger DNA deletions and insertions than classical NHEJ. However, it still remains unclear on the effect of FLT3-ITD on error-free HR and the error-prone NHEJ. 


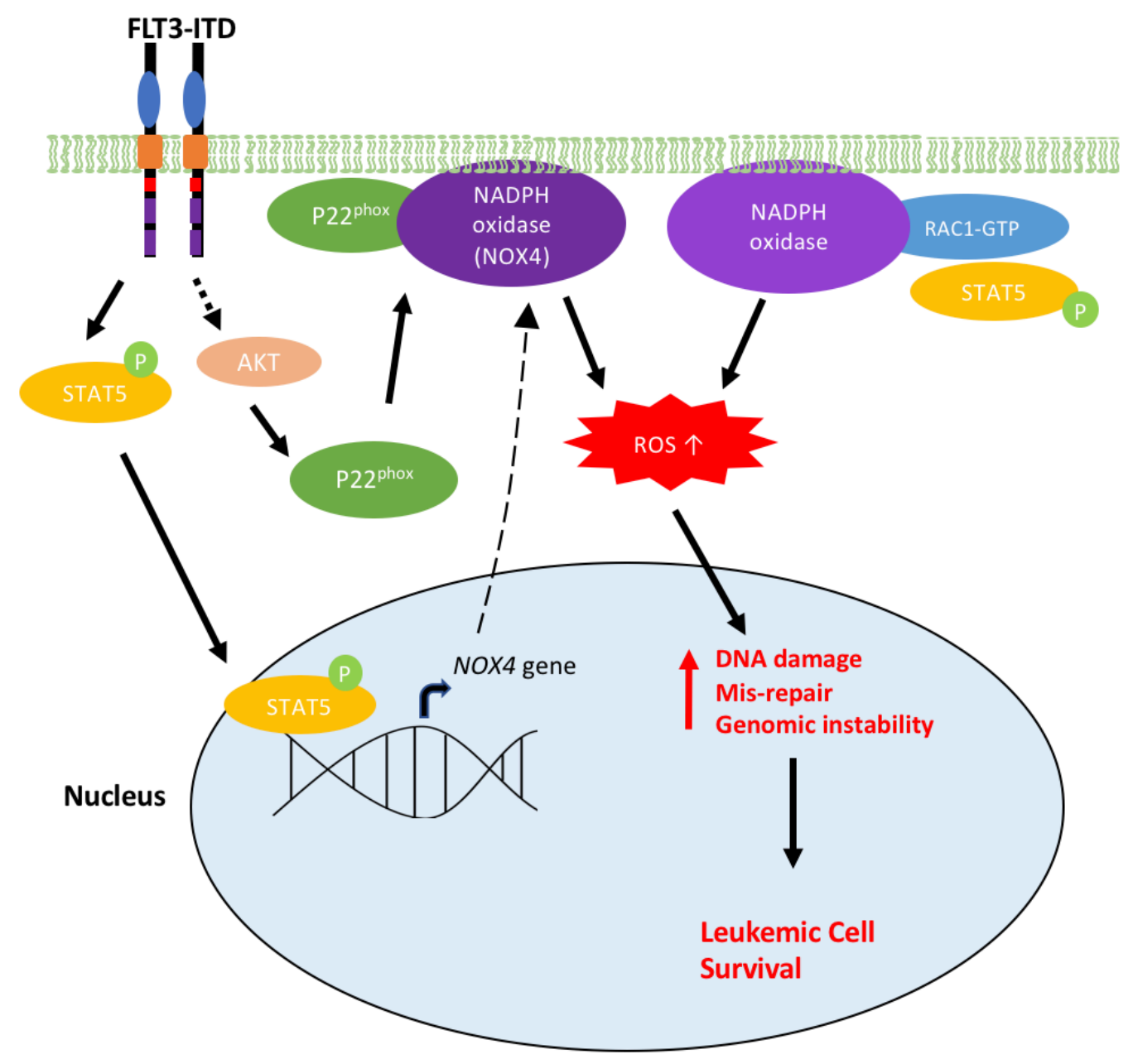

Figure 1.5 A schematic diagram showing the reported mechanism of elevated intracellular ROS via FLT3-ITD signaling.

FLT3-ITD signalling led to phosphorylation of STAT5. P-STAT5 subsequently translocated to nucleus and activated transcription of NOX4. P-STAT5 was also shown to keep RAC1 GTPase in its active GTP bound form. Active RAC1-GTP binding to NADPH complex was required for ROS production. FLT3-ITD signaling also stabilized $\mathrm{p} 22^{\text {phox }}$ protein via AKT signaling pathway and increased ROS production. The elevated ROS production in FLT3-ITD cells increased DNA damage and misrepair and caused genomic instability. A low level of ROS was known to enhance leukemic cell survival. 
The DDR pathway has become a target for therapeutic intervention in human cancers, exemplified by the use of poly (ADP-ribose) polymerase (PARP) inhibitor in the treatment of $B R C A$ mutant breast and ovarian cancers ${ }^{75,76}$. PARP detected and bound to DNA SSB breakpoint where it initiated synthesis of PAR chain to recruits other proteins involved in BER. PARP inhibition impaired BER and led to accumulation of SSB. Unrepaired SSB resulted in collapsed replication forks during DNA replication and hence the formation of DSB. In cancers with loss-of-function $B R C A 1 / 2$ mutation in which HR was defective, PARPi resulted in excess DSB that recruited error-prone NHEJ, causing genomic instability and apoptosis. The use of PARPi to induce synthetic lethality has been tested in clinical trials since $2003{ }^{77}$. And a decade later, PARP inhibitors Olaparib (2014) and rucaparib (2016) were FDA-approved to treat advanced, chemo-resistant ovarian cancer patients with germline $B R C A 1 / 2$ mutations. And later in 2017, niraparib was also approved for treatment of various solid tumours including primary peritoneal, ovarian, fallopian tube that are sensitive to platinum treatment ${ }^{78,79}$. Most importantly, AML carrying $\mathrm{t}(8 ; 21)$ and $\mathrm{t}(15 ; 17)$ showed downregulation of DDR genes and defective DDR and they were extremely sensitive to PARPi ${ }^{41}$. The aforementioned DDR defects in FLT3-ITD AML and the resulting increase in PARP1-depedent MMEJ repair support the proposition that PARP may be a therapeutic target in this AML subtype. 


\section{Chapter 2. Study Objectives}

Since its first description of FLT3-ITD in AML in 1996, much has been learnt about its prognostic significance, aberrant signaling and potential as a therapeutic target ${ }^{80}$. In particular, midostaurin was recently approved for treatment of newly diagnosed FLT3 mutant AML in combination of conventional chemotherapy and more potent and specific FLT3 inhibitors including quizartinib ${ }^{81}$, gilteritinib ${ }^{82}$ and crenolanib ${ }^{83,84}$ have also been tested and reported in relapsed or refractory settings. However, disease relapse remains to be an important cause of treatment failure of FLT3 inhibitor-based regimen.

The cumulative evidence about increased ROS production, genomic damage and defective DSB repair in FLT3-ITD AML collectively supported the hypothesis that DDR defect may provide a new direction for therapeutic targeting. The works described in my Ph.D. thesis aimed to ask 3 important questions in this area of AML leukemogensis:

i. Is HR defective in FLT3-ITD AML and what is/are the mechanisms?

ii. Is PARP inhibitor effective in FLT3-ITD AML and how?

iii. What is/are the candidate genetic targets that can be exploited in the treatment of FLT3-ITD AML in combination with PARP inhibitors?

To address these questions, laboratory platforms have been developed both in HKU and KCL and the methodologies were described in the following sections. 


\section{Chapter 3 Materials and Methods}

\subsection{Primary sample processing}

Bone marrow $(\mathrm{BM})$ blood or peripheral blood $(\mathrm{PB})$ collected from AML patients were stored at $4{ }^{\circ} \mathrm{C}$ prior to processing. The samples were usually processed on the same day or no later than the next morning. Ficoll-Paque ${ }^{\mathrm{TM}}$ Plus solution was used to isolate the mononuclear cell (MNC) fraction rich in AML blasts by density-gradient centrifugation. The processed primary samples were cryopreserved in our liquid nitrogen biobank.

The standard operating procedure (SOP) for primary sample processing was as following: The whole blood (WB) sample was centrifuged at $1100 \mathrm{rpm}$ for 10 minutes at room temperature to isolate the supernatant fraction. The plasma was purified by centrifuging the supernatant fraction at $3000 \mathrm{rpm}$ at $4{ }^{\circ} \mathrm{C}$ for 10 minutes to remove platelet or cell debris and stored at $-80^{\circ} \mathrm{C}$. The bottom fraction of $\mathrm{WB}$, containing the buffy coat and red cells were diluted with Hanks' Balanced Salt Solution (HBSS) to final volume of $20 \mathrm{~mL}$, carefully laid on $20 \mathrm{~mL}$ Ficoll-Paque ${ }^{\mathrm{TM}}$ Plus solution. The density-gradient centrifugation was performed at $1200 \mathrm{rpm}$ for 30 minutes at room temperature (acceleration $=7$, deceleration $=0$ ). The middle layer, containing the MNC fraction was isolated by disposable Pasteur pipette and washed twice with 40 $\mathrm{mL}$ of HBSS. The cells were resuspended in HBSS and counted with a hematocytometer with 1:1 ratio of Trypan Blue ( $0.4 \%$ solution). For RNA work, 5 million cells were resuspended in $1 \mathrm{~mL}$ TRIzol (Life Tech) and stored at $-80{ }^{\circ} \mathrm{C}$ for subsequent RNA extraction. The remaining MNC were resuspended in pre-cooled freezing medium (10\% dimethylsulfoxide (DMSO), 20\% fetal bovine serum (FBS) and $70 \% \mathrm{HBSS}$ ) to final concentration of 20 to 40 million cells/ $\mathrm{mL}$ and cryopreserved 
in Mr. Frosty ${ }^{\mathrm{TM}}$ freezing containers overnight at $-80{ }^{\circ} \mathrm{C}$ overnight prior to the transfer and long-term storage in liquid nitrogen tanks.

\subsection{Culture and maintenance of cell lines}

\subsubsection{Human acute myeloid leukemia cell lines}

Human leukemia cell lines (MOLM-13, MV-4-11 and NOMO-1) were originated from DSMZ and ATCC and maintained according to their protocols as listed in Appendix 1.

\subsubsection{Ba/F3 cell line and its derivatives}

Murine $\mathrm{B}$ lymphoid cell line, $\mathrm{Ba} / \mathrm{F} 3$, and its derivatives transduced with $p L K O .1$-blast (Addgene \#26655) carrying FLT3-ITD were generous gifts from Dr. Jerome Tamburini in the Institut Cochin, Université Paris Descartes, Paris, France. The cells were cultured in RPMI supplemented with $10 \%$ FBS and $1 \% \mathrm{P} / \mathrm{S}$. Murine IL-3 cytokine (PeproTech) was added to the parental $\mathrm{Ba} / \mathrm{F} 3$ line at final concentration of 2 $\mathrm{ng} / \mathrm{mL}$ but it was not required for the Ba/F3 FLT3-ITD line.

\subsection{In vitro drug treatment}

$\mathrm{Ba} / \mathrm{F} 3$ parental and $\mathrm{Ba} / \mathrm{F} 3$ FLT3-ITD cells were seeded in $96-$ well plate at $0.2 \times 10^{5}$ cells in $100 \mu \mathrm{L}$ culture medium and treated with different drug concentrations for three days. On day 3, $10 \mu \mathrm{L}$ PrestoBlue ${ }^{\circledR}$ cell viability reagent (Life Tech) was added into each well followed by 4 hours of incubation. The fluorescence signal of PrestoBlue ${ }^{\circledR}$ cell viability reagent was measured by FLUOstar OPTIMA microplate reader at 560 $\mathrm{nm}$ excitation and $590 \mathrm{~nm}$ emission. 
Colony forming assay of murine $F l t 3^{I T D /+} \times \mathrm{Npm}^{{ }^{c /+}}$ and $M L L-A F 9$ leukemic cells was carried out by plating $1-3 \times 10^{3}$ cells in MethoCult ${ }^{\mathrm{TM}}$ M3234 (Stemcell Technology) supplemented with murine cytokines: 20 ng/mL SCF, 10 ng/mL IL-3, 10 ng/mL IL-6 and $10 \mathrm{ng} / \mathrm{mL}$ (PeproTech) together with inhibitors at stated concentration. The number of colonies was scored after 7 days.

\subsection{RNA extraction and reverse transcription polymerase chain}

\section{reaction}

\subsubsection{RNA extraction}

The primary $\mathrm{MNC}$ was resuspended in $1 \mathrm{~mL}$ TRIzol (Chapter 3.1) and was homogenized in a $1 \mathrm{~mL} 29$-gauge syringe. The cell lysate was incubated for 5 minutes at room temperature. Then, $200 \mu 1$ of chloroform was added to the tube and incubated for 5 minutes at room temperature. The sample was then separated into aqueous, interphase and organic phase by centrifugation at $13,400 \mathrm{x} g$ for 15 minutes at $4{ }^{\circ} \mathrm{C}$. The upper aqueous phase containing RNA was transferred to a new sterile $1.5 \mathrm{ml}$ microcentrifuge tube, while the interphase (DNA) and lower organic phase (proteins) were discarded. To precipitate the RNA, $500 \mu \mathrm{l}$ of isopropanol was added and incubated at room temperature. RNA pellet was collected by centrifugation at 13,400 $\mathrm{x} g$ for 10 minutes at $4^{\circ} \mathrm{C}$, washed with $1 \mathrm{ml}$ of $75 \%(\mathrm{v} / \mathrm{v})$ ethanol, centrifuged at $13,400 \mathrm{x} \mathrm{g}$ for 5 minutes at $4^{\circ} \mathrm{C}$, air-dried for 10 minutes and dissolved in $20 \mu \mathrm{l}$ of DEPC-treated water. Purity and quantity of total RNA were determined by the absorbance ratio of $260 \mathrm{~nm} / 280 \mathrm{~nm}$ (protein impurity) and $260 \mathrm{~nm} / 230 \mathrm{~nm}$ (organic solvent impurity) by Thermo Scientific NanoDrop 2000 Spectrophotometer, of which most of RNA samples had both ratio greater than 1.8 . 


\subsubsection{Reverse transcription polymerase chain reaction}

Extracted RNA was reversed-transcribed to first strand complementary DNA (cDNA) using SuperScript II reverse transcriptase kit (Thermo Fisher Scientific). Of note, $1 \mu \mathrm{g}$ of RNA was used for input and $1 \mu \mathrm{l}$ of random primers $(50 \mathrm{ng} / \mathrm{mL})$ was used for amplification. The cDNA was stored at $-80{ }^{\circ} \mathrm{C}$ until use.

\subsection{Real-time quantitative PCR (RT-QPCR)}

The cDNA synthesized in chapter 3.4.2 was diluted 5-fold with RNase-free water as template for RT-QPCR using the SYBR Green Select Master Mix (Thermo Fisher Scientific) and StepOnePlus Real-Time PCR System (Applied Biosystems). The list of primers used for RT-QPCR is listed in Appendix 2. Relative quantification of the gene expression was calculated by the comparative algorithm $(\Delta \mathrm{Ct})$ using $\beta$-actin as internal control ${ }^{85}$. Comparison of relative gene expression was normalized to $\Delta \mathrm{Ct}$ control group. The relative gene expression was calculated as $2^{-\Delta \Delta \mathrm{Ct}}=2^{-(\Delta \mathrm{Ct} \text { target }-\Delta \mathrm{Ct} \text { control }) .}$

\section{$\underline{\text { 3.6 Western Blot }}$}

Cell pellet was lysed with CelLytic ${ }^{\mathrm{TM}}$ MT Cell Lysis Reagent (Sigma) with addition of protease and phosphatase inhibitors cocktail (Thermo Scientific) to extract soluble protein fraction. The extracted protein was mixed with Laemmli loading dye and denatured at $95^{\circ} \mathrm{C}$ for $5 \mathrm{~min}$, separated by sodium dodecyl sulfate polyacrylamide gel electrophoresis (SDS-PAGE) $(7.5,10$ or $12 \%)$ and was transferred to $0.2 \mu \mathrm{m}$ nitrocellulose membrane. The blot was then incubated with blocking buffer (5\% non-fat milk in PBST) for 30 mins and probed with primary antibody overnight 
at $4^{\circ} \mathrm{C}$ and secondary antibody at room temperature for 1 hour. Primary and secondary antibodies used are listed in Appendix 3. The ECL signal was developed with Luminate Forte Western HRP substrate (Millipore) and detected using the ChemiDoc MP Imaging System (Bio-Rad).

\subsection{Immunofluorescence Microscopy}

At the experimental endpoint, the cells were washed once with $1 \mathrm{X}$ PBS and resuspended at $1 \mathrm{million} / \mathrm{mL} .100 \mu \mathrm{L}$ of the cells were cytospun onto glass slides at $400 \mathrm{~g}$ for 5 mins and then fixed with 4\% PFA for 15 mins and blocked with $0.5 \%$ Triton X-100, 1\% BSA in PBS for 30 minutes. The slides were then incubated at $4^{\circ} \mathrm{C}$ overnight with mouse anti- $\gamma$-H2AX (ser139) (Upstate clone JBW301 \#05-636) at 1:200 dilution overnight. The slides were then washed 3 times with $0.5 \%$ Triton X100 in PBS and subsequently incubated with 1:200 goat anti-Mouse IgG Alexa Fluor 488 (ThermoFisher) at room temperature in dark for 1 hour. The slides were then washed 3 times with PBS and mounted with coverslips using fluorescence mounting medium (Dako).

Fluorescent images were taken with Olympus IX70 (Olympus) using 20X/0.3 NA objective and acquired by Olympus DP71 (Olympus) and Olympus DP-BSW basic Software.

\section{$\underline{\text { 3.8 Neutral comet assay }}$}

Comet assay was performed using CometAssay ${ }^{\circledR}$ kit (Trevigen) according to the manufacturer's neutral comet assay protocol. The comet images were captured using fluorescent microscope (Leica) were analysed using OpenComet ${ }^{86}$. 


\subsection{General flow cytometry experiments}

All flow cytometry (FACS) were performed with LSRII Fortessa Analyzer (BD Biosciences) or FC500 (Beckman Coulter), and data was analyzed using FlowJo 7.6.1 software (Tree Star, Inc.).

\subsubsection{Intracellular reactive oxidative species (ROS) level measurement}

Intracellular ROS was measured using the general oxidative stress indicator CMH2DCFDA dye. This dye was cell permeable and was retained in living cells. The subsequent oxidation of CM-H2DCFDA in cells yielded a fluorescent adduct that was quantified by flow cytometry using the FITC (FL-1) channel.

The CM-H2DCFDA was freshly reconstituted in DMSO at $10 \mathrm{mM}$ immediately before each experiment and all the experimental procedure must be kept in dark at all time prior to FACS analysis.

At experimental endpoint, cells were washed once with pre-warmed PBS and then incubated with $10 \mu \mathrm{M}$ of the probe in PBS at $37^{\circ} \mathrm{C}$ for 30 minutes. The probe was then washed off with PBS and incubated again at $37^{\circ} \mathrm{C}$ for 30 minutes to recover and to ensure the oxidation reaction was completed prior to flow cytometry.

\subsubsection{Immunophenotypic analysis of primary murine cells}

The leukemic mice were first euthanized using $\mathrm{CO}_{2}$ chamber. Total bone marrow cells were harvested from femurs and tibias, spleen and liver cells were homogenized and filtered with $0.45 \mu \mathrm{m}$ cell strainer. Red cells were lysed by BD Pharm Lyse ${ }^{\mathrm{TM}}$ for 5 minutes on ice in dark and washed with PBS with $2 \%$ FBS. The cells were stained 
with mouse-specific PE/Cy7 anti-CD11b (Mac-1, clone M1/70), PerCp/Cy5.5 antiGr1 (clone RB6-8C5), PE anti-c-Kit (clone 2B8), FITC anti-CD45.1 (clone A20) and APC anti-CD45.2 (clone 104) antibodies from BioLegend. All antibodies are used at a dilution of $1: 200$ at $4{ }^{\circ} \mathrm{C}$ for 30 mins and analysed by BD LSRII flow cytometer (BD Biosciences).

\subsection{Lentivirus packaging}

HEK293FT cells were used for packaging of lentivirus. The cells were seeded at 50\% confluent overnight in $100 \mathrm{~mm}$ dish. The next day, $4 \mu \mathrm{g}$ of the lentiviral packaging plasmid $p C M V-d R 8.91,4 \mu \mathrm{g}$ of the envelop plasmid $p M D 2 . G$ and $7 \mu \mathrm{g}$ of the transfer plasmid were co-transfected using $30 \mu \mathrm{l}$ of lipofectamine 2000 (Life tech) per $100 \mathrm{~mm}$ dish. At 8-hour post-transfection, the dishes were replaced with fresh complete DMEM medium. 48 hours later, the supernatant was harvested and filtered through a $0.45 \mu \mathrm{m}$ filter. The viral particles were concentrated 20 -fold by ultracentrifugation at $25,000 \mathrm{x} g$ for 2 hours at $4{ }^{\circ} \mathrm{C}$. The concentrated lentivirus was aliquoted and stored at $-80^{\circ} \mathrm{C}$

\subsection{Traffic Light Reporter (TLR) assay}

The TLR assay was developed by Certo et al in $2011^{87}$. The assay consisted of 2 separate plasmids: pCVL Traffic Light Reporter 1.1 (Addgene \#31482) and pCVL SFFV d14GFP EF1s HA.NLS.Sce (Addgene \#31476), in which both plasmids were packaged separately in lentivirus.

The cells were first transduced lentivirally with the TLR plasmids and the next day puromycin was added at final concentration of $1 \mu \mathrm{g} / \mathrm{mL}$ for selection of plasmid containing clones for additional 2 days. The cells were then washed with PBS and 
transduced with $p C V L S F F V$ d14GFP EF1s HA.NLS.Sce lentivirus which expressed the I-SceI endonuclease and contained the GFP donor template. Two days post transduction, the cells were analysed by FACS.

\subsection{DNA damage response (DDR) shRNA library screening}

The cloning protocol of $s h R N A$ library, the $s h R N A$ hairpin sequences with improved knockdown efficiency and Miseq library preparation protocol were provided by Dr. Johannes Zuber's group ${ }^{88}$. A brief procedure is described as below.

\subsubsection{Cloning of DDR shRNA library plasmids}

The DDR shRNA library consisted of all reported genes with functions annotated to DNA damage response pathways from published databases KEGG and REPAIRtoire, and review papers ${ }^{89,90}$. Multiple $s h R N A$ libraries were ordered from Agilent (United States) and each gene had 5 unique $s h R N A$ hairpins. The mouse DDR $s h R N A$ library was amplified by library-specific PCR primers with low PCR cycles and cloned into lentiviral vector $p R R L-G F P$-Puro. To ensure complete representation of the hairpin library pool, the target number of bacterial colonies was at least 100 -fold the total number of hairpins. In the case of mouse DDR library with $\sim 1,200$ unique hairpins, at least 120,000 single colonies were transformed. All colonies were recovered in LB broth overnight and plasmid DNA was extracted by Gigaprep (Qiagen).

\subsubsection{Experimental Scheme of DDR shRNA library screening}

Mouse DDR $s h R N A$ library was packaged into lentivirus and the virus was titrated such that less than $30 \%$ GFP+ cells post transduction, to ensure that MOI was around 
1. Twenty million of $\mathrm{Flt3}^{\mathrm{ITD} /+} \times \mathrm{Npml}^{\mathrm{c} /+}$ leukemic cells were transduced with mouse DDR $\operatorname{sh} R A$ lentivirus for 2 days. GFP+ cells were sorted using BD FACSAria cell sorter. 1 x $10^{5}$ sorted cells were transplanted into sub-lethally irradiated (500 Rads X 2 doses) CD45.1 SJL mice by intravenous injection. Two weeks post-transplantation, the experimental mice were divided into two groups and treated with either $50 \mathrm{mg} / \mathrm{kg}$ Olaparib or vehicle control by intraperitoneal injection 5 days per week for 2 weeks. After 4 additional weeks, the mice were euthanized. Total bone marrow cells were harvested from femurs and tibias.

\subsubsection{Preparation of sequencing library for MiSeq}

Genomic DNA was extracted from cell pellet using QIAamp DNA Mini Kit (Qiagen). To keep 1000-fold representation of a pool of $1,200 \operatorname{sh} R N A$ at $\mathrm{MOI}=1$, the total amount of DNA input for PCR is $7 \mu \mathrm{g}$ DNA, assuming 1ng genomic DNA contained the DNA from 167 diploid cells. Using PCR primers containing the P5 and P7 adaptor sequences and unique barcodes for the Illumina platform, individual DNA samples were amplified and barcoded. The purified DNA samples were quantified by Qubit and pooled together at $6 \mathrm{nM}$ final concentration. The final DNA samples were sequenced using single-read Miseq V2 50 cycle kit (Illumina) with custom sequencing primer at READ1 position.

\subsubsection{Bioinformatics analysis}

Ms. Claire Lynn, PhD student from Prof. Eric So's lab in Kings College London performed the majority of the bioinformatics analysis, including the processing of the raw sequencing data, demultiplexing of sequencing reads, mapping of reads to unique 
hairpins and the statistical analysis. I performed the final analysis and data interpretation.

\subsection{In vivo drug treatment of Olaparib and chemotherapy drugs in}

\section{MOLM-13 xenograft model}

8-10 weeks old $N O D / S C I D / I L 2 \mathrm{Rg}^{-/-}$(NSG) mice were sub-lethally irradiated with 250 cGy 4 hours before transplantation. 1 x $10^{5}$ of MOLM-13 cells with luciferase reporter were resuspended in $150 \mu \mathrm{L}$ PBS and transplanted into NSG by intravenous injection using 29 G syringe. At 4-day post-transplantation, experimental mice were injected with $150 \mathrm{mg} / \mathrm{kg}$ D-luciferin substrate intraperitoneally and bioluminescence imaging were acquired with PE IVIS Spectrum in vivo imaging system (PerkinElmer). The dosage and drug delivery method that mimicked the patient " $7+3$ " regimen was based on Wunderlich et al ${ }^{91}$, which comprised 5 days of cytarabine $(25 \mathrm{mg} / \mathrm{kg})$ by intraperitoneal injection and doxorubicin $(1.5 \mathrm{mg} / \mathrm{kg})$ by intravenous injection on day1-3. Olaparib $(25 \mathrm{mg} / \mathrm{kg}$ ) was administrated by intraperitoneal injection for 5 days. Post-treatment bioluminescence was taken on the $11^{\text {th }}$ day post-transplantation.

\subsection{Statistical analysis}

Unless otherwise specified, data were expressed as means \pm standard error of the mean (SEM). Comparisons between groups of numerical data were evaluated using Student's t-test. P-values $<0.05,<0.01$ and $<0.001$ were considered statistically significant, and were represented with asterisk $(*),(* *)$ or $\left({ }^{* *}\right)$. Survival analysis of mouse experiments was performed using the Kaplan-Meier method. Differences in survival were determined using log-rank test. Sample size $(N)$ and replicates (n) of all experiments were indicated in their corresponding figure legends. 


\section{Chapter 4. Homologous recombination in FLT3-ITD AML was affected with possible mechanistic linkage to down- regulation of $B R C A 2$.}

\section{$\underline{4.1 \text { Introduction }}$}

FLT3 is one of the most common mutations in AML ${ }^{1}$. Its molecular structure has been described in Chapter 1. The JM domain negatively regulates FLT3 function by inhibiting phosphorylation. ITD commonly occurs in JM domain, thereby disrupting the auto-regulatory function and giving rise to constitutive activation of FLT3 and its downstream signaling pathways such as AKT, ERK and STAT5 ${ }^{57}$. Emerging evidences show that FLT3-ITD AML is associated with increased ROS production and DNA damage. At the same time, DDR may be defective $70,72,74,92,93$ but the mechanistic link with particular reference to the relative contribution of HR and NHEJ is presently unclear.

\subsection{Down-regulation of BRCA2 in FLT3-ITD primary AML samples}

To investigate the link between FLT3-ITD AML and DDR, expression of critical DDR genes in primary AML samples was examined by quantitative real-time PCR. The study was restricted to de novo and cytogenetically normal AML at diagnosis to avoid changes in gene expression secondary to prior chemotherapy. To reduce variation in samples, only BM samples were used and all of them showed blast population $\geq 70 \%$. A total of 18 FLT3-WT and 13 FLT3-ITD samples were recruited. Six apheresis samples from healthy donors who donated peripheral blood stem cell (PBSC) were included as control. 
A panel of genes associated with apical kinase $A T M, A T R$ and DNA-PKcs; DNA damage mediators $B R C A 1, B R C A 2$ and $P A R P 1$; downstream response kinase $C H E K 1$ and $C H E K 2$ and effectors TP53, were examined. BRCA2 expression was significantly down-regulated in FLT3-ITD AML. Those of ATR and P53 were also down-regulated, albeit statistically significant (Fig. 4.1). Down-regulation of BRCA2 in FLT3-ITD AML was further validated in a microarray database GSE15434 from a multicenter study investigating gene expression profiles of normal karyotype AML (WT=148; $\mathrm{ITD}=86)\left(\right.$ Fig. 4.2) ${ }^{94}$.

\subsection{FLT3-ITD signaling was responsible for the suppression of}

\section{$\underline{B R C A 2 \text { expression }}$}

The mechanistic link between FLT3-ITD and DDR genes with particular reference to BRCA2 was evaluated in human FLT3-ITD+ AML cell lines MOLM-13 and MV-411 that carried $M L L-A F 9$ and $M L L-A F 4$ fusions respectively. NOMO-1 cell line that similarly harbored MLL translocation but wild-type FLT3 was included as control. $B R C A 2$ expression was significantly reduced in MOLM-13 and MV-4-11 compared with that in NOMO-1, consistent with the observations made in primary samples (Fig. 4.3).

To ascertain if BRCA2 downregulation was secondary to FLT3-ITD signaling, gene expression was examined after treating the 3 cell lines with a FLT3-specific inhibitor quizartinib. At a dose up to $5 \mathrm{nM}$ that had been shown to suppress FLT3 signaling in MOLM-13 and MV4-11, BRCA2 expression was significantly increased ${ }^{95}$. However, there was no significant effect in NOMO-1 (Fig. 4.4). 
A

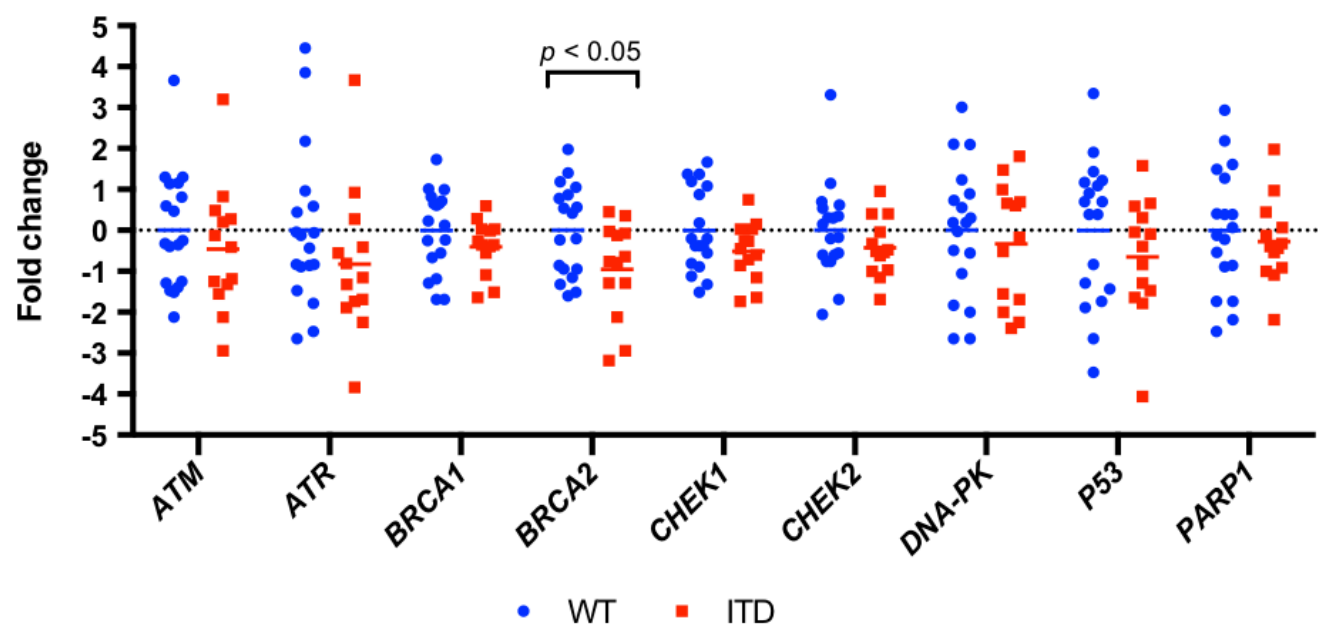

B

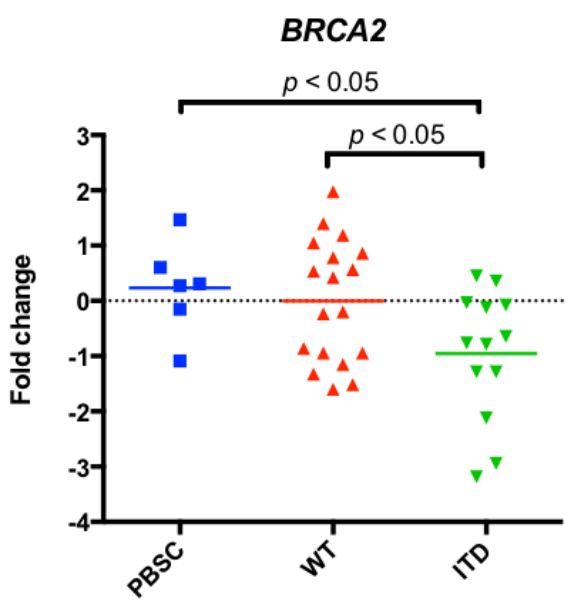

Figure 4.1 Gene expression profile of DNA repair genes in primary AML patients.

(A) Quantitative Real Time PCR was performed using complementary DNA (cDNA) of leukemic myeloblasts from bone marrow of normal karyotype AML patients. Wildtype FLT3 (WT): N=18; FLT3-ITD (ITD): N=13. (B) Among all DNA repair genes tested, only $B R C A 2$ was significantly down-regulated when compared to normal PBSC control $(\mathrm{N}=6)$ and also wild-type FLT3 AML samples. 


\section{BRCA2}

(GSE15434)

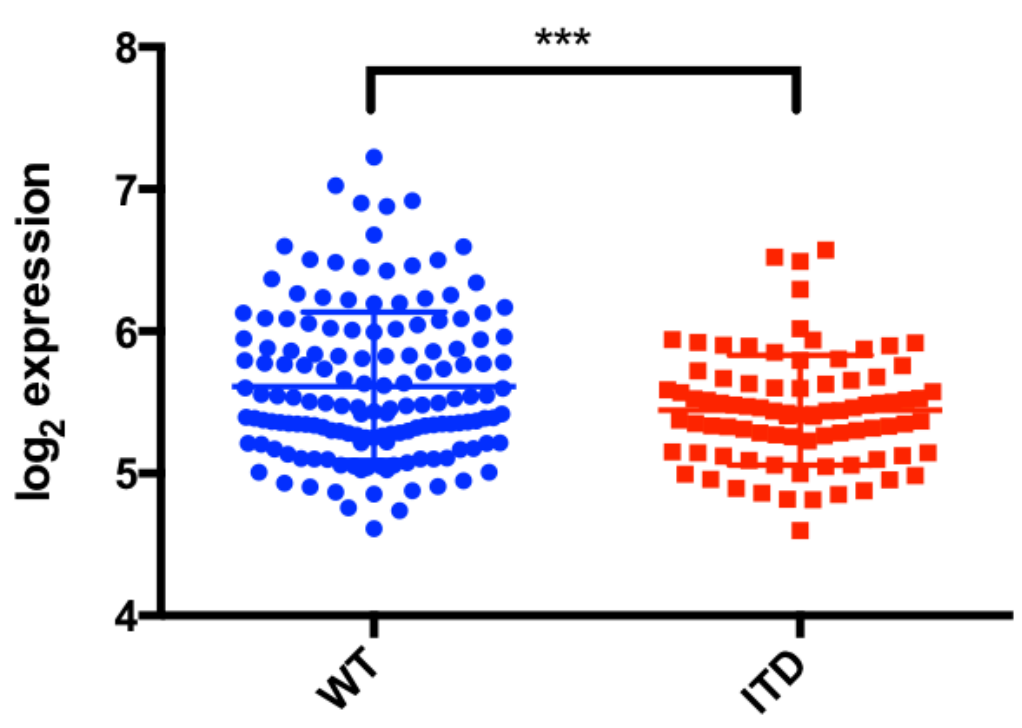

Figure 4.2 BRCA2 expression profile from GSE15434.

All the samples in this study were normal karyotype AML samples obtained from untreated patients at the time of diagnosis. Purified mononuclear cells were collected for microarray analysis. Samples were collected from Dresden, Munich and Ulm. The data was downloaded from Gene Expression Omnibus under the accession GSE15434. The 214727_at probe was used to hybridize and quantity expression of BRCA2. Wildtype FLT3 (WT): N=148; FLT3-ITD (ITD): N=86. p-value $<0.001$. 


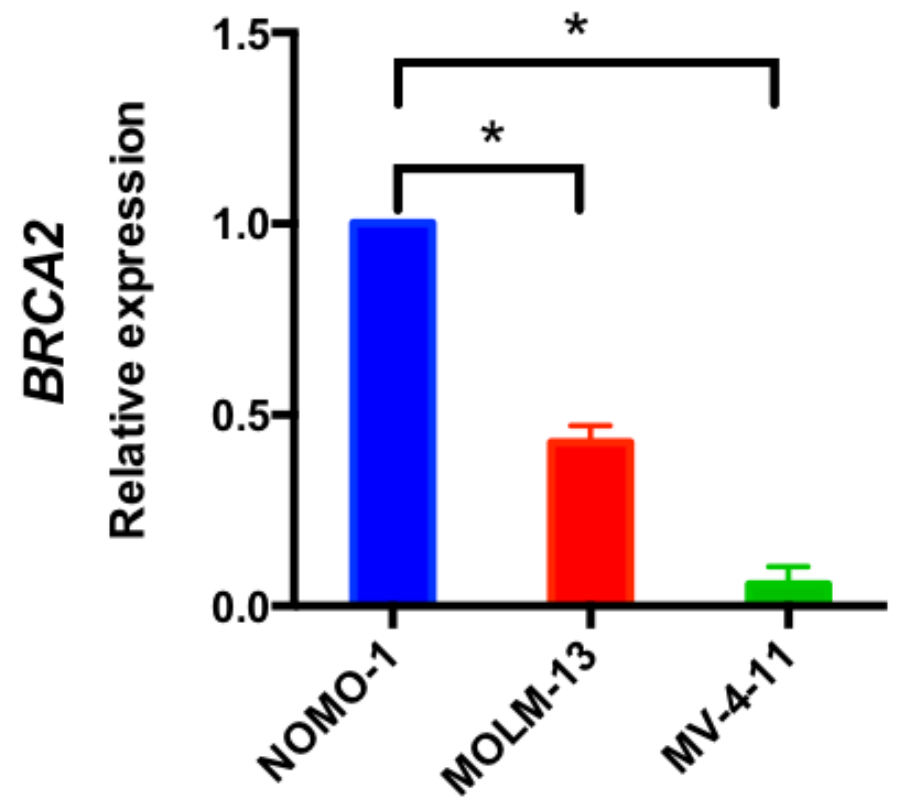

Figure 4.3 BRCA2 expression of human AML cell lines.

Quantitative Real Time PCR was performed using cDNA of human AML cell lines. All the cells here harbored MLL-fusion mutations: NOMO1 (MLL-AF9); MOLM-13 (MLL-AF9); and MV-4-11 (MLL-AF4) respectively. NOMO1 with wild-type FLT3 serves as the control cell lines. MOLM-13 was heterozygous for FLT3-ITD mutations whereas MV-4-11 was homozygous for FLT3-ITD. $\mathrm{n}=2 ; * \mathrm{p}<0.05$. 
A

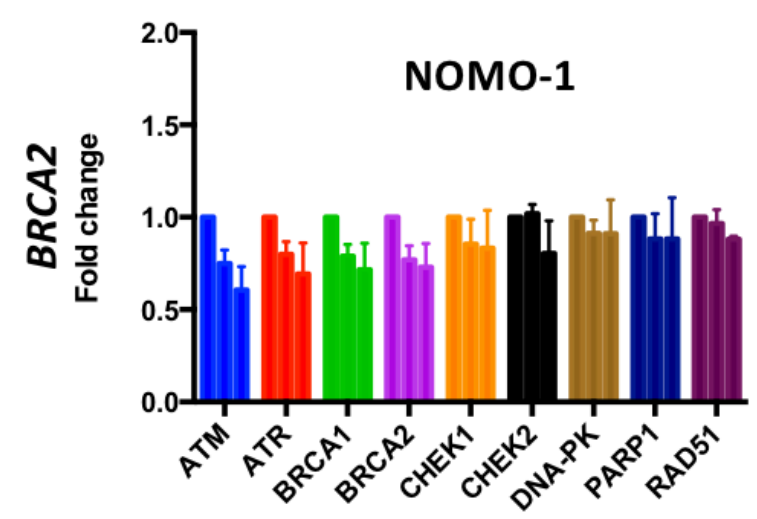

B

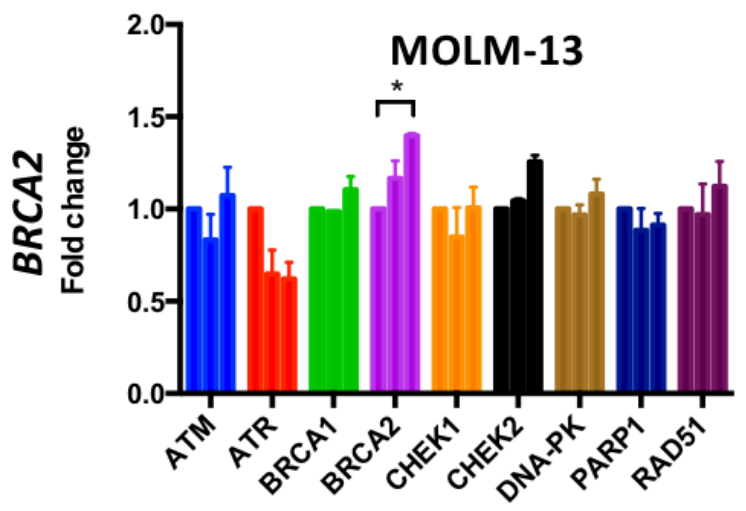

C

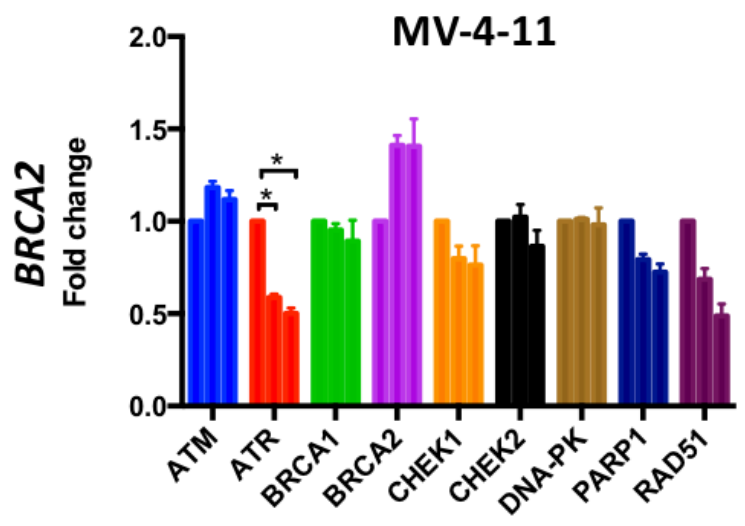

Figure 4.4 Gene expression profile of DNA repair genes in human AML cell lines after treatment of FLT3 inhibitor, quizartinib.

(A) NOMO-1, (B) MOLM-13 and (C) MV-4-11 AML cell lines were treated with 0, 1 and $5 \mathrm{nM}$ of quizartinib for 4 hours. Relative gene expression was quantified by QPCR and normalized to vehicle control. Increase in BRCA2 was observed in FLT3ITD AML cell line MOLM-13 and MV-4-11 after quizartinib treatment but not in FLT3-WT NOMO-1 control. $\mathrm{n}=2 .{ }^{*} \mathrm{p}<0.05$. 
To more clearly define the link between FLT3-ITD signaling and DDR, an isogenic $\mathrm{Ba} / \mathrm{F} 3$ FLT3-ITD cell model was used in which Ba/F3 FLT3-ITD cells survived on autonomous FLT3-ITD signaling while parental Ba/F3 cells survived on IL3 that was supplemented in culture medium. Consistent with the observations in primary AML samples and cell lines, murine Brca2 was significantly down-regulated in $\mathrm{Ba} / \mathrm{F} 3$ FLT3-ITD line (Fig. 4.5A) and quizartinib induced a significant increase in these cells (Fig. 4.5B).

\subsection{Homologous recombination activity was decreased in FLT3-ITD}

\section{cells}

Effective DDR is critical for the maintenance of genomic integrity in cells that are exposed to genotoxic agent ${ }^{96,97}$. Without timely repair, DNA breaks can cause genomic instability and cell death. DSB repair is accomplished by error-free HR that utilizes the sister chromatin as a template for DSB repairs and is dependent on intact BRCA2 protein that regulates the intracellular location and DNA binding of RAD51 98-100. Loss-of-function $B R C A 2$ mutation resulted in defective DSB repair and predisposes patients to breast or ovarian cancers ${ }^{101,102}$. Therefore, the observations of BRCA2 down-regulation in FLT3-ITD+ AML supported the proposition that DDR may be defective in this AML subtype and it was tested in subsequent experiments.

The Traffic Light Reporter (TLR) assay was used to evaluate the efficiency and repair

fidelity of DSB in Ba/F3 FLT3-ITD line ${ }^{87}$, which allowed a direct measurement of the relative efficiency of error-free homologous recombination (HR) and error-prone non-homologous end-joining (NHEJ) at a particular DSB site induced by 
A

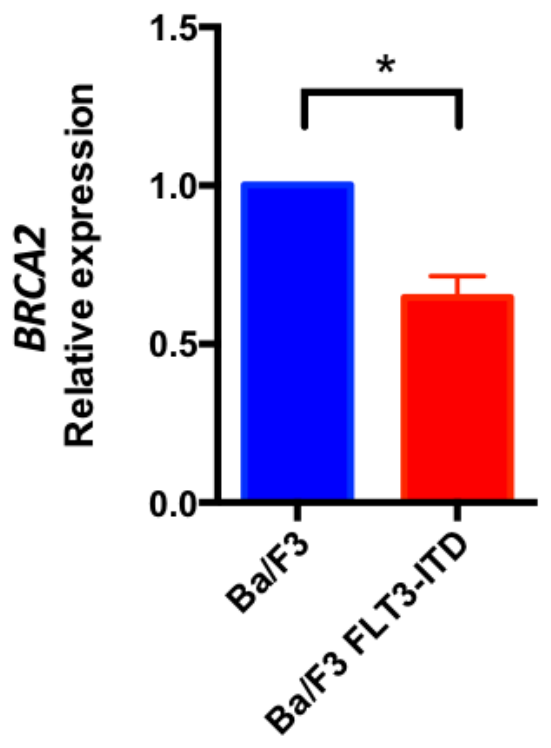

B

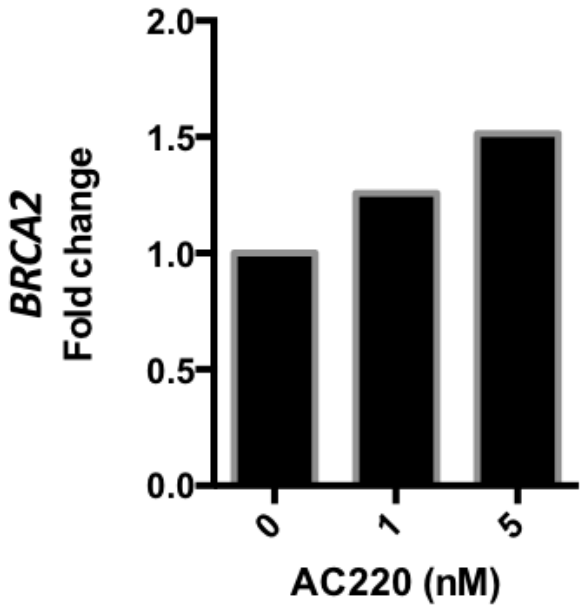

Figure 4.5 Brca2 expression in Ba/F3 FLT3-ITD isogenic model.

Murine pro-B cell line was lentivirally transduced with coding sequence of human FLT3-ITD. (A) QPCR result of Brca2 transcript level shows down-regulation of Brca2 in $\mathrm{Ba} / \mathrm{F} 3$ FLT3-ITD line when compares to parental control. $\mathrm{n}=3$; $\mathrm{p}<0.05$. (B) Inhibition of FLT3-ITD signaling with AC220 results in rescue of Brca2 expression in Ba/F3 FLT3-ITD line by QPCR. $\mathrm{n}=1$. 
endonuclease. The mutant $G F P$ (containing a premature termination codon, $\triangle G F P$ ) and $m$ Cherry open reading frame (ORF) in the TLR were fused by a ribosome skipping sequence $(T 2 A)$ that allowed translation of 2 distinct polypeptides without forming a peptide bond. GFP and $m$ Cherry ORF were positioned in different frames and DSB was induced at a unique recognition site for endonuclease I-Scel in the mutant GFP ORF. If NHEJ repair had occurred, it would place $\triangle G F P$ in frame with $m C h e r r y$ in 1 out of 3 events, leading to mCherry fluorescence. If HR repair had occurred, the GFP donor template that was lentivirally transduced after TLR would replace $\triangle G F P$ in TLR, leading to GFP fluorescence (Fig. 4.6). Compared with the parental line control, DSB repair by HR was significantly decreased in $\mathrm{Ba} / \mathrm{F} 3$ FLT3-ITD while DSB repair by NHEJ was not significantly different (Fig. $4.7 \&$ 4.8). In summary, the data demonstrated that FLT3-ITD down-regulated $B R C A 2$, impaired HR and DSB repair fidelity in FLT3-ITD AML. 
B

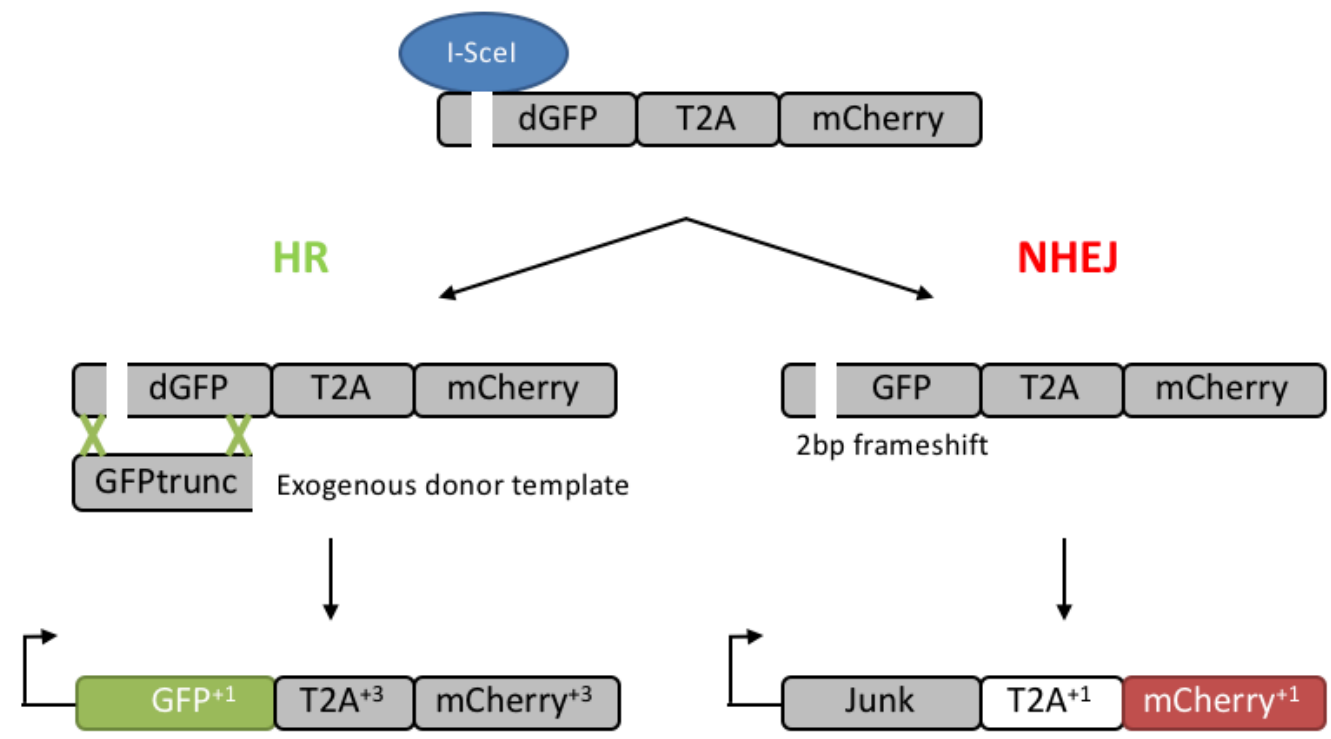

Figure 4.6 Principle of the Traffic Light Reporter (TLR) assay.

(A) The simplified vector map of the TLR plasmid illustrating the structure of the TLR transcript. The open reading frame relative to the initial defective GFP (dGFP) was indicated in superscript. (B) I-SceI nuclease cleaved the TLR at the target site and induced double-stranded break (DSB). The DSB could be either repaired via the homology-directed recombination using the exogenous donor template and reconstituted the full GFP sequence and the cells would emit green fluorescence. If the DSB underwent non-homologous end joining (NHEJ), one in third chance would result in $2 \mathrm{bp}$ frameshift and translated an in-frame mCherry protein and emitted red fluorescence. The diagram was adopted from the original TLR paper ${ }^{87}$. 

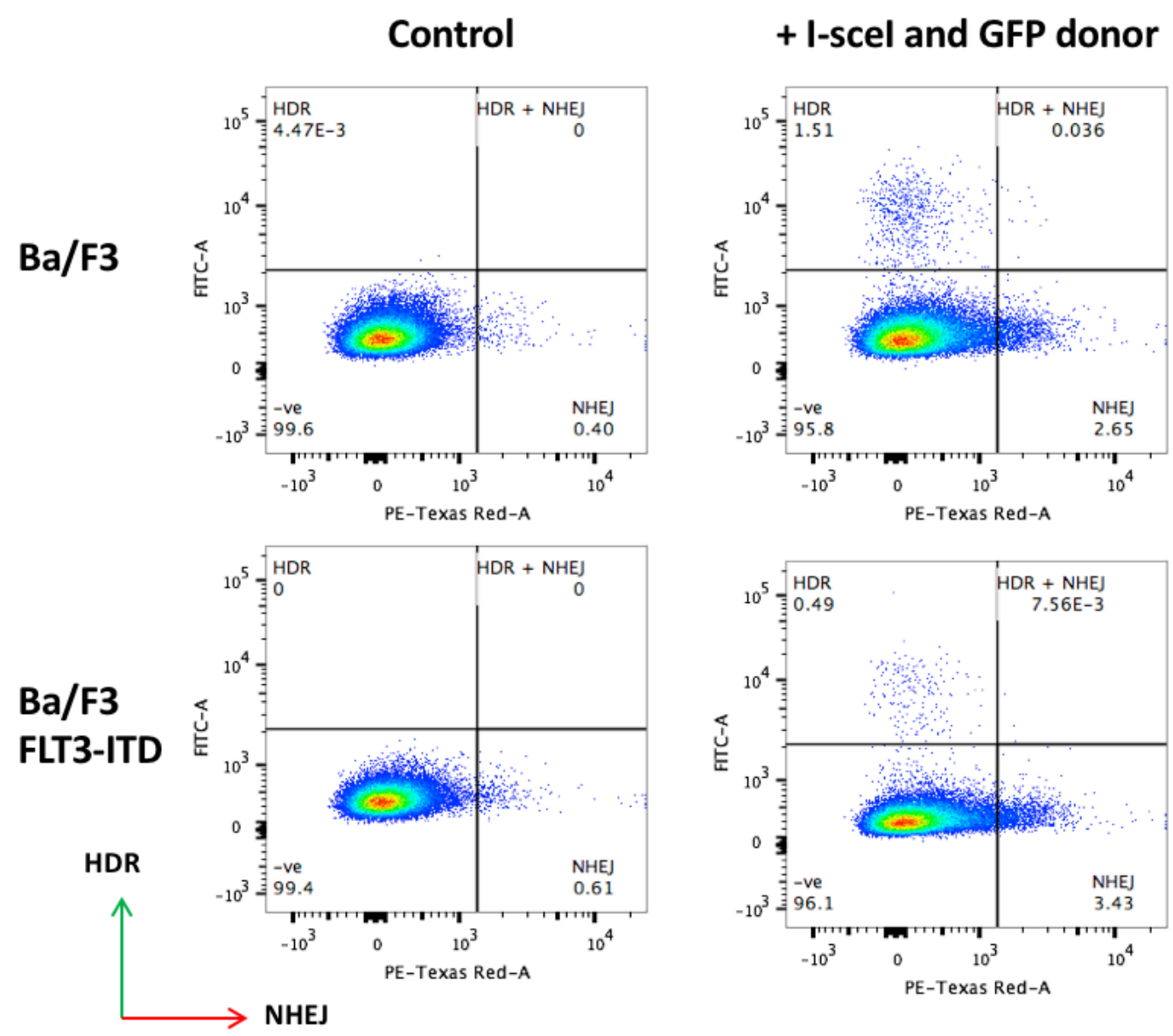

Figure 4.7 Representative flow plot of the TLR reporter assay.

The Ba/F3 parental and FLT3-ITD cells stably expressing the TLR reporter construct were lentivirally transduced with a plasmid expressing I-SceI and GFP donor template. The transduced cells were analyzed by flow cytometer 2 days post transduction. Top left quadrat gated on GFP+ cells: cells underwent HR and bottom right quadrat gated on mCherry+ cells: those underwent NHEJ. 
A

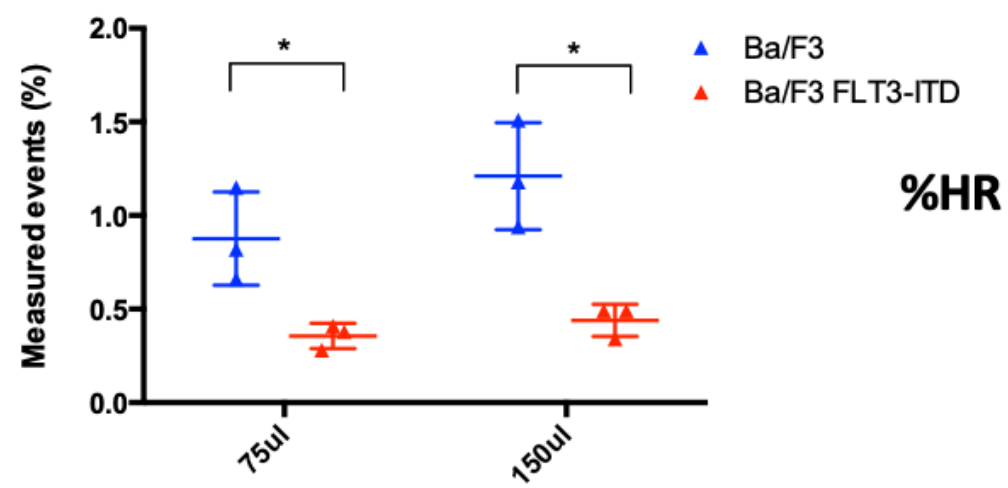

B

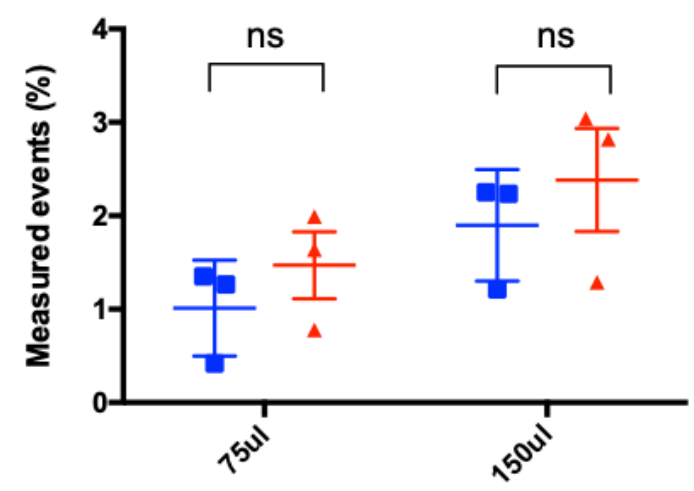

\% NHEJ

C

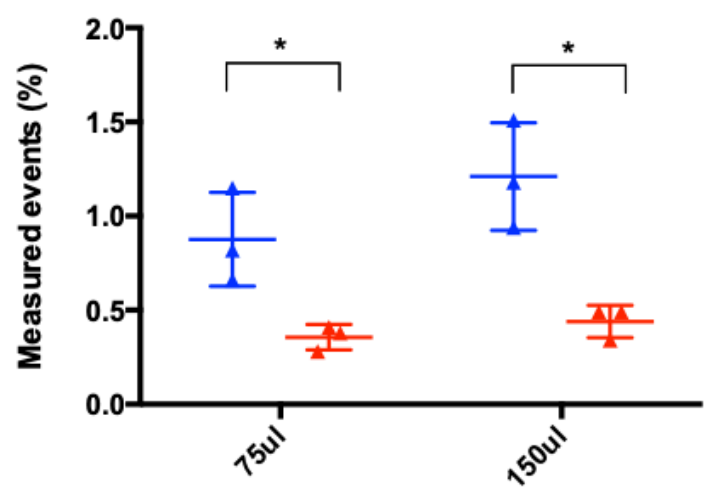

\section{Ratio of HR} to NHEJ

Figure 4.8 Statistical analysis of the TLR assay.

(A) \& (B) Quantification of \% measured events of GFP + cells (HR) and mCherry+ cells (NHEJ) respectively. (C) Ratio of HR to NHEJ, representing the relative DSB repair fidelity. $\mathrm{n}=3$. Error bar=SEM; $p$-value: $*<0.05 ; * * *<0.001$; ns: not significant. 


\section{Chapter 5. Targeting FLT3-ITD AML with PARP inhibitor}

\subsection{Introduction}

Defective DDR plays an important role in the pathogenesis of AML ${ }^{18}$. Myeloblasts from FLT3-ITD+ AML patients showed a significantly higher level of reactive oxidative species (ROS) than AML patients with FLT3 wild type alleles (FLT3-WT) 93. Elevated level of both cytoplasmic and nuclear reactive oxidative stress (ROS) were observed in FLT3-ITD AML cell lines as well as murine cell line transduced with FLT3-ITD constructs ${ }^{71,73,103,104}$. In particular, decreased NHEJ and increased PARP1dependent MMEJ activity resulted in large DNA insertions and deletions ${ }^{74}$. The data from Chapter 3 showed that FLT3-ITD+ cells had BRCA2 down-regulation and reduced HR activity, this chapter examined whether drugs targeting DNA repair pathways, in particular, PARPi, could be used to intervene the leukemic development of FLT3-ITD transformed $\mathrm{Ba} / \mathrm{F} 3$ cells.

\subsection{PARP inhibitors selectively targeted FLT3-ITD AML in vitro by}

\section{cell proliferation assay}

To target key components in DDR, FLT3-ITD AML was treated with a panel of small molecular inhibitors targeting ATM, ATR, CHEK1/2 and PARP. Effects on leukemia growth in vitro were evaluated by Presto Blue colourimetric assay up to maximum plasma concentration reported in patients. Of the 4 inhibitors tested, PARP inhibitor Olaparib showed preferential inhibitory effects on Ba/F3 FLT3-ITD over the parental. ATM inhibitor KU-55933 also showed a modest but significant preferential effect on Ba/F3 FLT3-ITD (Fig. 5.1) 

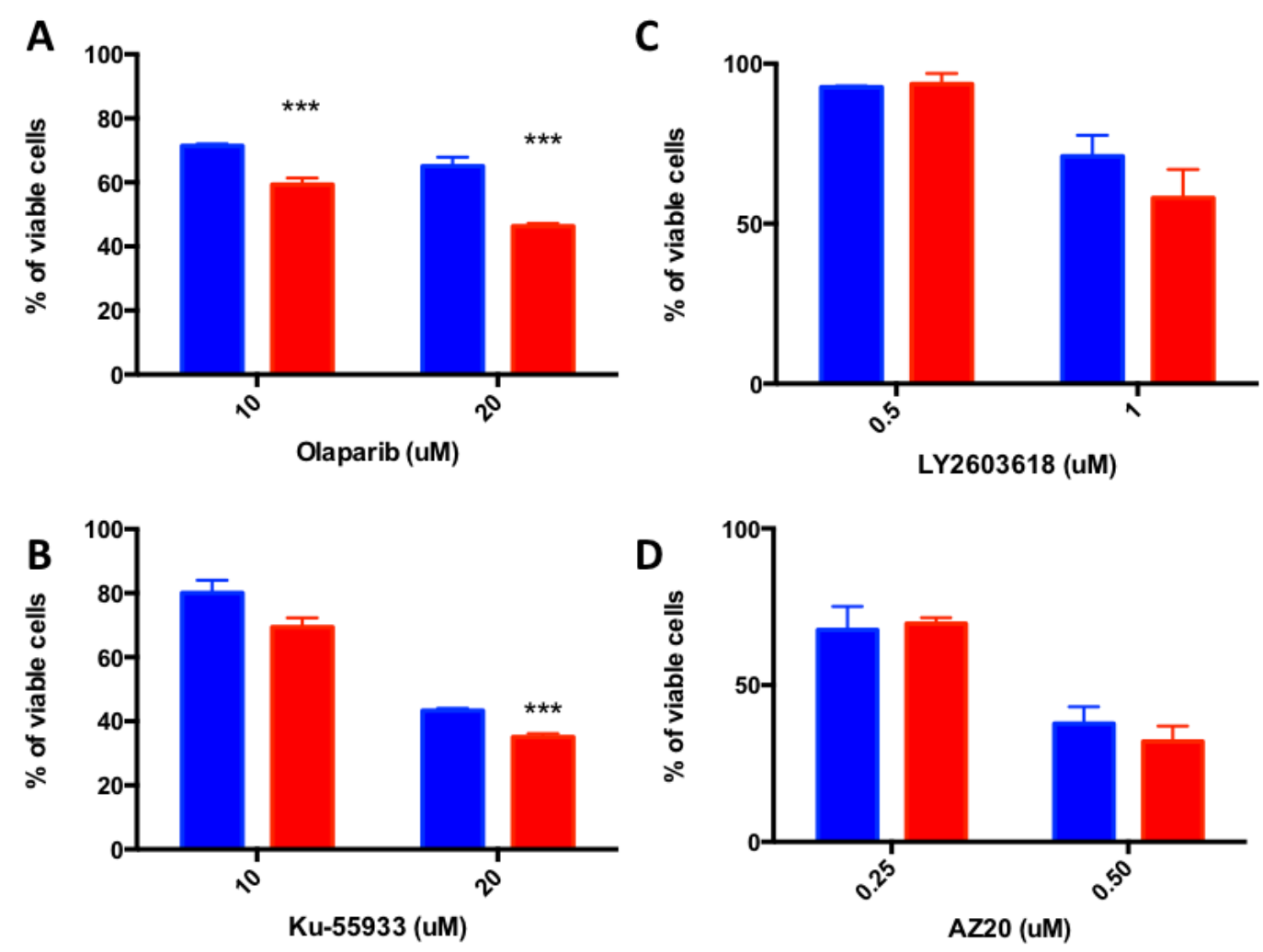

Figure 5.1 Cell proliferation assay of inhibitors targeting DNA repair proteins. $\mathrm{Ba} / \mathrm{F} 3$ FLT3-ITD cells and the parental control line were treated with inhibitors for 3 days. The number of viable cells was measured by cell viability dye Presto Blue relative to the vehicle control. The inhibitors targeted (A) PARP; Olaparib, (B) ATM; Ku-55933, (C) CHEK1; LY2603618, and (D) ATR; AZ20. n=3; *** p $<0.001$. 


\subsection{FLT3-ITD cells showed higher basal level of double-stranded}

\section{DNA breaks that was accentuated by Olaparib.}

In this section, the genotoxic effect of PARP inhibition in FLT3-ITD cells was examined, predicating on the premise that PARPi should impair SSB repair and cause DSB accumulation, driving FLT3-ITD cells to NHEJ pathway for DDR as BRCA2 expression and HR activity were suppressed in this AML subtype. The error-prone NHEJ might induce genomic instability and apoptosis.

Gamma-H2AX $(\gamma-\mathrm{H} 2 \mathrm{AX})$ is a biomarker for DNA double-stranded breaks, of which DSBs in the chromatin initiate the phosphorylation of the histone H2AX at serine 139 25. By immunoblot analysis and immunofluorescence, basal level of $\gamma-\mathrm{H} 2 \mathrm{AX}$ was higher in $\mathrm{Ba} / \mathrm{F} 3$ FLT3-ITD cells when compared to control (Fig. 5.2), indicating a higher level of basal DSB. Olaparib treatment significantly accentuated DSB as demonstrated by an increase in $\gamma \mathrm{H} 2 \mathrm{AX}$ immunostaining.

The neutral comet assay, a single cell gel electrophoresis assay to detect genomic DSB for single cell, was performed to directly quantify the genomic DNA damage caused by FLT3-ITD oncogenic protein and the effects of Olaparib (Fig. 5.4A). The comet assay images were analysed by OpenComet (Fig. 5.4B) ${ }^{86}$. FLT3-ITD induced higher level of DNA DSB which was accentuated by Olaparib treatment. 
A

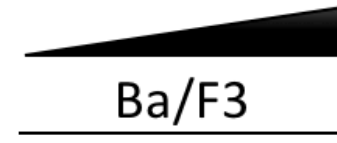

B

$\mathrm{Ba} / \mathrm{F3}$

$\mathrm{Ba} / \mathrm{F3}$

FLT3-ITD
Control
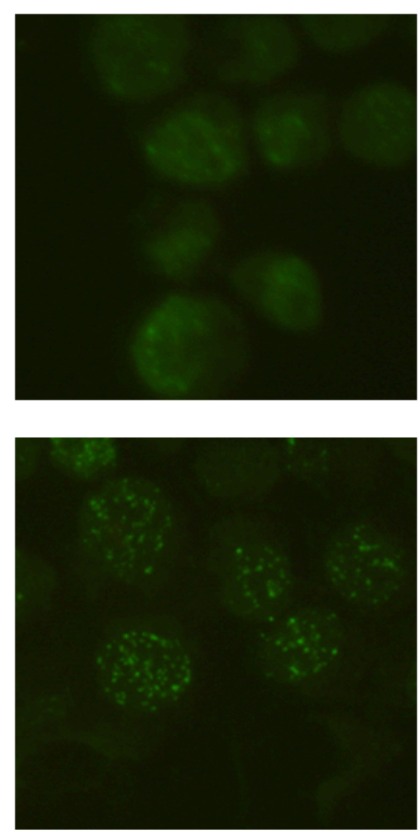

Olaparib

Ba/F3 FLT3-ITD

$\gamma-\mathrm{H} 2 \mathrm{AX}$

FLT3

Tubulin

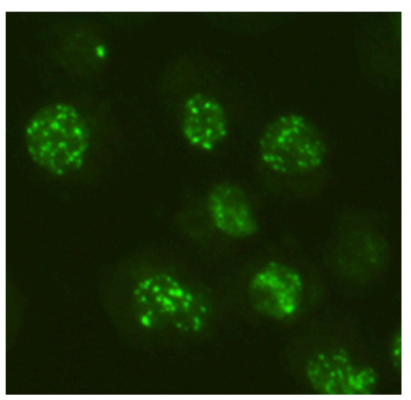




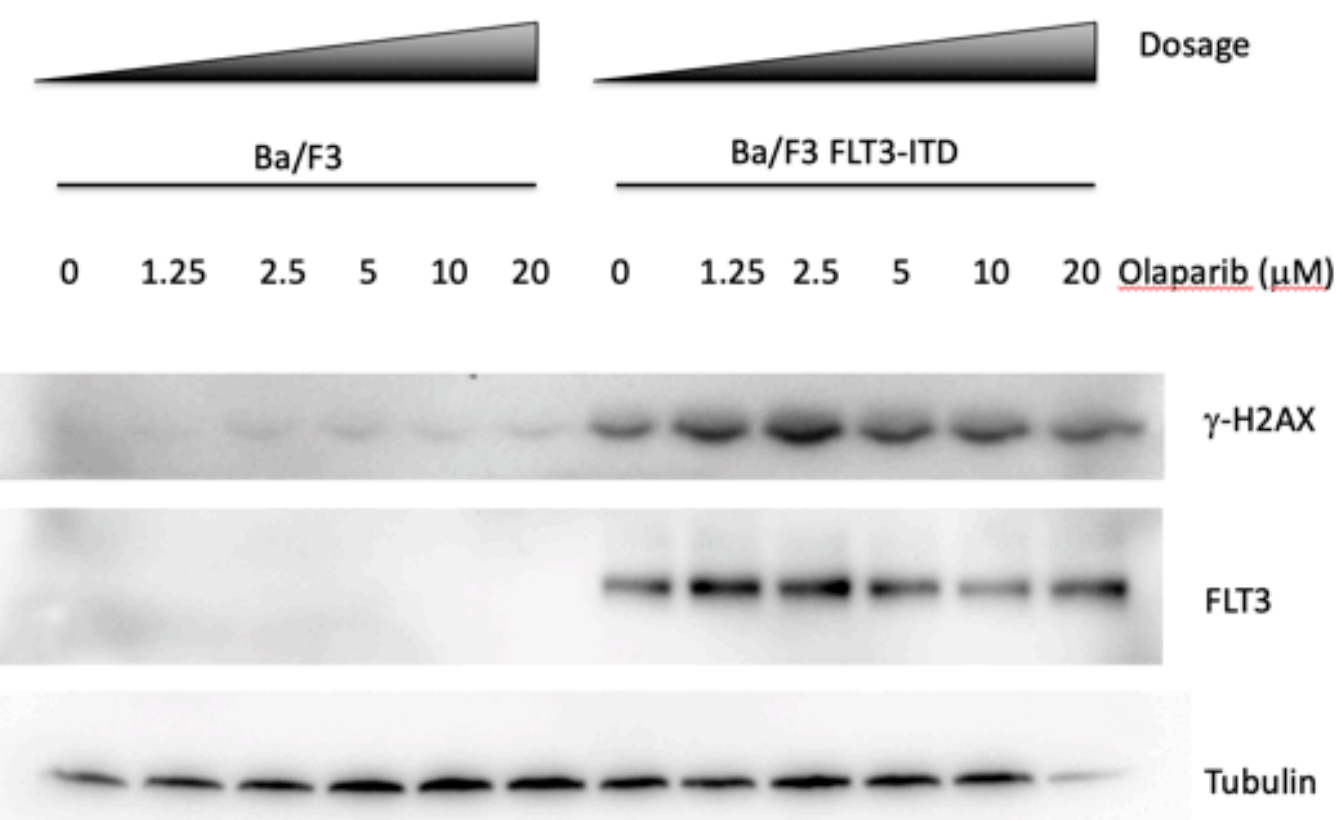

Figure 5.2 Analysis of $\gamma-\mathrm{H} 2 \mathrm{AX}$ level in Ba/F3 FLT3-ITD cells treated with Olaparib by immunoblot analysis and immunofluorescence microscopy.

$\mathrm{Ba} / \mathrm{F} 3$ FLT3-ITD cells and the $\mathrm{Ba} / \mathrm{F} 3$ control line were treated with of Olaparib. The cells were harvested after 24 hours for immunoblot and immunofluorescence analysis. (A) Representative immunoblot result with increasing dose of Olaparib at 1 and 2.5 $\mu \mathrm{M}$ of Olaparib. The (B) Representative immunofluorescence image captured with Olympus IX70 using 40X objective. $n=3$. (C) Original immunoblot of (A). 

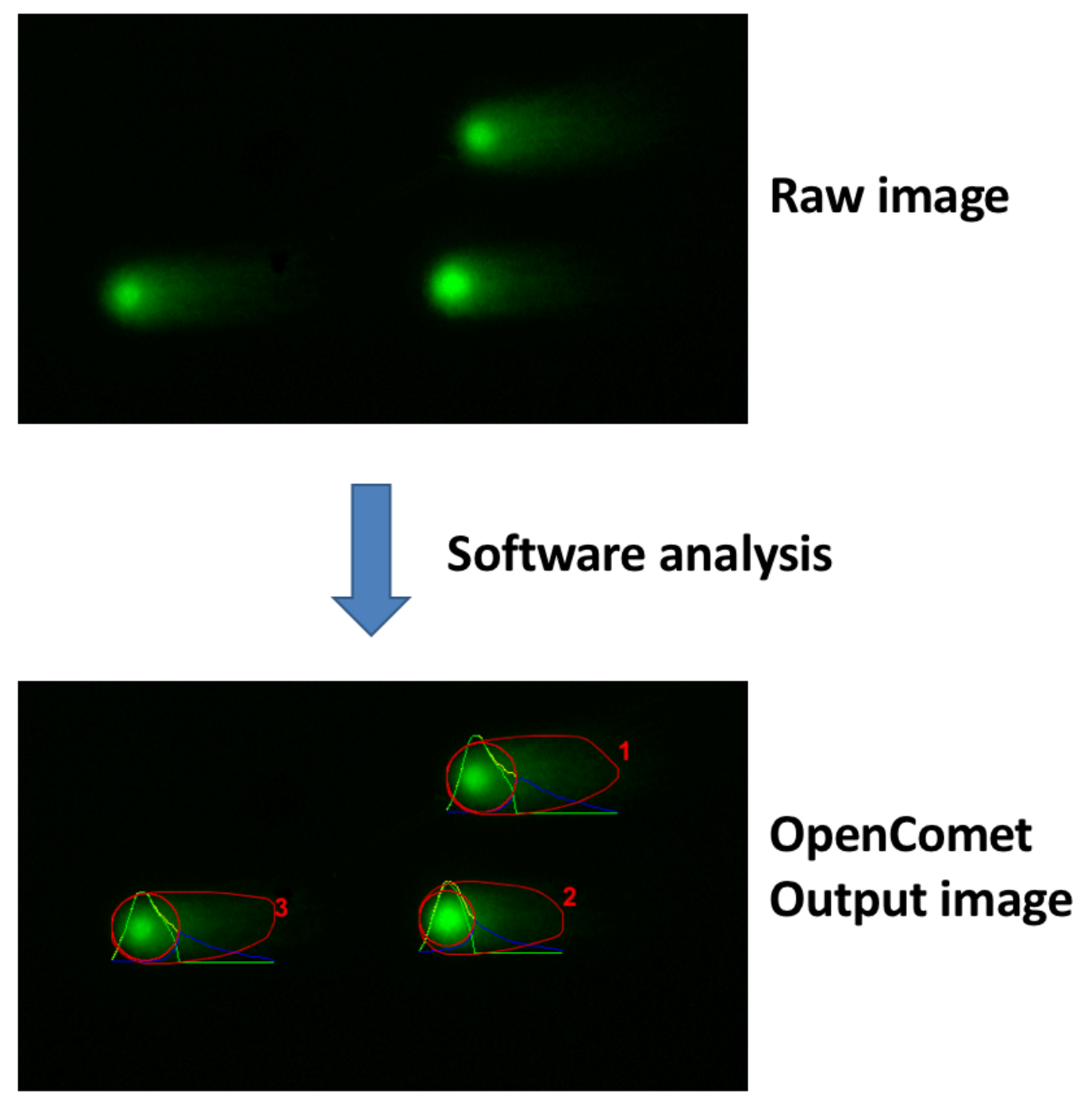

Figure 5.3 Diagrammatic illustration of neutral comet assay analysis using OpenComet Software.

The raw comet image was imported to OpenComet plugin in ImageJ and the analysis was run automatically. Individual comet was identified by the Comet Head Finding Algorithm as shown in the figure as 1,2 and 3. The olive circle represented whole comet and the regular circle represented comet head. The tail moment was calculated as the length of comet tail times tail DNA \%. 


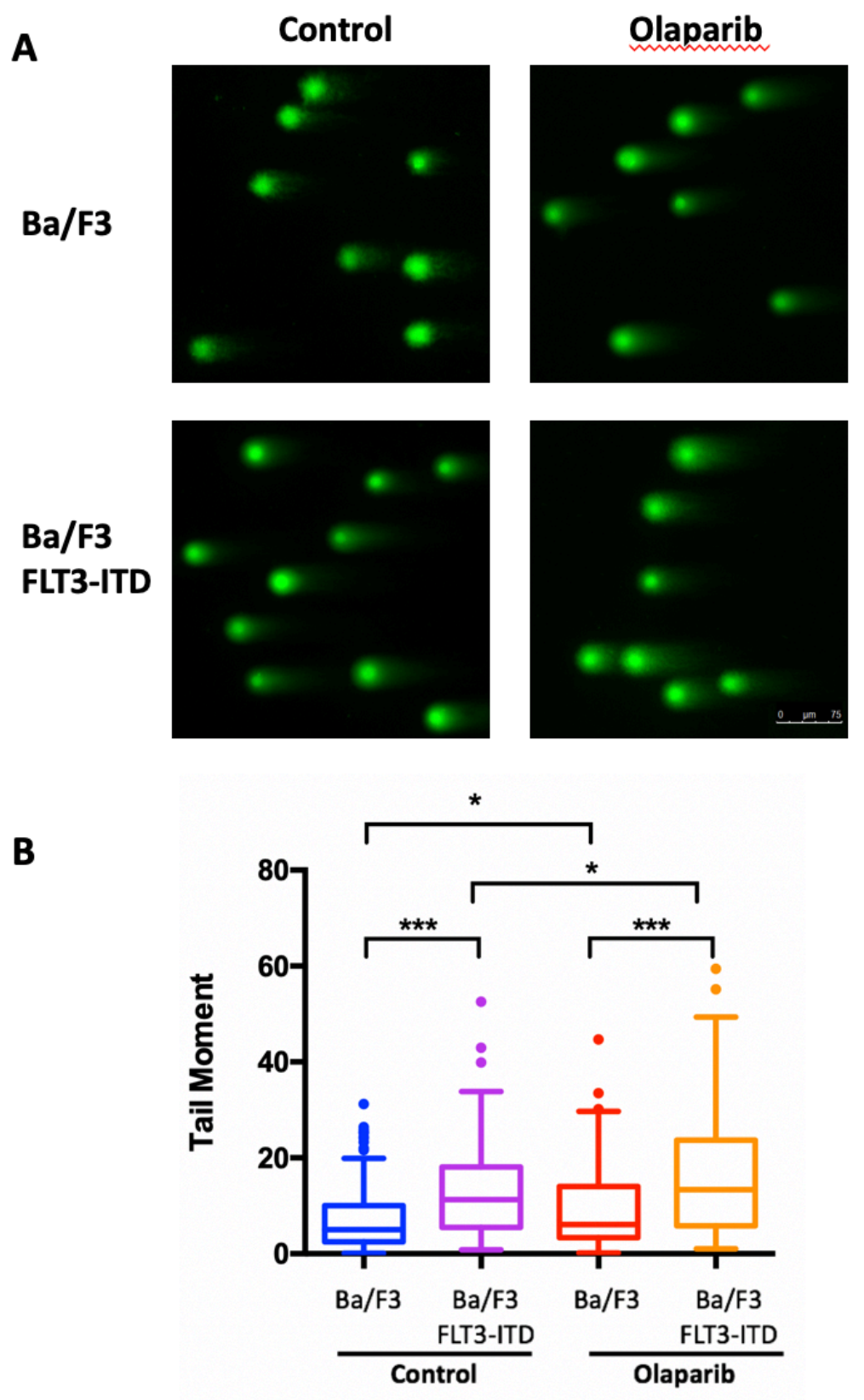

Figure 5.4 Neutral comet assay in Ba/F3 FLT3-ITD cells treated with Olaparib.

The cells were treated with $1 \mu \mathrm{M}$ of Olaparib for 24 hours and subjected to neutral comet assay to detect DNA double-stranded breaks. (A) Representative comet images. White bar $=75 \mathrm{~mm}$. (B) Statistical analysis of comet images using the OpenComet software. The double-stranded DNA breaks were quantified by tail moment $(\%$ of DNA tail $x$ length of tail). ${ }^{*} \mathrm{p}<0.05 ;{ }^{* * *} \mathrm{p}<0.001 . \mathrm{N}=3$ and $\mathrm{n}=117 ; 113 ; 102 \& 112$ respectively. 


\subsection{Elevated ROS level modulated sensitivity of FLT3-ITD to PARP}

\section{inhibitor}

To identify the cause of increased DSB in FLT3-ITD AML, intracellular ROS was measured in $\mathrm{Ba} / \mathrm{F} 3$ FLT3-ITD. The level of ROS was significantly higher in FLT3ITD compared with its parental control (Fig. 5.5). Intriguingly, Olaparib treatment accentuated the increase in ROS in Ba/F3 FLT3-ITD cells but not the parental control.

\subsection{Combination of PARP inhibitors and chemotherapy}

The result of defective HR repair and anti-leukemic effect of PARPi in FLT3-ITD AML suggested that it might be used to sensitize leukemic cells to chemotherapy. The effects of Olaparib in combination with chemotherapy were evaluated in MOLM-13 NSG xenograft model (see Chapter 3.13). Leukemia engraftment was monitored at real-time by bioluminescence imaging after intraperitoneal luciferin injection. Olaparib in combination with chemotherapy suppressed leukemic growth in vivo (Fig. 5.6). However, the small number of animals in each group had precluded robust statistical evaluation. 


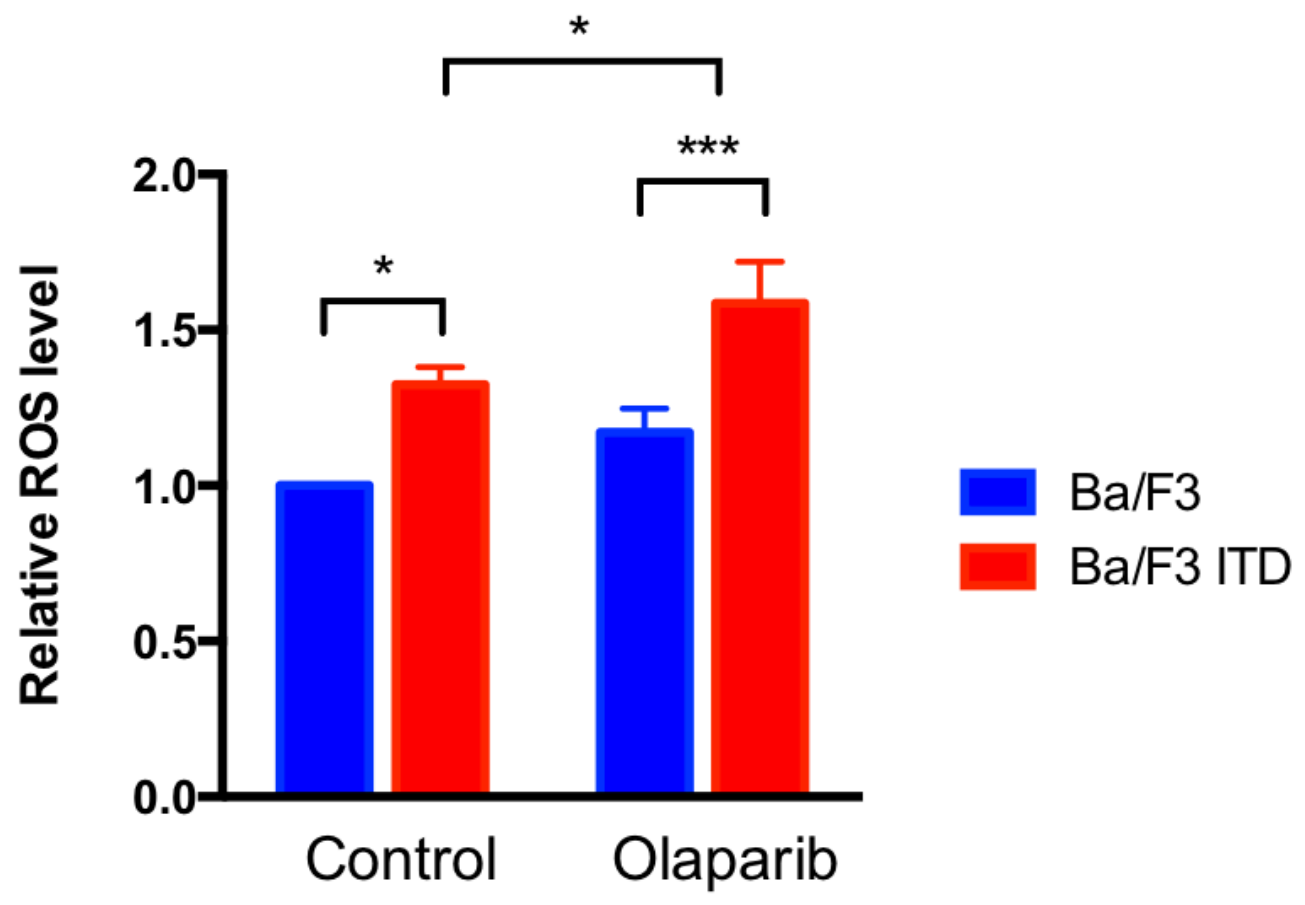

Figure 5.5 Intracellular ROS measurement of Ba/F3 FLT3-ITD cells treated with Olaparib.

$\mathrm{Ba} / \mathrm{F} 3$ parental and FLT3-ITD cells were treated with Olaparib for 24 hours and followed by loading of ROS detecting probe 2'7'-dichlorodihydro-fluorecein diacetate (H2DCFDA). The intracellular ROS level was measured by flow cytometry and normalized to $\mathrm{Ba} / \mathrm{F} 3$ parental vehicle control. $\mathrm{n}=3, * \mathrm{p}<0.05 ; * * * \mathrm{p}<0.001$. 
A

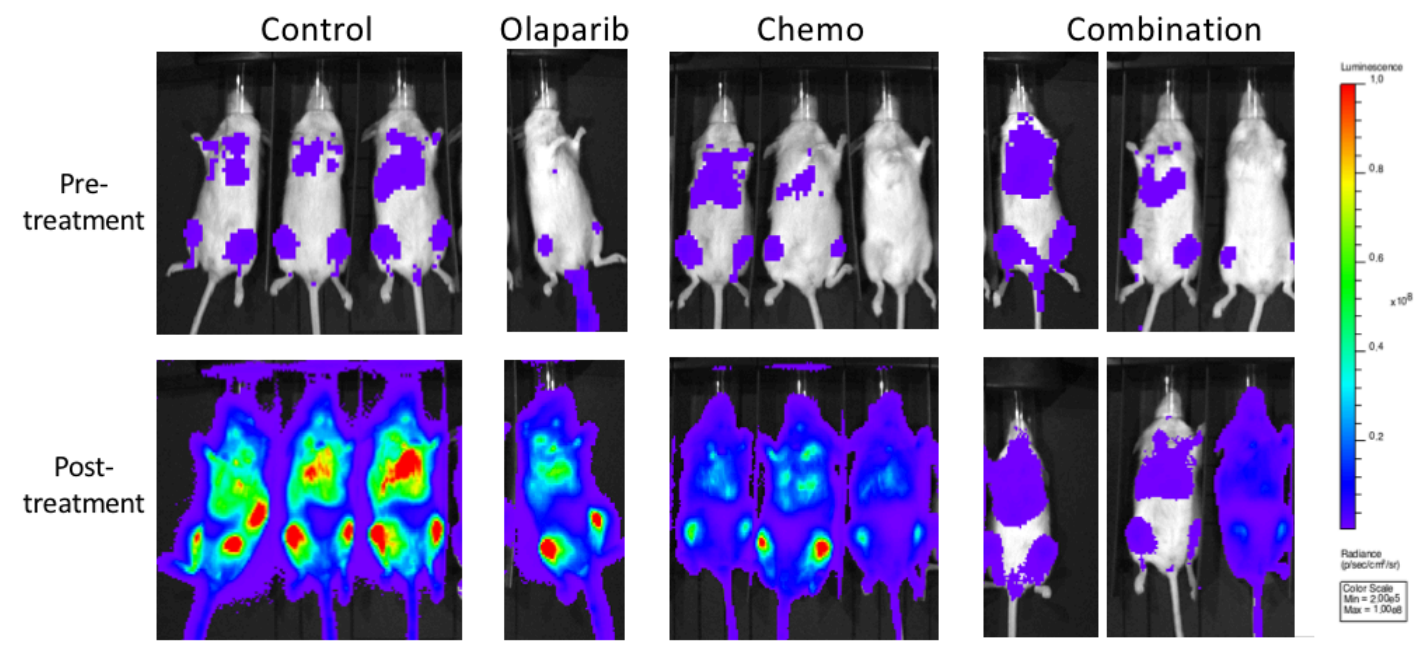

B

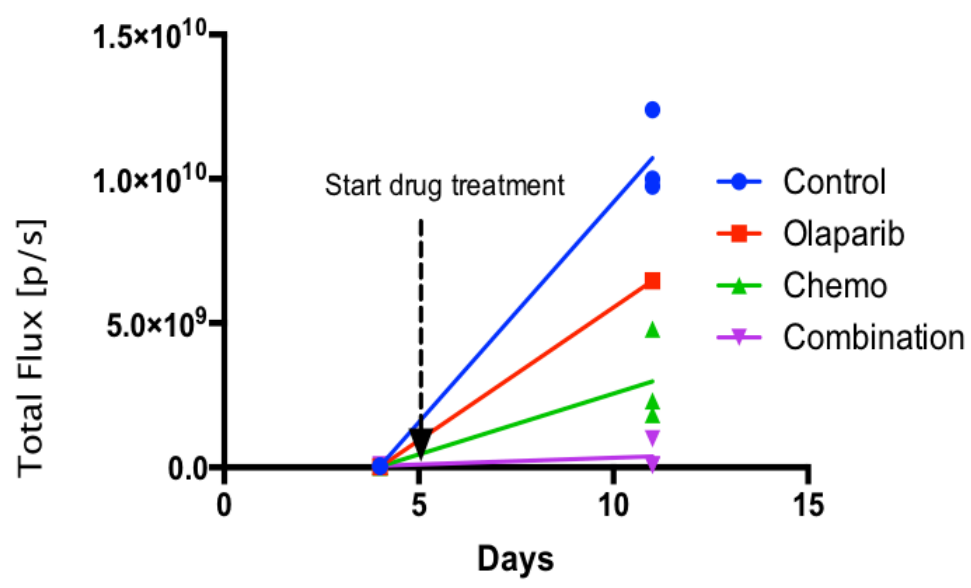

Figure 5.6 In vivo drug treatment of Olaparib and chemotherapy in MOLM-13 xenograft model.

(A) MOLM-13 AML cells transduced with a luciferase reporter were intravenous injected into NSG mice. The pre-treatment bioluminescence image was captured at 4day post-transplantation. At the $5^{\text {th }}$ day of the experiment, mice were divided into 4 groups for drug treatment for 5 days. The post-treatment image was taken at $11^{\text {th }}$ day post-transplantation. The experiment was terminated due to cytotoxic effect of chemo drugs. (B) The graph showing the change in luminescence intensity with individual experimental mouse. 


\section{Chapter 6 Screening of synthetic lethal candidate of DDR}

\section{genes with PARP inhibitors by shRNA library screen}

The works described in the previous chapters has led to identification of PARP inhibitor Olaparib as a potential therapeutic agent in FLT3-ITD AML. However, the effects of Olaparib were generally modest and more effective regimen comprising Olaparib and its therapeutic partners were needed. This could be accomplished by a comprehensive $\operatorname{sh} R N A$-based screening and was based on the principle of synthetic lethality.

\subsection{Methodology}

The DDR shRNA library consisted of all reported genes with functions annotated to DDR pathways from publications and published databases KEGG and REPAIRtoire $8,14,15,17,18,89,90$. A total of 248 genes were included in this study. The screening was performed in collaboration with Dr. Johannes Zuber (Research Institute of Molecular Pathology, Vienna) ${ }^{88}$. List of clinical trials involving DDR inhibitors was summarized in Appendix $4^{78}$. The workflow of the procedure was shown in Figure 6.1.

\subsection{Characterization and generation of Flt $3^{I T D} \mathrm{Npm}^{c+}$ cell line}

To generate murine $\mathrm{Flt} 3^{\mathrm{ITD} /+} \mathrm{Npm} 1^{\mathrm{c}^{/+}}$leukemic cell line, spleen cells from Flt3 ${ }^{\text {ITD/+ }}$ $N p m 1^{c /+}$ double knockin mouse (generously provided by Dr. George S Vassiliou, Sanger Institute, UK) were transplanted into recipient mice to develop AML ${ }^{105}$. Once AML occurred, BM cells were isolated and established into a stable and proliferating cell line. The immunophenotypes of leukemic cells in BM, spleen and liver of the 


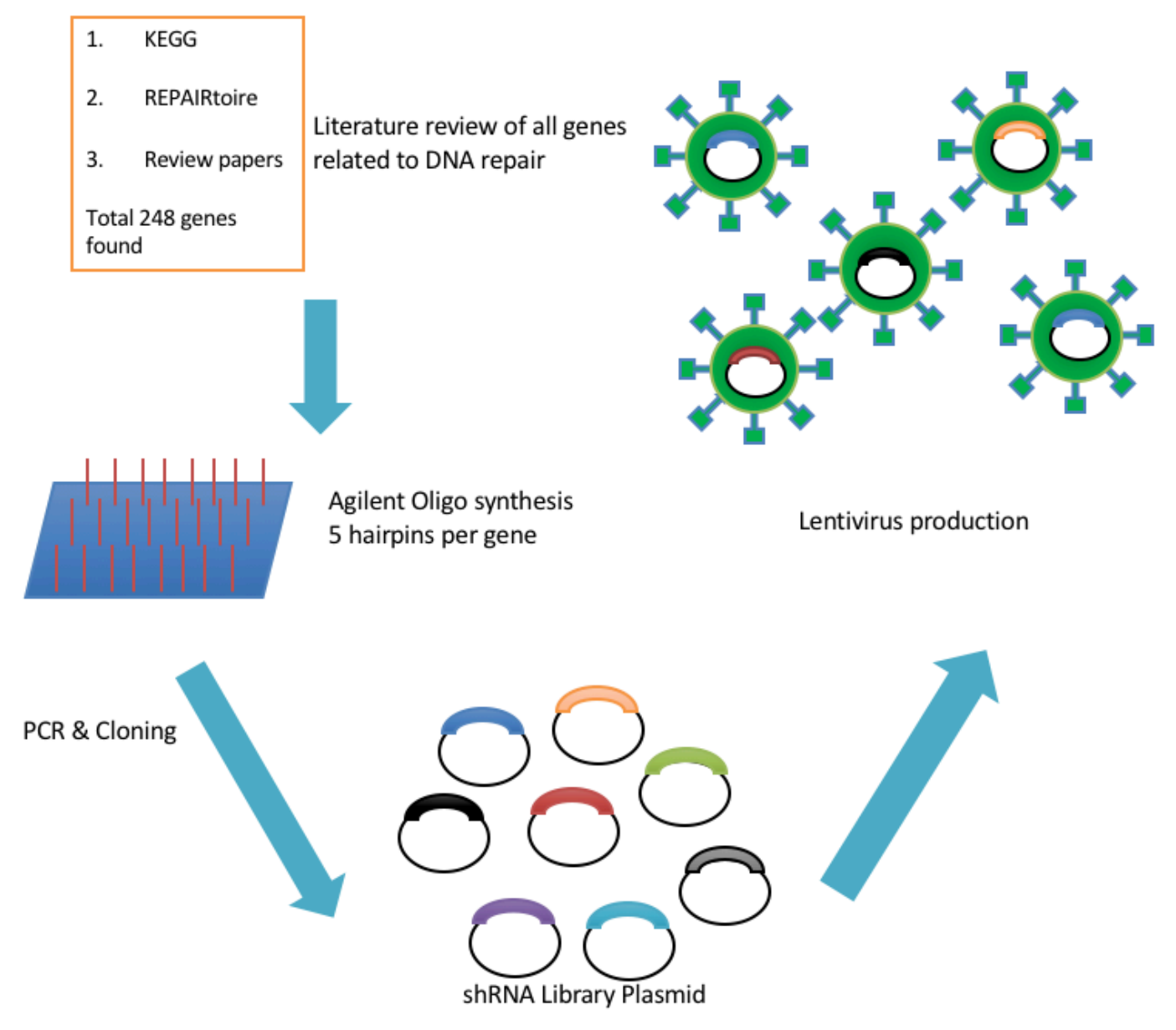

Figure 6.1 Construction of mouse DDR $\operatorname{sh} R A$ library.

Based on literature review, a total of 248 genes with reported DNA damage response were selected. Top 5 hairpins of each gene were selected for oligo synthesis. Following the cloning of $\operatorname{sh} R A$ library plasmid, the DDR $\operatorname{sh} R A$ library was packaged into lentivirus for subsequent experiments. 
recipient mice were shown in Figure 6.2, showing a predominant mature granulocytic $\left(\mathrm{Gr}^{+} 1^{+} / \mathrm{Macl}^{+}\right)$, monocytic $\left(\mathrm{Gr}-1^{-} / \mathrm{Macl}^{+}\right)$and immature myelomoncytic (c-kit $\left.{ }^{+}\right)$ populations, resembling the immunophenotype in previous publication ${ }^{105}$. Those of the AML cell line established in vitro were shown in Figure 6.3. and they were all $\mathrm{Mac}^{+} 1^{+} / \mathrm{Gr}-1^{+}$mature granulocytic leukemic cells, indicating successful establishment of a Flt3 ${ }^{I T D /} \mathrm{Npml}^{\mathrm{cl}+}$ myeloid-lineage leukemic cell line. The in vitro effects of Olaparib on their clonogenicity were examined. Olaparib suppressed the colony forming ability of the $\mathrm{Flt} 3 \mathrm{ITD} /+^{\mathrm{Npm} 1^{\mathrm{c} /+}}$ leukemic cells more significantly than the MLL-AF9 transformed AML cells (Fig. 6.4).

\subsection{Experimental scheme of DDR shRNA screening in vivo}

The experimental scheme was designed with the purpose of screening for novel therapeutic agents that could work synergistically with Olaparib (Fig. 6.5). Flt3 ITD/+ $N p m 1^{c /+}$ AML cells were transduced with lentivirus carrying $p R R L-G F P$-Puro-mouse $D D R-s h R N A$. AML cells that were successfully transduced were purified by FACS 2 days post-transduction and transplanted into recipient mice intravenously. Two weeks post-transplantation, one group of recipient mice were treated with Olaparib $(50 \mathrm{mg} / \mathrm{kg})$ intraperitoneally for 2 weeks and another group received vehicle control (same volume of DMSO solvent control) by the same route and for the same duration. All mice were euthanized and analyzed 4 weeks after completion of the 2-week treatment or if they showed symptoms of debilitation which was most likely related to underlying AML. Genomic DNA was extracted from their BM samples and Miseq sequencing library was prepared as per protocol from Dr. Johnannes Zuber. The list of DNA samples submitted for sequencing was shown in Appendix 5. Diagrammatic representation of the final PCR product of Miseq sequencing library was shown in 


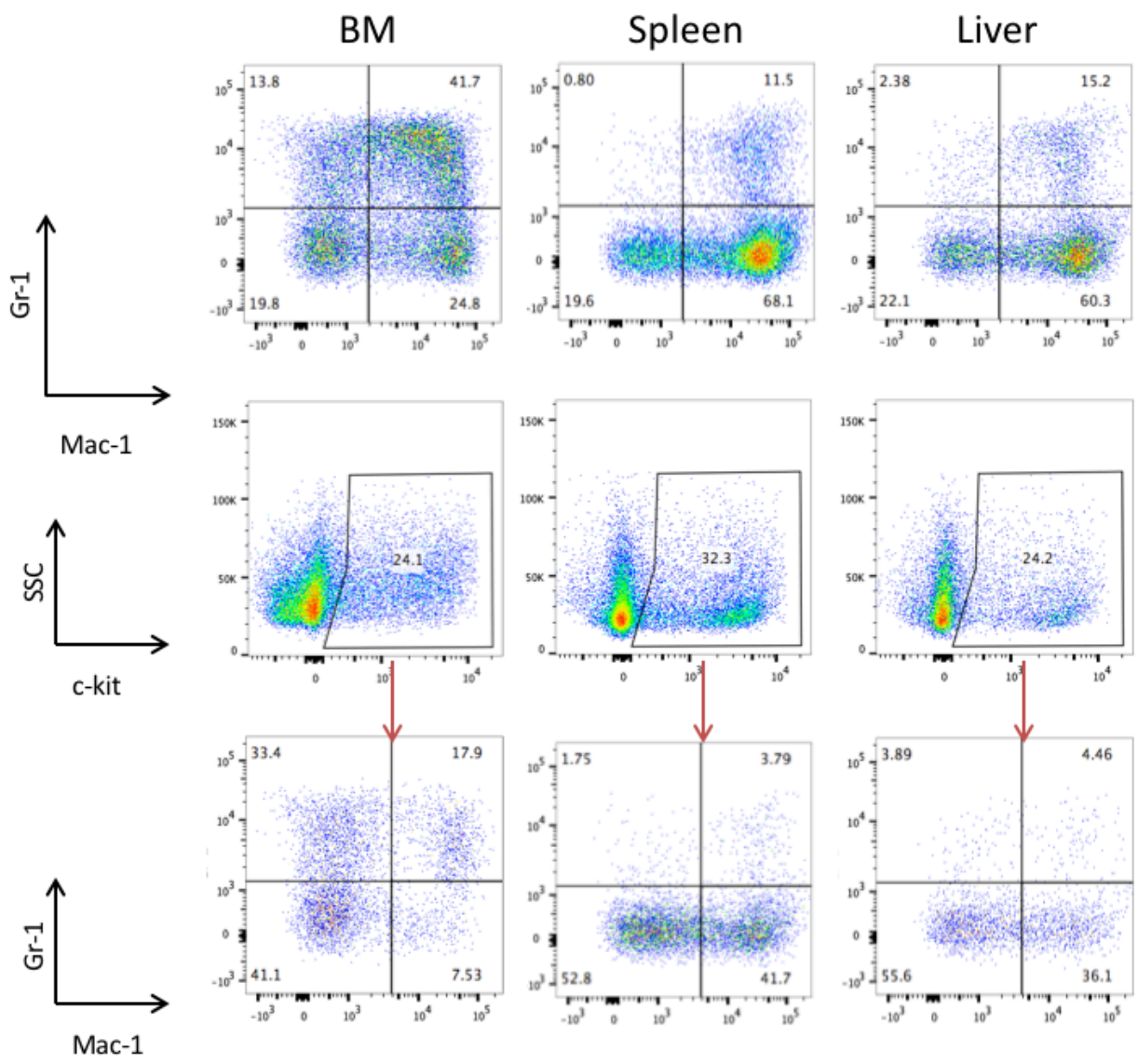

Figure 6.2 Immunophenotype analysis of leukemic mice transplanted with spleen cells recovered from $\mathrm{Flt}^{I T D /+} \mathrm{Npm}^{\mathrm{ct/+}}$ knockin mouse.

Representative flow cytometry data of Flt3 ${ }^{I T D /+} \mathrm{Npm}^{\mathrm{c} /+}$ leukemic cells gated on CD45.2 population of bone marrow (BM), spleen and liver cells of the recipient mice. Result showed that the leukemic cells resided in BM were predominantly $\mathrm{Mac}-1^{+} /$ Gr- $1^{+}$mature granulocytic cells while leukemic cells resided in spleen and liver were Gr-1 ${ }^{-} / \mathrm{Mac}^{+}$monocytic cells. 

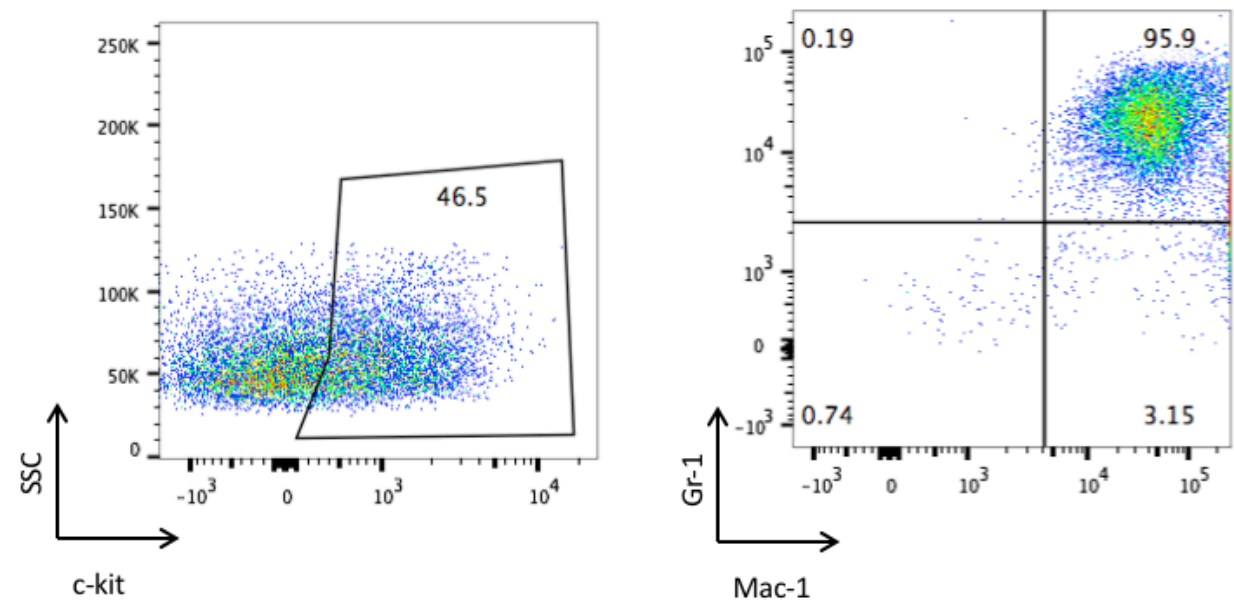

Figure 6.3 Immunophenotype analysis of primary murine $\mathrm{Flt3}^{\mathrm{ITD} /+} \mathrm{Npm}^{\mathrm{c/+}}$ cell line.

Representative flow cytometry data of the in vitro established Flt $3^{\text {ITD/ }} \mathrm{Npm} 1^{\mathrm{c} / \mathrm{t}}$ leukemic cells line. Result showed that the cell line was predominantly Mac-1 ${ }^{+} / \mathrm{Gr}-$ $1^{+}$mature granulocytic cells and around half of those cells were c-kit ${ }^{+}$. 
A

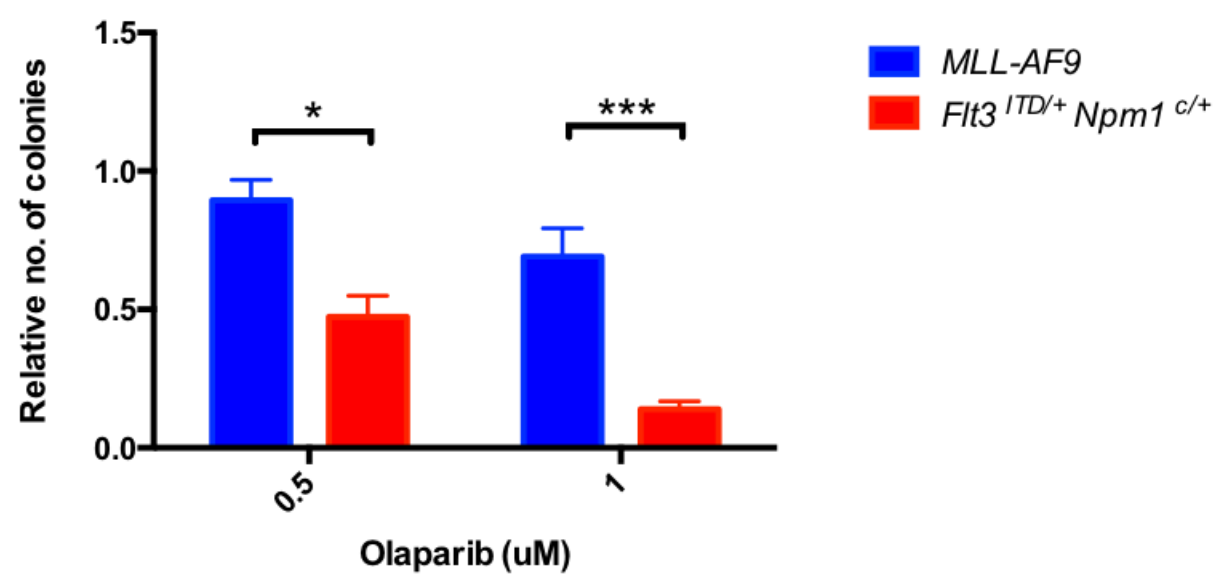

B

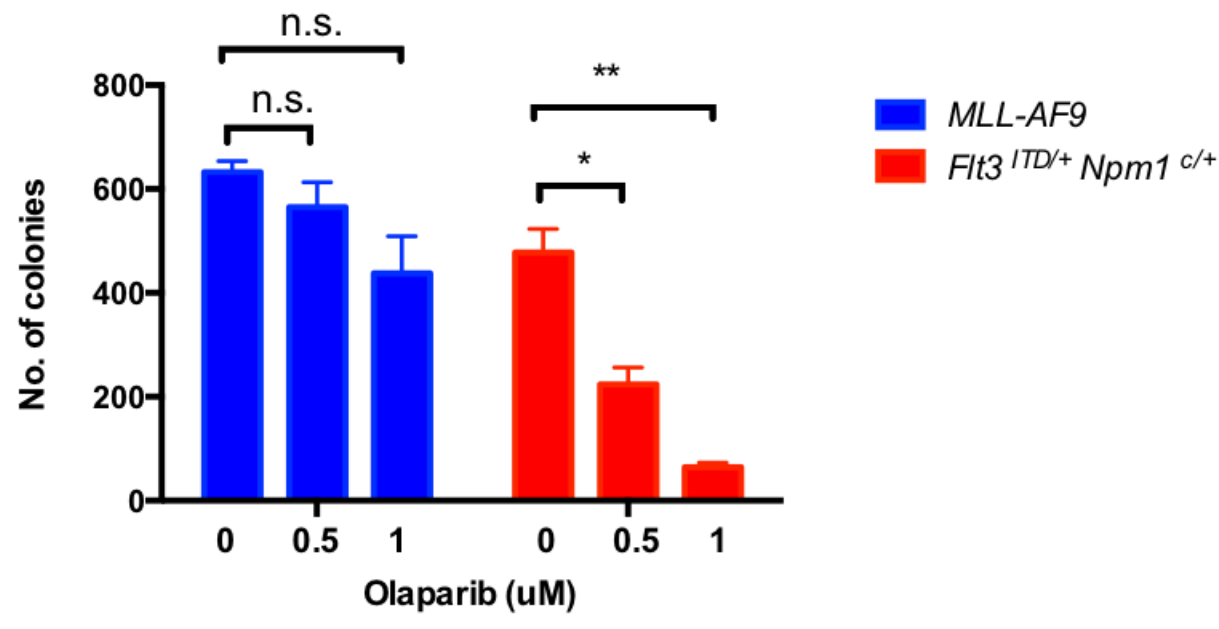

Figure 6.4 Colony formation assay of leukemic cells of $M L L-A F 9$ or Flt ${ }^{I T D /+}$ $\mathrm{Npm}^{c /+}$ treated with Olaparib for 5 days in methyl cellulose.

(A) Relative no. of colonies normalized to vehicle control and (B) Absolute no. of colonies. $\mathrm{n}=3,{ }^{*} \mathrm{p}<0.05 ; * * \mathrm{p}<0.01 ; * * \mathrm{p}<0.001 ;$ n.s. not significant. 


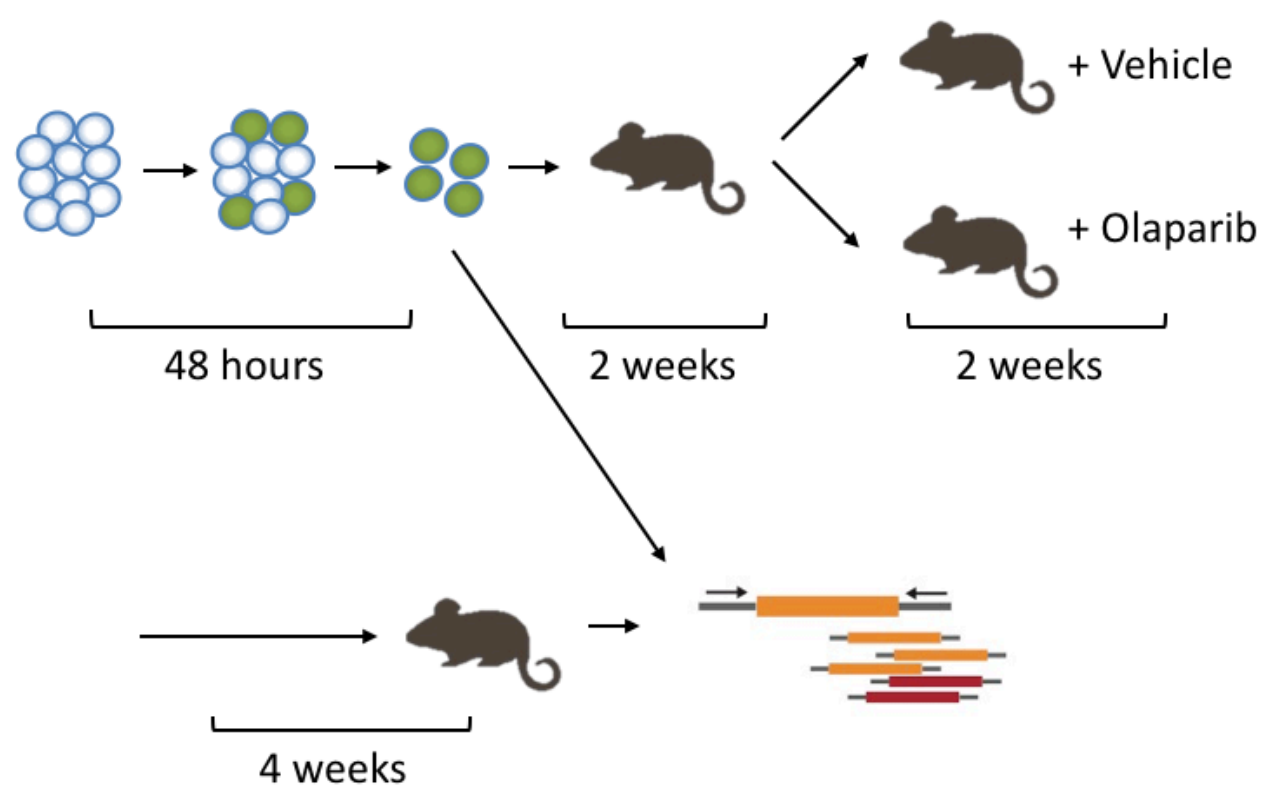

Figure 6.5 Experimental scheme of in vivo shRNA library screening.

The Flt3 ${ }^{I T D /+} \mathrm{Npm}^{\mathrm{c} /+}$ leukemic cells were lentivirally transduced with mouse DDR library $\operatorname{sh} R A$ s. At $48^{\text {th }}$ hours post-transduction, the GFP+ transduced cells were sorted out by FACS and 0.1 million of sorted cells were transplanted into each recipient CD45.1 SJL mouse. Two weeks post-transplantation, the experimental mice were divided into two groups and treated with either $50 \mathrm{mg} / \mathrm{kg}$ Olaparib or vehicle control for 2 weeks. The drug-resistant clones were allowed to recover for 4 additional weeks in vivo. The genomic DNA of total bone marrow leukemic cells were harvested, together with the pre-transplant samples to prepare sequencing library for Miseq run. 
Figure 6.6A. Prior to Miseq sequencing, the pooled final PCR product was subjected to Sanger sequencing using Illumina P5 adaptor primer to confirm correct amplification of ShRNA hairpin region, unique barcoding region and custom sequencing primer binding site (Figure 6.6B). The sequencing library was sequenced by Illumina Miseq platform using Miseq V2 50 cycle kit.

\subsection{Basic bioinformatics filtering of the MiSeq run}

Basic bioinformatics analysis, including FASTQC of sequencing run, trimming of reads, de-multiplexing and mapping of $\operatorname{sh} R A A$ hairpins and statistical analysis were performed by Ms Claire Lynn. The FASTQC confirmed the 22bp reads of shRNA hairpins followed by the common sequencing adapter and unique barcodes (Fig. 6.7). With the spiking of $20 \%$ PhiX control DNA, the remaining $80 \%$ of the reads were uniquely mapped to the $s h R N A$ library, indicating that the Miseq run was successful.

The mapping of unique $s h R N A$ hairpins showed that the starting material, the $p R R L$ GFP-puro-mouse DDR shRNA library plasmid (\#14), contained all 1240 unique mouse DDR shRNA hairpins (Fig. 6.8A). Similarly, most unique hairpins were detected in the pre-transplantation samples (\#1 \& 7) and were mapped to 1235 and 1228 unique hairpins respectively. The number of unique hairpins was decreased in endpoint samples, indicating that cells carrying those hairpins were dropped out overtime.

The quality filtered mapped reads of individual samples were shown in Figure 6.8B. The number of reads that would give a good representation of hairpins distribution 
A

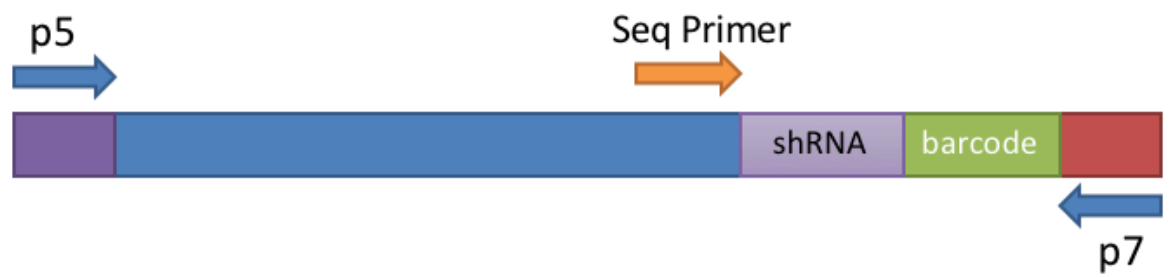

B

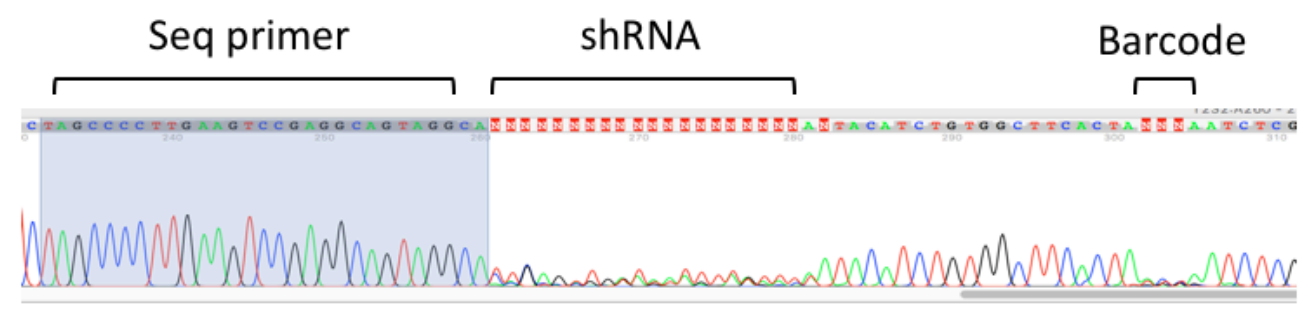

Figure 6.6 Information of DNA sample for Miseq.

(A) Diagram showing the final PCR product generated for Miseq sequencing. (B)

Chromatogram of the final pooled DNA sample by Sanger sequencing using Illumina P5 sequencing primer. 


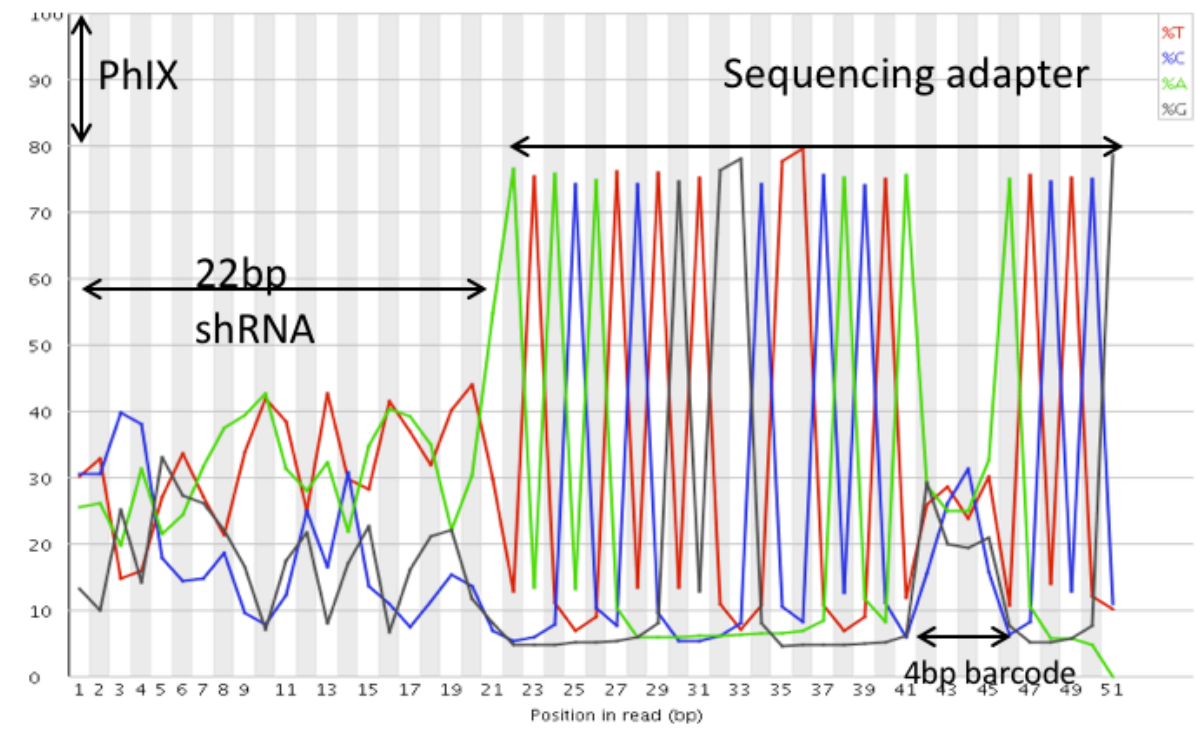

Figure 6.7 FASTQC plot of the Miseq sequencing run.

The diagram showed the read alignment of pooled sequencing reads with the $20 \%$ PhiX control DNA filtered out. Starting from read position 1-22 was the unique $\operatorname{sh} R N A$ sequences following by the common sequencing adapter from position $23-50$. The unique $4 \mathrm{bp}$ barcodes marked individual samples. 
A

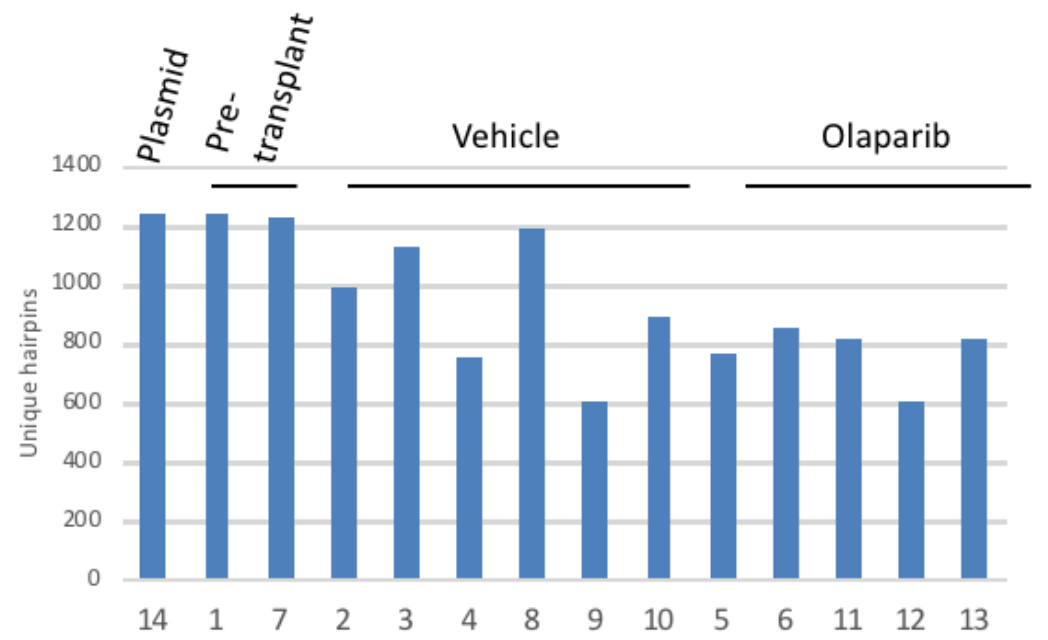

B

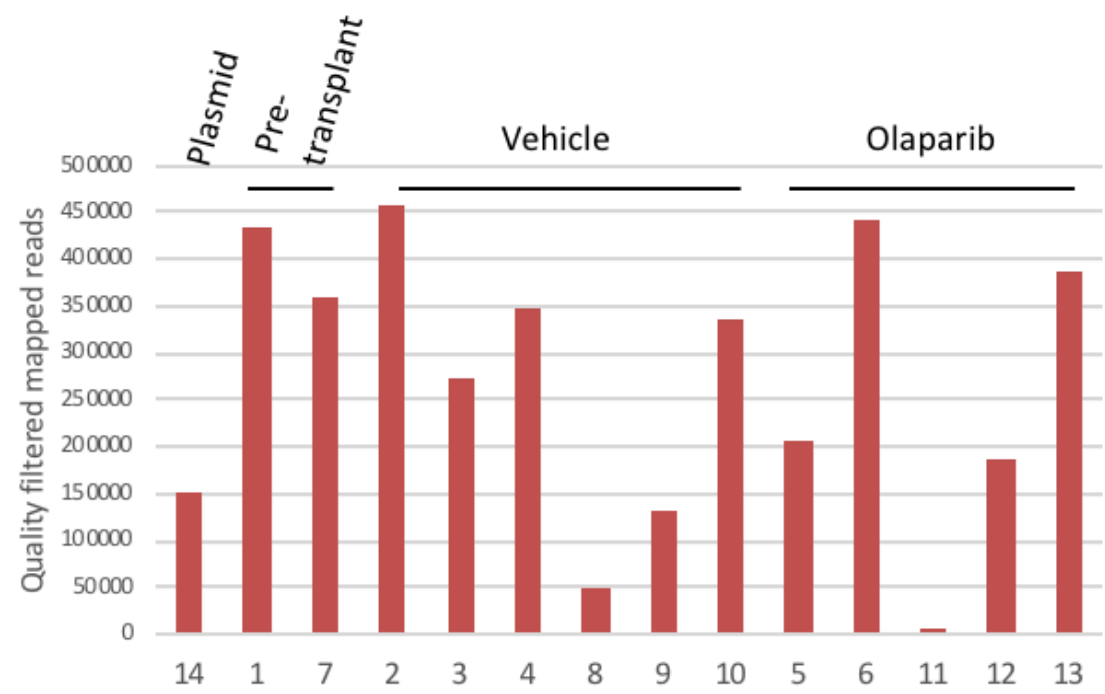

Figure 6.8 Alignment result of Miseq run to unique hairpin sequences.

(A) Result of mapping of reads to unique hairpins. Total number of hairpins in the mouse DDR library was 1240. (B) Result of mapping the quality filtered mapped reads. 
was 1000 -fold of the number of total hairpins, i.e. $1.2 \times 10^{6}$ reads. In this study, the number of reads of individual samples ranged from 7397 (\#11) to $0.46 \times 10^{6}$ (\#2) (Fig. 6.8B). Cutoff for downstream analysis was set to $0.12 \times 10^{6}$ reads. Therefore, sample \# 8 and 11, with 47,197 and 7,397 mapped reads, were not included for further analysis.

\subsection{Dropout analysis of $\operatorname{sh} R N A$ library screening}

Analysis of $\operatorname{sh} R A A$ screen was performed using an open-source processing pipeline optimized for analyzing pooled library sequencing screens in edge $\mathrm{R}^{106}$. The overall distribution of probability of hairpin dropout was shown in Figure 6.9.

A gene was considered as dropped out if the probability of hairpin dropout (Pdrop) $\geq$ 0.6 , i.e. 3 out of 5 hairpins of that gene were significantly dropped out ( $p$-value $<0.05$ ) compared with pre-transplant samples. There were 206 dropout genes in Olaparibtreated group and 70 in the vehicle-treated group. To identify genes that were dropped out preferentially in Olaparib-treated group, the group specific dropout was examined based on the probability of dropout Olaparib minus vehicle-treated (Pdrop of O-V) of which the cutoff threshold was set at $\geq 0.6$ (Figure 6.10), i.e. at least 3 out of 5 hairpins of the same gene were dropped out in the Olaparib-treated group compared with the vehicle-treated group.

183 genes were dropped out in both vehicle-treated and Olaparib-treated leukemic cells (Fig. 6.10). They were considered candidates with oncogenic potential independent of the effects of Olaparib, including genes that were important for cell survival in general as well as those for leukemogenesis of $F l t 3^{I T D /+} \mathrm{Npm}^{c /+} \mathrm{AML}$ cells. 
- Vehicle Olaparib
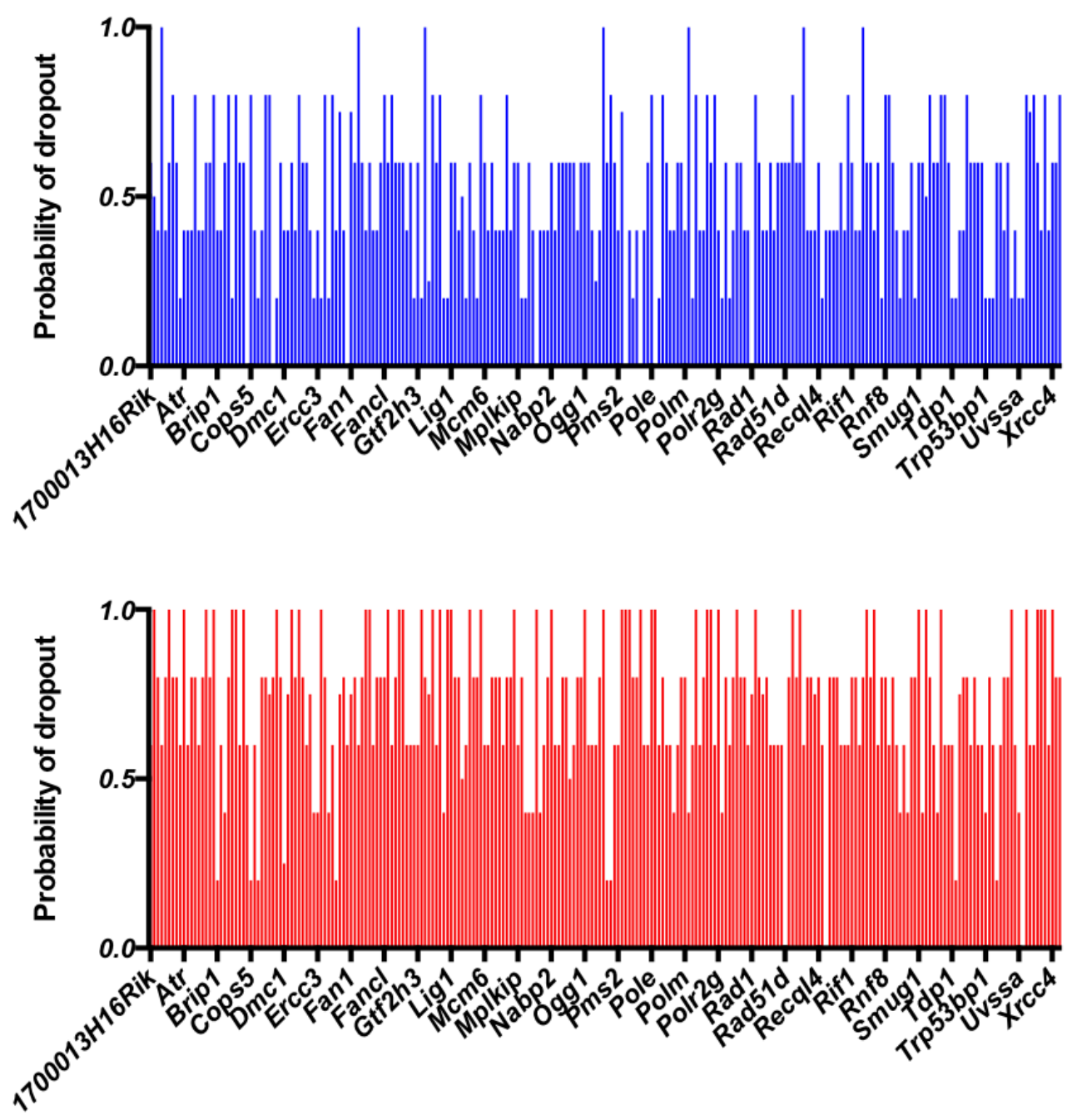

Figure 6.9 Overall distribution of probability of gene dropout in the $\operatorname{sh} R \boldsymbol{N} A$ screen.

Distribution plots showing the probability of dropout of all murine DDR genes in the shRNA screening. Top plot was overall distribution of dropout of comparing in vivo vehicle-treated endpoint samples verse pre-transplant samples while bottom plot showed the result of in vivo Olaparib-treated endpoint samples versus pre-transplant samples. 


\section{A}

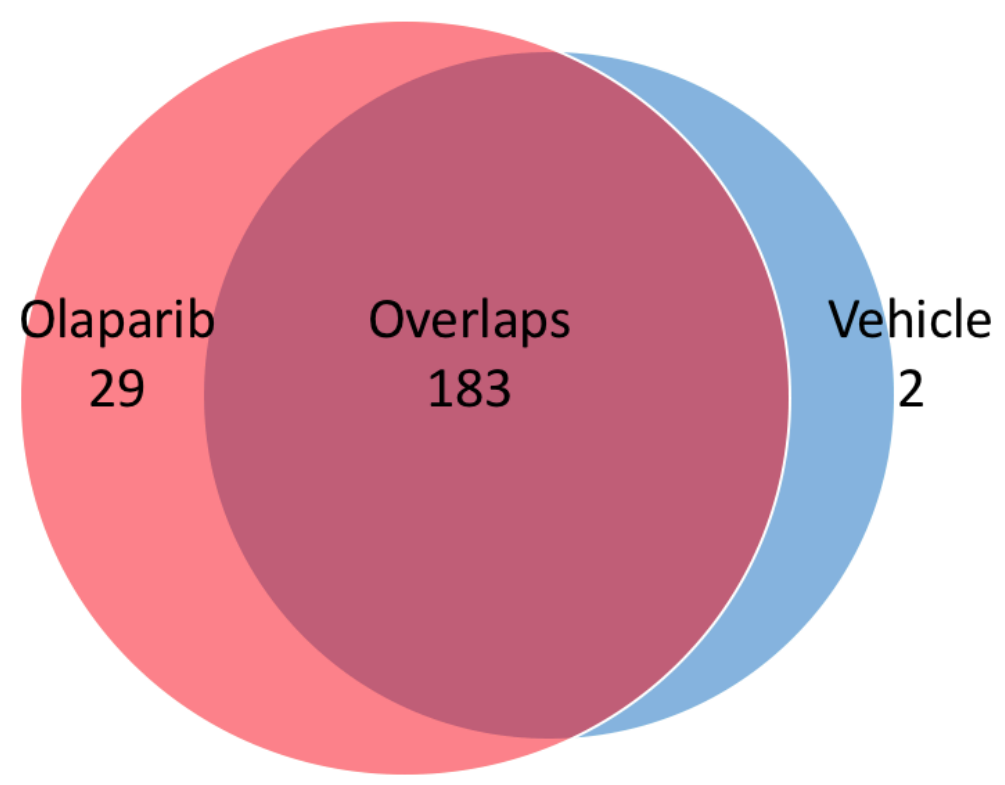

B

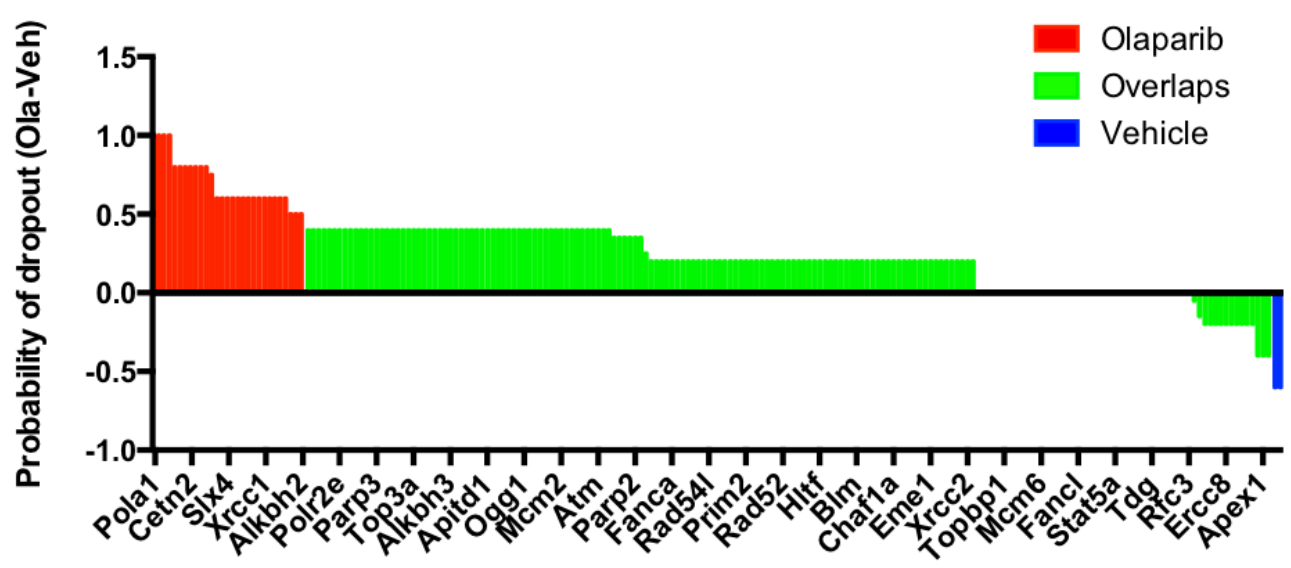

Figure 6.10 Distribution of unique hairpin dropouts.

(A) Venn diagram showing the number of unique gene dropouts in vehicle-treated group (2), Olaparib-treated group (29) and the overlaps gene dropouts (183). (B) The plot showing the difference of probability dropout of Olaparib-treated group and vehicle-treated group.

The dropout probability of important DDR genes was listed in Appendix 6. Surprisingly, HR genes such as Brca2 were categorized in the common dropout group because the baseline cutoff of Pdrop was set at 0.6 (Appendix 7). Nevertheless, all 5 
hairpins of $\mathrm{Brca} 2$ were dropped out in Olaparib-treated group while 3 hairpins were dropped out in the control group, demonstrating the effectiveness of targeting Brca2down-regulated clones using Olaparib.

29 genes were dropped out specifically in the Olaparib-treated group (Fig. 6.10). They were enriched in checkpoint factors and DNA replication factors (Fig. 6.11). For instance, members of the Family B Polymerase are involved in nuclear DNA replications and they include Polymerase alpha $(\alpha)$, delta $(\delta)$ and epsilon $(\varepsilon)$ (Appendix 5) ${ }^{107-109}$. The Atr (ATM and rad3-related) gene encodes a master regulator kinase that is activated by replication stress and single stranded DNA damage ${ }^{110-112}$. 


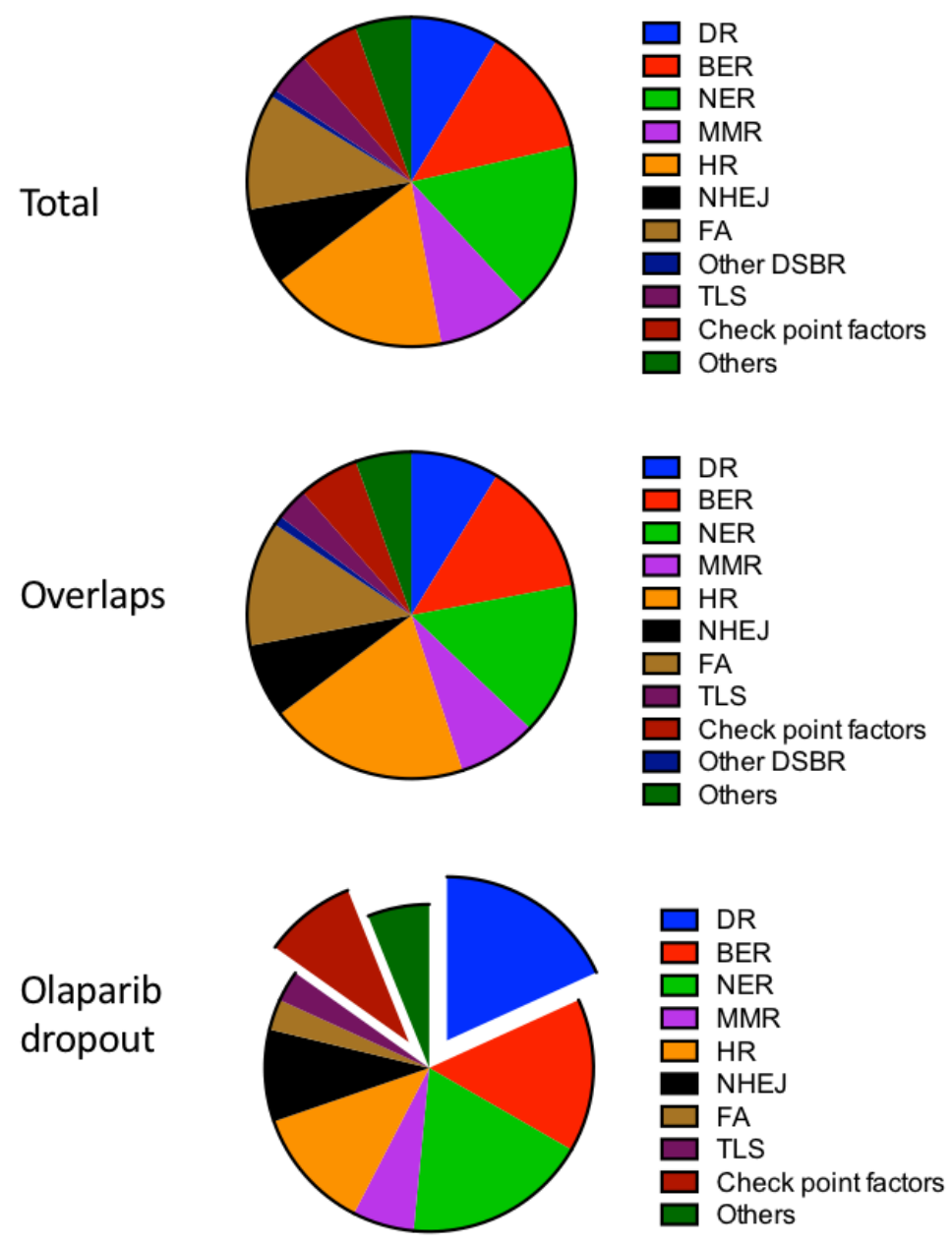

Figure 6.11 Pie chart of overall distribution of dropout genes categorized by their role in DNA damage response pathways.

Top chart showed the percentage of total DDR library genes sorted by DNA repair pathways, and similar distribution was found in the Middle chart: the overlap group. The percentage of check point factors and DNA repair genes were increased in Olaparib droupout drop (Bottom chart).

Abbreviations: DR (DNA repair); BER (base excision repair); NER (nucleotide excision repair); MMR (mismatch repair); HR (homologous recombination); NHEJ (non-homologous end-joining); FA (fanconi anemia); Other DSBR (double stranded breaks repair); TLS (translesion repair) 


\section{Chapter 7. Summary and Discussions}

Despite their diversity of clinicopathologic, cytogenetic abnormalities and genetic mutations, current treatment for AML has been uniform ${ }^{1,3-6}$. FLT3-ITD is one of the most common mutations in cytogenetically normal AML with higher relapse rates and poorer overall survivals. Although clinical studies have shown the effectiveness of multi-kinase or specific FLT3 inhibitors in clearing myeloblasts from blood and BM, the response was invariably transient ${ }^{61-65}$. There is an urgent need to develop novel effective strategy for this AML subtype.

The research began by the observation that BRCA2 expression was significantly suppressed in primary AML samples and human AML cell lines carrying FLT3-ITD as well as mouse B-lymphoid $\mathrm{Ba} / \mathrm{F} 3$ cells transduced with FLT3-ITD, consistent with the GSE15434 gene expression data deposited by Dugas's group in University of Münster. BRCA2 was regulated by FLT3-ITD signaling and its expression could be restored by a specific FLT3 inhibitor quizartinib. On the other hand, defective HR repair was evident by Traffic Light Reporter assay. Increased DSB was demonstrated by increased $\gamma$-H2AX staining as well as the neutral comet assay and was likely secondary to an increase in ROS. The results have shed important lights to the pathogenesis of FLT3-ITD AML and were of clinical significance to the development of therapeutic strategies for this AML subtype.

This study highlighted the importance of defective DDR in the pathogenesis of FLT3ITD AML. The results were consistent with published data about defective DDR in this subtype, but the underlying mechanisms were reportedly different among studies. In this study, it was associated with down-regulation of $B R C A 2$ expression and HR. On the other hand, down-regulation of $K u 70$ and $K u 80$, key components of classical 
NHEJ pathway and up-regulation of DNA ligase III $\alpha$, key enzyme in alt-NHEJ pathway component, have been reported in both FLT3-ITD AML cell lines and mouse Flt3-ITD knockin model ${ }^{74}$. Paradoxically, increase in RAD51 expression and HR activity have also been reported in FLT3-ITD AML ${ }^{20,103,113}$. Very recently, both HR and NHEJ, but not the alt-NHEJ pathway, were shown to be dependent on FLT3 signaling ${ }^{20}$. Differences in cell line models and the use of FLT3 inhibitors in terms of doses and timing might have contributed to the different observations. These discrepancies notwithstanding, our study provided functional readout of HR and NHEJ, showing defective HR but not NHEJ in an isogenic Ba/F3 FLT3-ITD cell model.

Results arising from this study were of clinical relevance. PARP inhibitors have been shown effective in the treatment of $B R C A$ mutant breast and ovarian cancers ${ }^{75,76}$, a condition known as synthetic lethality in which PARP becomes a therapeutic target when DSB repair is defective due to $B R C A$ mutation. Similarly, the observations that $B R C A 2$ expression was down-regulated in FLT3-ITD AML supported the proposition that PARP inhibitors might be an effective treatment. In fact, Olaparib suppressed leukemia cell proliferation and clonogenicity in both Ba/F3 FLT3-ITD and Flt3 ${ }^{\text {ITD/+ }}$ $N p m 1^{c /+}$ cell line models. Combination of Olaparib and chemotherapy was also effective in reducing leukemia growth in vivo based on small number of animals studied so far. Intriguingly, treatment of Olaparib further increased the intracellular ROS level. There were also emerging evidences that DNA damage could induce ROS generation through the H2AX-Nox1-Rac1 pathway ${ }^{114}$, uncovering a mechanistic link of two dysregulated pathways in FLT3-ITD AML. Therefore, it is possible that the PARP inhibitor Olaparib not only increased the level of DSB but also induced more 
ROS stress, generating a feedback loop to induce more DSB. These observations supported a selectively toxic effect of Olaparib towards FLT3-ITD AML cells.

The experimental model developed in this study might provide important foundation for larger scale genomic studies. Specifically, an in vivo DDR shRNA library dropout screening based on a mouse $F l t 3^{I T D /} \mathrm{Npm}^{\mathrm{c} /+}$ double knockin model was designed to identify potential therapeutic targets that might become effective when used in combination with Olaparib. First, the nuclear DNA replication Family B Polymerase was particularly enriched as dropout candidates. While DNA polymerases are not a good target in cancer therapy, antimetabolite such as cytarabine that interferes with DNA replication, is widely used as the frontline induction therapy for AML patients. This finding further consolidated the proposal of adding Olaparib to standard " $7+3$ " chemotherapy for FLT3-ITD AML patients. Second, clinical trials of ATR inhibitors are currently in Phase 1/2 for advanced solid tumors as a single agent and in combination with chemotherapy, radiotherapy and PARP inhibitors ${ }^{115}$. Functional studies are ongoing to validate these results and the database will provide leads for future mechanistic and clinical studies.

There are a number of limitations in this study. The importance of proving decrease in BRCA2 at the protein level was not neglected and multiple optimizations and antibodies had been used to detect BRCA2 protein, yet it remained problematic to detect this high molecular weight protein in primary AML samples. It is of urgent need to obtain this critical data in primary samples. BRCA2 protein level would also be compared among human AML cell lines and isogenic 32D and $\mathrm{Ba} / \mathrm{F} 3$ lines transduced with FLT3-ITD. Furthermore, FLT3 inhibitor quizartinib restored BRCA2 expression, supporting the proposition that $B R C A 2$ transcription was regulated by FLT3-ITD 
signaling. Therefore, further experiments using the Tet-on-pLKO doxycycline inducible shRNA system (Addgene \#21915) would be performed to demonstrate the direct link between FLT3 and BRCA2. How FLT3-ITD signaling suppressed BRCA2 remained unknown and future work by means of transcriptomic and proteomic analysis as well as $B R C A 2$ promoter region by chromatin immunoprecipitation (ChIP)-PCR and ChIP-seq should be considered.

Another technical challenge in the study of FLT3-ITD AML was the need of robust models in both in vitro and in vivo studies. The commonly used model included mouse pro-B Ba/F3 cells and 32D myeloblast cells that overexpressed FLT3-ITD oncogene and proliferated independent of ambient IL3, with the caveat that they were not strictly

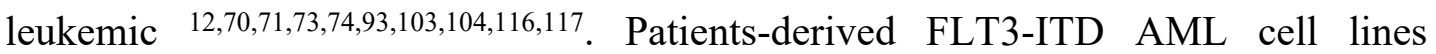
MOLM-13 and MV-4-11 have also been compared with other human AML cell lines carrying wildtype FLT3. However, these cell lines might have accumulated various mutations during repeated passages and might not truly represent the biology of the original AML from which they were derived. Flt3-ITD knockin mouse model has been generated by inserting an ITD mutation into the juxtamembrane domain of murine Flt3 allele, resulting in a myeloproliferative state ${ }^{92,118}$. Concurrent oncogenic events could cooperate with Flt3-ITD to develop bona fide AML model in mice. These oncogenic events included conditional knockout of Runx1, Dmnt3a and knockin of Npml type A mutation ${ }^{105,116,119-122}$. Thus, the murine Flt $^{I T D /+} \mathrm{Npm}^{\mathrm{c/+}}$ leukemic cell line was generated for the $s h R N A$ screening. Further experiments that include control cell lines without FLT3-ITD signaling should be performed to identify FLT3-ITD specific targets. 
In summary, the work described in this thesis demonstrated increased DSB in FLT3ITD AML due to increase in ROS production and defective DDR efficiency and fidelity due to reduced $B R C A 2$ down-regulation and HR activity (Fig. 7.1). The latter was exploited as a potential therapeutic target as evident by the use of PARP inhibitor Olaparib, singly or in combination with conventional chemotherapy in this AML subtype. This information would become a solid foundation for future mechanistic and translational studies in FLT3-ITD AML. 


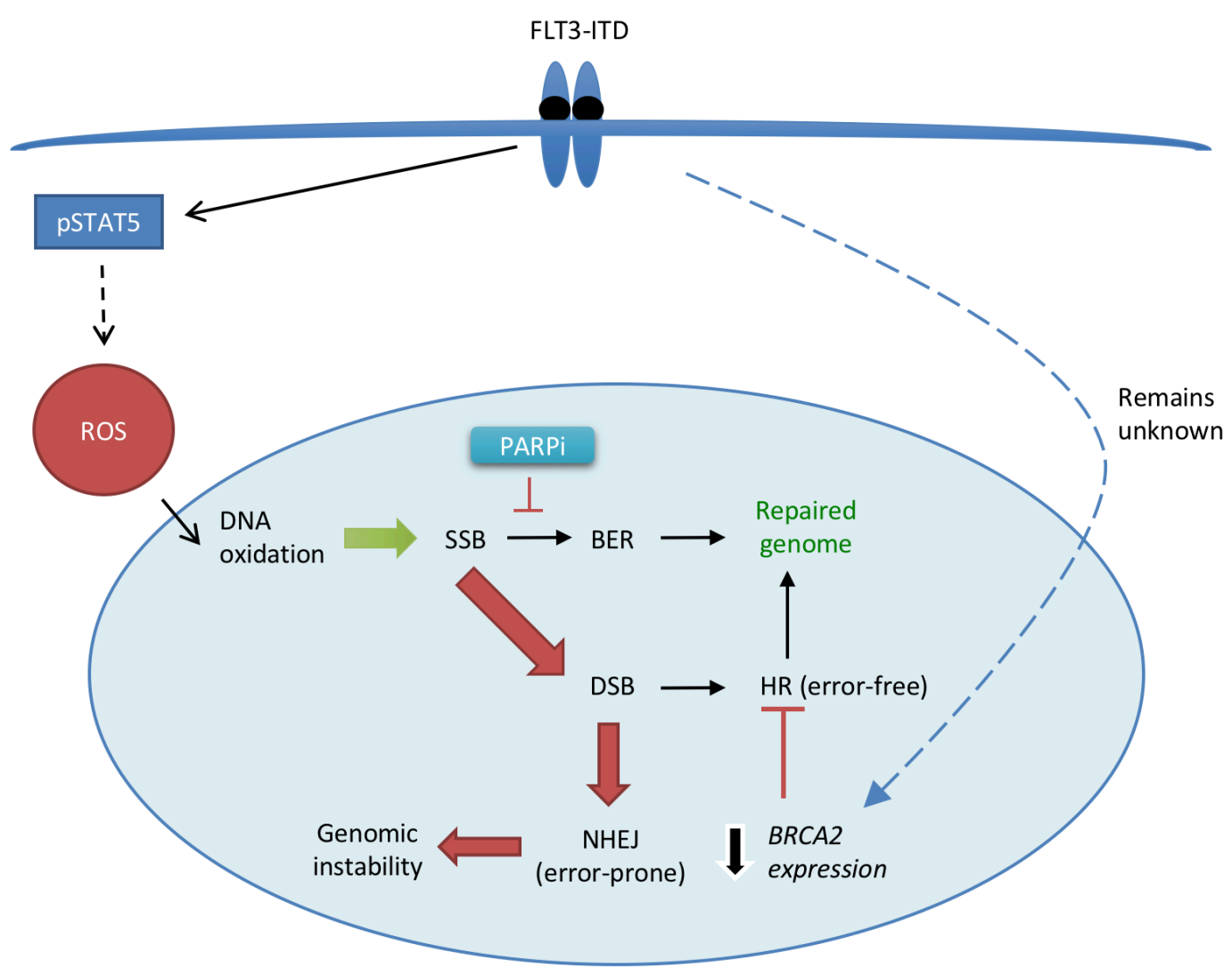

\section{Figure 7.1. Diagrammatic summary of work.}

ITD mutation in FLT3 receptor caused constitutive activation of FLT3 signaling and led to ligand-independent phosphorylation of STAT5. The FLT3-ITD-STAT5 pathway increased ROS generation which oxidized genomic DNA and hence SSB formation. On the other side, FLT3-ITD down-regulated $B R C A 2$ expression and impaired the DSB repair via the error-free HR pathway. The inhibition of BER by PARPi resulted in accumulation of SSB during DNA replication and thus led to formation of DSB. The unrepaired DSB was mainly repaired by error-prone NHEJ and led to genomic instability. 


\section{Appendix}

Appendix 1 Culture conditions of human AML cell lines.

\begin{tabular}{|c|c|c|c|c|}
\hline Cell lines & FLT3 status & Key mutation & Cell passage density & Culture medium \\
\hline MOLM-13 & WT/ITD & $M L L-A F 9$ & $0.3 \times 10^{6} / \mathrm{mL}$ & RPMI+10\% FBS \\
\hline MV-4-11 & ITD/ITD & $M L L-A F 4$ & $0.3 \times 10^{6} / \mathrm{mL}$ & IMDM+10\% FBS \\
\hline NOMO-1 & $W T / W T$ & $M L L-A F 9$ & $0.5 \times 10^{6} / \mathrm{mL}$ & RPMI+10\% FBS \\
\hline
\end{tabular}

Appendix 2 List of primers used for RT-QPCR.

\begin{tabular}{|c|c|c|}
\hline qPCR primer & Forward & Reverse \\
\hline$A T M$ & CCAAATCCCTCCACCTGCAT & AGAACACACATTGGATAGTGGT \\
\hline ATR & ACTGCTTGTTATGACAGGGCT & GTCCACTCGGACCTGTTAGC \\
\hline$B R C A 1$ & GTCCCATCTGTCTGGAGTTGA & AAAGGACACTGTGAAGGCCC \\
\hline BRCA2 & AGCACTCCAGATGGCACAATA & TTCTTGACCAGGTGCGGTAAA \\
\hline CHEK2 & AGGGGTGGTTTATCTGCATGG & CTGTTGCCAAGCCAAAGTCT \\
\hline ANA-PK & GAGAAGGCGGCTTACCTGAG & AGCGCCCTTATACATTAGCAT \\
\hline$P 53$ & TGACACGCTTCCCTGGATTG & TTTTCAGGAAGTAGTTTCCATAGGT \\
\hline$P A R P 1$ & AGCTCCCAGGAGTCAAGAGT & GTCGTTCTGAGCCTTTAGGG \\
\hline GAPDH & AGGGCTGCTTTTAACTCTGGT & CCCCACTTGATTTTGGAGGGA \\
\hline$m B r c a 2$ & AGATAGGCCTGAGACTTCCTT & TGTGGTTCATAACCGTGGGG \\
\hline$m G a p d h$ & TGGCCTTCCGTGTTCCTAC & GAGTTGCTGTTGAAGTCGCA \\
\hline
\end{tabular}


Appendix 3 List of antibodies used.

\begin{tabular}{|c|c|c|}
\hline Antibody & Dilution & Company \\
\hline Rabbit anti-total FLT3 & $1: 500$ & Santa Cruz Biotechnology, USA \\
\hline mouse anti- $\gamma$-H2AX (ser139) & $1: 2000$ & Millipore \\
\hline Mouse anti- $\beta$-actin & $1: 5000$ & Sigma, USA \\
\hline
\end{tabular}

\section{Appendix 4 Clinical trials involving DDR inhibitors}

\begin{tabular}{|c|c|c|c|c|}
\hline Target & Agent & Phase & Cancer(s) enrolled & $\begin{array}{l}\text { Trial } \\
\text { identifier }\end{array}$ \\
\hline \multirow[t]{2}{*}{ DNA-PK } & MSC2490484A & I & Solid tumors, CLL & NCT02316197 \\
\hline & $\begin{array}{l}\text { MSC2490484A } \\
\text { VX-984 }\end{array}$ & $\begin{array}{l}\text { I } \\
\text { I }\end{array}$ & $\begin{array}{l}\text { Solid tumors } \\
\text { Solid tumors }\end{array}$ & $\begin{array}{l}\text { NCT02516813 } \\
\text { NCT02644278 }\end{array}$ \\
\hline ATM & AZD0156 & I & Solid tumors & NCT02588105 \\
\hline \multirow[t]{14}{*}{ ATR } & \multirow[t]{6}{*}{$\begin{array}{l}\text { VX-970 } \pm \\
\text { chemotherapy }\end{array}$} & I & Solid tumors & $\begin{array}{l}\text { EudraCT: } 2013- \\
\text { 005100-34 }\end{array}$ \\
\hline & & I & Solid tumors & NCT02157792 \\
\hline & & II & $\begin{array}{l}\text { Ovarian, primary peritoneal or } \\
\text { Fallopian tube }\end{array}$ & NCT02595892 \\
\hline & & $\mathrm{I}$ & Solid tumors & NCT02595931 \\
\hline & & II & Advanced gynecologic cancers & NCT02627443 \\
\hline & & $\mathrm{I} / \mathrm{II}$ & $\begin{array}{l}\text { Advanced NSCLC, SCLC, Gynae or } \\
\text { neuroendocrine }\end{array}$ & NCT02487095 \\
\hline & \multirow{3}{*}{ VX-970 \pm RT } & II & Advanced urothelial & NCT02567409 \\
\hline & & $\mathrm{I}$ & Locally advanced HNSCC & NCT02567422 \\
\hline & & I & NSCLC brain metastases & NCT02589522 \\
\hline & $\begin{array}{l}\text { VX-970 + targeted } \\
\text { therapy }\end{array}$ & I & Solid tumors & NCT02723864 \\
\hline & AZD6738 & I & $\begin{array}{l}\text { Relapsed CLL, PLL, B-cell } \\
\text { lymphomas }\end{array}$ & NCT01955668 \\
\hline & \multirow[t]{2}{*}{$\begin{array}{l}\text { AZD6738 } \pm \\
\text { chemotherapy }\end{array}$} & I & $\begin{array}{l}\text { Solid tumors, HNSCC, } \\
\text { ATMloss NSCLC, gastric or GOJ } \\
\text { carcinoma }\end{array}$ & NCT02264678 \\
\hline & & I & Solid tumors & NCT02630199 \\
\hline & \multirow{4}{*}{$\begin{array}{l}\text { AZD6738 + RT } \\
\text { MK8776 (SCH } \\
900776)\end{array}$} & I & Solid tumors & NCT02223923 \\
\hline HK1 & & II & Relapsed AML & NCT01870596 \\
\hline & & I & Relapsed lymphoma & NCT00779584 \\
\hline & & I & Relapsed AML & NCT00907517 \\
\hline \multirow[t]{20}{*}{ CHK1/2 } & \multirow[t]{6}{*}{ LY2603618 } & $\mathrm{I} / \mathrm{II}$ & NSCLC & NCT01139775 \\
\hline & & $\mathrm{I} / \mathrm{II}$ & Pancreatic carcinoma & NCT00839332 \\
\hline & & II & NSCLC & NCT00988858 \\
\hline & & $\mathrm{I}$ & Solid tumors & NCT01296568 \\
\hline & & I & Solid tumors & NCT01341457 \\
\hline & & I & Solid tumors & NCT00415636 \\
\hline & \multirow[t]{2}{*}{ CCT245737 } & I & Solid tumors & NCT02797964 \\
\hline & & I & Solid tumors & NCT02797977 \\
\hline & \multirow{8}{*}{$\begin{array}{l}\text { GDC- } 0575 \pm \\
\text { chemotherapy } \\
\text { LY2606368 }\end{array}$} & I & Solid tumors, relapsed lymphoma & NCT01564251 \\
\hline & & II & Refractory SCLC & NCT02735980 \\
\hline & & II & Ovarian, breast, prostate & NCT02203513 \\
\hline & & II & Solid tumors & NCT02873975 \\
\hline & & $\mathrm{I}$ & Solid tumors & NCT01115790 \\
\hline & & I & Solid tumors & NCT02778126 \\
\hline & & I & Solid tumors & NCT02514603 \\
\hline & & I & Pediatric solid tumors & NCT02808650 \\
\hline & \multirow[t]{2}{*}{$\begin{array}{l}\text { LY2606368+ } \\
\text { chemotherapy }\end{array}$} & I & Relapsed AML, high risk MDS & NCT02649764 \\
\hline & & I & Solid tumors & NCT02124148 \\
\hline & \multirow{2}{*}{$\begin{array}{l}\text { LY2606368 + } \\
\text { targeted therapy } \\
\text { LY2606368 + RT }\end{array}$} & I & Solid tumors & NCT02860780 \\
\hline & & I & Locally advanced HNSCC & NCT02555644 \\
\hline
\end{tabular}




\begin{tabular}{|c|c|c|c|c|}
\hline \multirow[t]{24}{*}{ WEE1 } & \multirow{16}{*}{$\begin{array}{l}\text { AZD1775 + } \\
\text { chemotherapy }\end{array}$} & II & SCLC & NCT02593019 \\
\hline & & I & Solid tumors & NCT01748825 \\
\hline & & I & Solid tumors & NCT02482311 \\
\hline & & I & Solid tumors & NCT02610075 \\
\hline & & II & Ovarian, TP53mut & NCT01357161 \\
\hline & & II & $\begin{array}{l}\text { Ovarian, TP53mut, or platinum } \\
\text { resistant }\end{array}$ & NCT01164995 \\
\hline & & II & $\begin{array}{l}\text { Ovarian, primary peritoneal, or } \\
\text { fallopian }\end{array}$ & NCT02101775 \\
\hline & & II & NSCLC, 1st line & NCT02087241 \\
\hline & & II & NSCLC, 2nd line & NCT02087176 \\
\hline & & II & NSCLC & NCT02513563 \\
\hline & & II & Gastric carcinoma & NCT02448329 \\
\hline & & II & HNSCC & NCT02196168 \\
\hline & & I/II & Pancreatic & NCT02194829 \\
\hline & & I/II & Pediatric solid tumors & NCT02095132 \\
\hline & & I & Locally advanced HNSCC & NCT02508246 \\
\hline & & I & Solid tumors & NCT00648648 \\
\hline & \multirow{2}{*}{$\begin{array}{l}\text { AZD1775 + targeted } \\
\text { therapy }\end{array}$} & I & Solid tumors & NCT02511795 \\
\hline & & & AML, other myeloid malignancies & NCT02381548 \\
\hline & \multirow[t]{5}{*}{ AZD1775 + RT } & $\mathrm{I} / \mathrm{II}$ & Pancreatic & NCT02037230 \\
\hline & & I & HNSCC & NCT02585973 \\
\hline & & I & Locally advanced cervical cancer & NCT01958658 \\
\hline & & I & GBM & NCT01849146 \\
\hline & & I & Pediatric DIPG & NCT01922076 \\
\hline & $\begin{array}{l}\text { AZD1775 + immune } \\
\text { checkpoint inhibitor }\end{array}$ & I & Solid tumors & NCT02617277 \\
\hline \multirow[t]{6}{*}{ BER } & TRC102 & I & Solid tumors, lymphoma & NCT01851369 \\
\hline & \multirow{4}{*}{$\begin{array}{l}\text { TRC102+ } \\
\text { chemotherapy }\end{array}$} & II & GBM & NCT02395692 \\
\hline & & $\mathrm{I} / \mathrm{II}$ & Solid tumors & NCT02535312 \\
\hline & & I & Solid tumors & NCT00692159 \\
\hline & & I & Hematologic malignancies & NCT01658319 \\
\hline & $\mathrm{TRC} 102+\mathrm{RT}$ & I & NSCLC & NCT02535325 \\
\hline
\end{tabular}

Adapted from ${ }^{78}$. 
Appendix 5 Miseq sequencing run samples.

\begin{tabular}{|c|c|c|c|}
\hline Seq ID & Experiment & Type & Description \\
\hline 1 & 1 & in vivo & GFP sorted, pre-transplant sample \\
\hline 2 & 1 & in vivo & End point; BM \#1; vehicle \\
\hline 3 & 1 & in vivo & End point; BM \#2; vehicle \\
\hline 4 & 1 & in vivo & End point; BM \#3; vehicle \\
\hline 5 & 1 & in vivo & End point; BM \#5; Olaparib 50mg/kg \\
\hline 6 & 1 & in vivo & End point; BM \#6; Olaparib 50mg/kg \\
\hline 7 & 2 & in vivo & GFP sorted, pre-transplant sample \\
\hline 8 & 2 & in vivo & End point; BM \#1; vehicle \\
\hline 9 & 2 & in vivo & End point; BM \#2; vehicle \\
\hline 10 & 2 & in vivo & End point; BM \#3; vehicle \\
\hline 11 & 2 & in vivo & End point; BM \#4; Olaparib 50mg/kg \\
\hline 12 & 2 & in vivo & End point; BM \#5; Olaparib 50mg/kg \\
\hline 13 & 2 & in vivo & End point; BM \#6; Olaparib 50mg/kg \\
\hline 14 & l & plasmid & $\begin{array}{c}\text { pRRL GFP puro; Mouse DDR library } \\
\text { plasmid }\end{array}$ \\
\hline
\end{tabular}




\section{Appendix 6 Candidate dropout gene list specific to Olaparib treatment.}

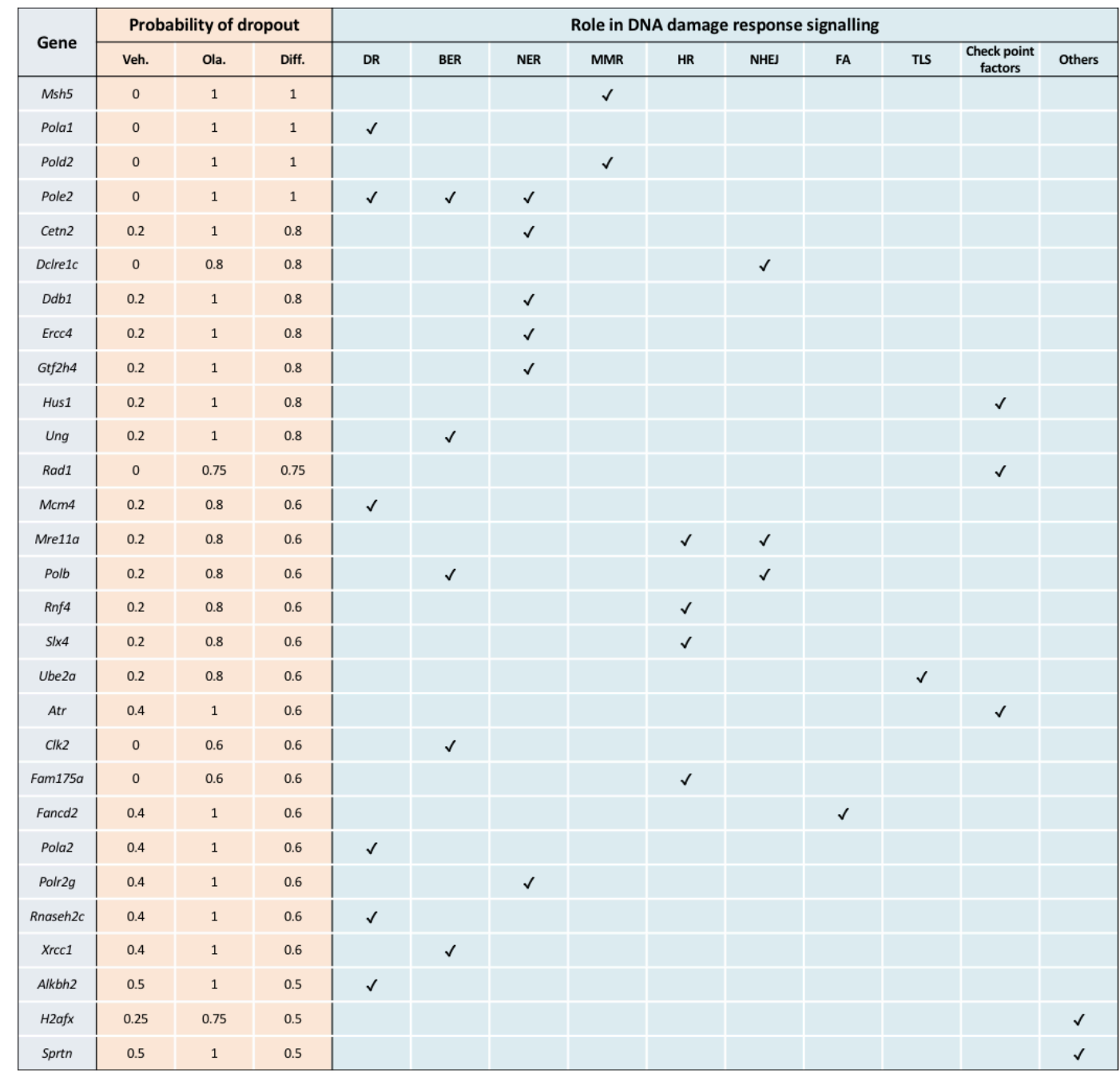

Abberviations: Veh. (vehicle); Ola. (Olaparib); Diff. (difference); DR (DNA repair); BER (base excision repair); NER (nucleotide excision repair); MMR (mismatch repair); HR (homologous recombination); NHEJ (non-homologous end-joining); FA (fanconi anemia); Other DSBR (double stranded breaks repair); TLS (translesion repair) 


\section{Appendix 7 Dropout probability of important DDR genes in the screening.}

\begin{tabular}{|c|c|c|c|c|c|c|c|c|c|c|c|c|}
\hline \multirow{2}{*}{ Gene } & \multicolumn{3}{|c|}{ Probability of dropout } & \multirow{2}{*}{$\begin{array}{l}\text { Dropout } \\
\text { group }\end{array}$} & \multicolumn{8}{|c|}{ Role in DNA damage response signalling } \\
\hline & Veh. & Ola. & Diff. & & DR & BER & NER & MMR & HR & NHEJ & FA & $\begin{array}{c}\text { Check point } \\
\text { factors }\end{array}$ \\
\hline Atm & 0.2 & 0.6 & 0.4 & Common & & & & & & & & $\checkmark$ \\
\hline Atr & 0.4 & 1 & 0.6 & Ola. & & & & & & & & $\checkmark$ \\
\hline Brca1 & 0.4 & 0.8 & 0.4 & Common & & & & & $\checkmark$ & & $\checkmark$ & \\
\hline Brca2 & 0.6 & 1 & 0.4 & Common & & & & & $\checkmark$ & & $\checkmark$ & \\
\hline Chek1 & 0.6 & 0.6 & 0 & Common & & & & & & & & $\checkmark$ \\
\hline Chek2 & 0.6 & 1 & 0.4 & Common & & & & & & & & $\checkmark$ \\
\hline Lig3 & 0.6 & 0.8 & 0.2 & Common & & $\checkmark$ & & & & & & \\
\hline Lig4 & 0.4 & 0.8 & 0.4 & Common & & & & & & $\checkmark$ & & \\
\hline Mre11a & 0.2 & 0.8 & 0.6 & Ola. & & & & & $\checkmark$ & $\checkmark$ & & \\
\hline $\mathrm{Nbn}$ & 0.4 & 0.6 & 0.2 & Common & & & & & $\checkmark$ & & & \\
\hline Prkdc & 0.4 & 0.8 & 0.4 & Common & & & & & & $\checkmark$ & & \\
\hline Rad50 & 0.6 & 0.6 & 0 & Common & & & & & $\checkmark$ & $\checkmark$ & & \\
\hline Rad51 & 0.4 & 0.6 & 0.2 & Common & & & & & $\checkmark$ & & $\checkmark$ & \\
\hline Rpa1 & 0.8 & 0.6 & -0.2 & Common & & & $\checkmark$ & $\checkmark$ & $\checkmark$ & & & \\
\hline $\operatorname{Trp53}$ & 0.6 & 0.6 & 0 & Common & & & & & & & & $\checkmark$ \\
\hline
\end{tabular}

Abberviations: Veh. (vehicle); Ola. (Olaparib); Diff. (difference); DR (DNA repair); BER (base excision repair); NER (nucleotide excision repair); MMR (mismatch repair); HR (homologous recombination); NHEJ (non-homologous end-joining); FA (fanconi anemia); Other DSBR (double stranded breaks repair); TLS (translesion repair) 


\section{Reference}

1 Cancer Genome Atlas Research, N. et al. Genomic and epigenomic landscapes of adult de novo acute myeloid leukemia. N Engl J Med 368, 2059-2074, doi:10.1056/NEJMoa1301689 (2013).

2 Vardiman, J. W. et al. The 2008 revision of the World Health Organization (WHO) classification of myeloid neoplasms and acute leukemia: rationale and important changes. Blood 114, 937-951, doi:10.1182/blood-2009-03-209262 (2009).

3 Vogler, W. R. et al. A phase III trial comparing idarubicin and daunorubicin in combination with cytarabine in acute myelogenous leukemia: a Southeastern Cancer Study Group Study. J Clin Oncol 10, 1103-1111, doi:10.1200/JCO.1992.10.7.1103 (1992).

4 Berman, E. et al. Results of a randomized trial comparing idarubicin and cytosine arabinoside with daunorubicin and cytosine arabinoside in adult patients with newly diagnosed acute myelogenous leukemia. Blood 77, 16661674 (1991).

5 Wiernik, P. H. et al. A multicenter trial of cytarabine plus idarubicin or daunorubicin as induction therapy for adult nonlymphocytic leukemia. Semin Oncol 16, 25-29 (1989).

6 Vogler, W. R., Velez-Garcia, E., Omura, G. \& Raney, M. A phase-three trial comparing daunorubicin or idarubicin combined with cytosine arabinoside in acute myelogenous leukemia. Semin Oncol 16, 21-24 (1989).

7 Cornelissen, J. J. \& Blaise, D. Hematopoietic stem cell transplantation for patients with AML in first complete remission. Blood 127, 62-70, doi:10.1182/blood-2015-07-604546 (2016).

8 Ciccia, A. \& Elledge, S. J. The DNA damage response: making it safe to play with knives. Mol Cell 40, 179-204, doi:10.1016/j.molcel.2010.09.019 (2010). David, S. S., O'Shea, V. L. \& Kundu, S. Base-excision repair of oxidative DNA damage. Nature 447, 941-950, doi:10.1038/nature05978 (2007).

Khanna, K. K. \& Jackson, S. P. DNA double-strand breaks: signaling, repair and the cancer connection. Nat Genet 27, 247-254, doi:10.1038/85798 (2001).

Schar, P. Spontaneous DNA damage, genome instability, and cancer--when DNA replication escapes control. Cell 104, 329-332 (2001).

12 Sallmyr, A., Fan, J. \& Rassool, F. V. Genomic instability in myeloid malignancies: increased reactive oxygen species (ROS), DNA double strand breaks (DSBs) and error-prone repair. Cancer Lett 270, 1-9, doi:10.1016/j.canlet.2008.03.036 (2008).

13 Kushner, B. H. et al. High risk of leukemia after short-term dose-intensive chemotherapy in young patients with solid tumors. J Clin Oncol 16, 30163020, doi:10.1200/JCO.1998.16.9.3016 (1998).

14 Jackson, S. P. \& Bartek, J. The DNA-damage response in human biology and disease. Nature 461, 1071-1078, doi:10.1038/nature08467 (2009).

15 Mills, K. D., Ferguson, D. O. \& Alt, F. W. The role of DNA breaks in genomic instability and tumorigenesis. Immunol Rev 194, 77-95 (2003).

Coutts, A. S. \& La Thangue, N. The p53 response during DNA damage: impact of transcriptional cofactors. Biochem Soc Symp, 181-189 (2006). 
17 Mandal, P. K., Blanpain, C. \& Rossi, D. J. DNA damage response in adult stem cells: pathways and consequences. Nat Rev Mol Cell Biol 12, 198-202, doi:10.1038/nrm3060 (2011).

18 Esposito, M. T. \& So, C. W. DNA damage accumulation and repair defects in acute myeloid leukemia: implications for pathogenesis, disease progression, and chemotherapy resistance. Chromosoma 123, 545-561, doi:10.1007/s00412-014-0482-9 (2014).

19 Helleday, T., Petermann, E., Lundin, C., Hodgson, B. \& Sharma, R. A. DNA repair pathways as targets for cancer therapy. Nat Rev Cancer 8, 193-204, doi:10.1038/nrc2342 (2008).

20 Maifrede, S. et al. Tyrosine kinase inhibitor-induced defects in DNA repair sensitize FLT3(ITD)-positive leukemia cells to PARP1 inhibitors. Blood, doi:10.1182/blood-2018-02-834895 (2018).

21 Karanam, K., Kafri, R., Loewer, A. \& Lahav, G. Quantitative live cell imaging reveals a gradual shift between DNA repair mechanisms and a maximal use of HR in mid S phase. Mol Cell 47, 320-329, doi:10.1016/j.molcel.2012.05.052 (2012).

22 Sinha, S., Villarreal, D., Shim, E. Y. \& Lee, S. E. Risky business: Microhomologymediated end joining. Mutat Res 788, 17-24, doi:10.1016/j.mrfmmm.2015.12.005 (2016).

23 Truong, L. N. et al. Microhomology-mediated End Joining and Homologous Recombination share the initial end resection step to repair DNA doublestrand breaks in mammalian cells. Proc Natl Acad Sci U S A 110, 7720-7725, doi:10.1073/pnas.1213431110 (2013).

24 Lamarche, B. J., Orazio, N. I. \& Weitzman, M. D. The MRN complex in doublestrand break repair and telomere maintenance. FEBS Lett 584, 3682-3695, doi:10.1016/j.febslet.2010.07.029 (2010).

25 Dickey, J. S. et al. H2AX: functional roles and potential applications. Chromosoma 118, 683-692, doi:10.1007/s00412-009-0234-4 (2009).

26 Rogakou, E. P., Pilch, D. R., Orr, A. H., Ivanova, V. S. \& Bonner, W. M. DNA double-stranded breaks induce histone H2AX phosphorylation on serine 139. J Biol Chem 273, 5858-5868 (1998).

27 Gaymes, T. J., Mufti, G. J. \& Rassool, F. V. Myeloid leukemias have increased activity of the nonhomologous end-joining pathway and concomitant DNA misrepair that is dependent on the Ku70/86 heterodimer. Cancer Res 62, 2791-2797 (2002).

28 Brady, N., Gaymes, T. J., Cheung, M., Mufti, G. J. \& Rassool, F. V. Increased error-prone NHEJ activity in myeloid leukemias is associated with DNA damage at sites that recruit key nonhomologous end-joining proteins. Cancer Res 63, 1798-1805 (2003).

29 Slupianek, A. et al. Fusion tyrosine kinases induce drug resistance by stimulation of homology-dependent recombination repair, prolongation of $\mathrm{G}(2) / \mathrm{M}$ phase, and protection from apoptosis. Mol Cell Biol 22, 4189-4201 (2002).

30 Majsterek, I., Blasiak, J., Mlynarski, W., Hoser, G. \& Skorski, T. Does the $\mathrm{bcr} / \mathrm{abl}$-mediated increase in the efficacy of DNA repair play a role in the drug 
resistance of cancer cells? Cell Biol Int 26, 363-370, doi:10.1006/cbir.2002.0865 (2002).

31 Pytel, D., Wysocki, T. \& Majsterek, I. Comparative study of DNA damage, cell cycle and apoptosis in human K562 and CCRF-CEM leukemia cells: role of BCR/ABL in therapeutic resistance. Comp Biochem Physiol C Toxicol Pharmacol 144, 85-92, doi:10.1016/j.cbpc.2006.06.010 (2006).

32 Skorski, T. BCR/ABL regulates response to DNA damage: the role in resistance to genotoxic treatment and in genomic instability. Oncogene 21, 8591-8604, doi:10.1038/sj.onc.1206087 (2002).

33 Nowicki, M. O. et al. BCR/ABL oncogenic kinase promotes unfaithful repair of the reactive oxygen species-dependent DNA double-strand breaks. Blood 104, 3746-3753, doi:10.1182/blood-2004-05-1941 (2004).

34 Sattler, M. et al. The BCR/ABL tyrosine kinase induces production of reactive oxygen species in hematopoietic cells. J Biol Chem 275, 24273-24278, doi:10.1074/jbc.M002094200 (2000).

Melo, J. V. \& Barnes, D. J. Chronic myeloid leukaemia as a model of disease evolution in human cancer. Nat Rev Cancer 7, 441-453, doi:10.1038/nrc2147 (2007).

36 Cortes, J. E., Talpaz, M. \& Kantarjian, H. Chronic myelogenous leukemia: a review. Am J Med 100, 555-570 (1996).

37 Rassool, F. V. et al. Reactive oxygen species, DNA damage, and error-prone repair: a model for genomic instability with progression in myeloid leukemia? Cancer Res 67, 8762-8771, doi:10.1158/0008-5472.CAN-06-4807 (2007). Downward, J. Targeting RAS signalling pathways in cancer therapy. Nat Rev Cancer 3, 11-22, doi:10.1038/nrc969 (2003).

39 Padua, R. A. et al. RAS, FMS and p53 mutations and poor clinical outcome in myelodysplasias: a 10-year follow-up. Leukemia 12, 887-892 (1998).

Sulkowski, P. L. et al. 2-Hydroxyglutarate produced by neomorphic IDH mutations suppresses homologous recombination and induces PARP inhibitor sensitivity. Sci Transl Med 9, doi:10.1126/scitranslmed.aal2463 (2017).

41 Esposito, M. T. et al. Synthetic lethal targeting of oncogenic transcription factors in acute leukemia by PARP inhibitors. Nat Med 21, 1481-1490, doi:10.1038/nm.3993 (2015).

Inoue, S. et al. Mutant IDH1 Downregulates ATM and Alters DNA Repair and Sensitivity to DNA Damage Independent of TET2. Cancer Cell 30, 337-348, doi:10.1016/j.ccell.2016.05.018 (2016).

43 Wang, D., Kreutzer, D. A. \& Essigmann, J. M. Mutagenicity and repair of oxidative DNA damage: insights from studies using defined lesions. Mutat Res 400, 99-115 (1998).

44 Irani, K. \& Goldschmidt-Clermont, P. J. Ras, superoxide and signal transduction. Biochem Pharmacol 55, 1339-1346 (1998).

Cairns, R. A. \& Mak, T. W. Oncogenic isocitrate dehydrogenase mutations: mechanisms, models, and clinical opportunities. Cancer Discov 3, 730-741, doi:10.1158/2159-8290.CD-13-0083 (2013).

Paschka, P. et al. IDH1 and IDH2 mutations are frequent genetic alterations in acute myeloid leukemia and confer adverse prognosis in cytogenetically normal acute myeloid leukemia with NPM1 mutation without FLT3 internal 
tandem duplication. J Clin Oncol 28, 3636-3643, doi:10.1200/JCO.2010.28.3762 (2010).

47 Zhao, L. \& So, C. W. E. PARPi potentiates with current conventional therapy in MLL leukemia. Cell Cycle 16, 1861-1869, doi:10.1080/15384101.2017.1288325 (2017).

48 Rosnet, O., Mattei, M. G., Marchetto, S. \& Birnbaum, D. Isolation and chromosomal localization of a novel FMS-like tyrosine kinase gene. Genomics 9, 380-385, doi:0888-7543(91)90270-0 [pii] (1991).

49 Carow, C. E. et al. Localization of the human stem cell tyrosine kinase-1 gene (FLT3) to 13q12-->q13. Cytogenet Cell Genet 70, 255-257 (1995).

50 Agnes, F. et al. Genomic structure of the downstream part of the human FLT3 gene: exon/intron structure conservation among genes encoding receptor tyrosine kinases (RTK) of subclass III. Gene 145, 283-288 (1994).

51 Griffith, J. et al. The structural basis for autoinhibition of FLT3 by the juxtamembrane domain. Mol Cell 13, 169-178, doi:S1097276503005057 [pii] (2004).

52 Lyman, S. D. \& Jacobsen, S. E. c-kit ligand and Flt3 ligand: stem/progenitor cell factors with overlapping yet distinct activities. Blood 91, 1101-1134 (1998).

53 Markovic, A., Mackenzie, K. L. \& Lock, R. B. FLT-3: a new focus in the understanding of acute leukemia. Int J Biochem Cell Biol 37, 1168-1172, doi:S1357-2725(04)00431-5 [pii]

10.1016/j.biocel.2004.12.005 (2005).

54 Zhang, S. et al. Essential role of signal transducer and activator of transcription (Stat)5a but not Stat5b for Flt3-dependent signaling. J Exp Med 192, 719-728 (2000).

55 Grafone, T., Palmisano, M., Nicci, C. \& Storti, S. An overview on the role of FLT3-tyrosine kinase receptor in acute myeloid leukemia: biology and treatment. Oncol Rev 6, e8, doi:10.4081/oncol.2012.e8 (2012).

56 Chen, W. et al. mTOR signaling is activated by FLT3 kinase and promotes survival of FLT3-mutated acute myeloid leukemia cells. Mol Cancer 9, 292, doi:10.1186/1476-4598-9-292 (2010).

57 Leung, A. Y., Man, C. H. \& Kwong, Y. L. FLT3 inhibition: a moving and evolving target in acute myeloid leukaemia. Leukemia 27, 260-268, doi:10.1038/leu.2012.195 (2013).

58 Gale, R. E. et al. The impact of FLT3 internal tandem duplication mutant level, number, size, and interaction with NPM1 mutations in a large cohort of young adult patients with acute myeloid leukemia. Blood 111, 2776-2784, doi:10.1182/blood-2007-08-109090 (2008).

59 Meshinchi, S. et al. Structural and numerical variation of FLT3/ITD in pediatric AML. Blood 111, 4930-4933, doi:10.1182/blood-2008-01-117770 (2008).

60 Santos, F. P. et al. Prognostic value of FLT3 mutations among different cytogenetic subgroups in acute myeloid leukemia. Cancer 117, 2145-2155, doi:10.1002/cncr.25670 (2011).

61 Bagrintseva, K. et al. FLT3-ITD-TKD dual mutants associated with AML confer resistance to FLT3 PTK inhibitors and cytotoxic agents by overexpression of Bcl-x(L). Blood 105, 3679-3685, doi:10.1182/blood-2004-06-2459 (2005). 

in human acute myeloid leukaemia. Nature 485, 260-263, doi:10.1038/nature11016 (2012).

63 Zhou, J. et al. Enhanced activation of STAT pathways and overexpression of survivin confer resistance to FLT3 inhibitors and could be therapeutic targets in AML. Blood 113, 4052-4062, doi:10.1182/blood-2008-05-156422 (2009).

64 Kojima, K. et al. p53 activation of mesenchymal stromal cells partially abrogates microenvironment-mediated resistance to FLT3 inhibition in AML through HIF-1alpha-mediated down-regulation of CXCL12. Blood 118, 44314439, doi:10.1182/blood-2011-02-334136 (2011).

65 Man, C. H. et al. A novel tescalcin-sodium/hydrogen exchange axis underlying sorafenib resistance in FLT3-ITD+ AML. Blood 123, 2530-2539, doi:10.1182/blood-2013-07-512194 (2014).

66 Krokan, H. E., Standal, R. \& Slupphaug, G. DNA glycosylases in the base excision repair of DNA. Biochem J 325 ( Pt 1), 1-16 (1997).

67 Neeley, W. L. \& Essigmann, J. M. Mechanisms of formation, genotoxicity, and mutation of guanine oxidation products. Chem Res Toxicol 19, 491-505, doi:10.1021/tx0600043 (2006).

68 Grollman, A. P. \& Moriya, M. Mutagenesis by 8-oxoguanine: an enemy within. Trends Genet 9, 246-249 (1993).

69 Holmstrom, K. M. \& Finkel, T. Cellular mechanisms and physiological consequences of redox-dependent signalling. Nat Rev Mol Cell Biol 15, 411421, doi:10.1038/nrm3801 (2014).

70 Sallmyr, A. et al. Internal tandem duplication of FLT3 (FLT3/ITD) induces increased ROS production, DNA damage, and misrepair: implications for poor prognosis in AML. Blood 111, 3173-3182, doi:10.1182/blood-2007-05-092510 (2008).

71 Woolley, J. F. et al. H2O2 production downstream of FLT3 is mediated by p22phox in the endoplasmic reticulum and is required for STAT5 signalling. PLoS One 7, e34050, doi:10.1371/journal.pone.0034050 (2012).

72 Stanicka, J., Russell, E. G., Woolley, J. F. \& Cotter, T. G. NADPH oxidasegenerated hydrogen peroxide induces DNA damage in mutant FLT3expressing leukemia cells. J Biol Chem 290, 9348-9361, doi:10.1074/jbc.M113.510495 (2015).

73 Jayavelu, A. K. et al. NOX4-driven ROS formation mediates PTP inactivation and cell transformation in FLT3ITD-positive AML cells. Leukemia 30, 473-483, doi:10.1038/leu.2015.234 (2016).

74 Fan, J., Li, L., Small, D. \& Rassool, F. Cells expressing FLT3/ITD mutations exhibit elevated repair errors generated through alternative NHEJ pathways: implications for genomic instability and therapy. Blood 116, 5298-5305, doi:10.1182/blood-2010-03-272591 (2010).

75 Farmer, H. et al. Targeting the DNA repair defect in BRCA mutant cells as a therapeutic strategy. Nature 434, 917-921, doi:10.1038/nature03445 (2005).

76 Bryant, H. E. et al. Specific killing of BRCA2-deficient tumours with inhibitors of poly(ADP-ribose) polymerase. Nature 434, 913-917, doi:10.1038/nature03443 (2005). 

polymerase (PARP) inhibitors: Exploiting a synthetic lethal strategy in the clinic. CA Cancer J Clin 61, 31-49, doi:10.3322/caac.20095 (2011).

Hengel, S. R., Spies, M. A. \& Spies, M. Small-Molecule Inhibitors Targeting DNA Repair and DNA Repair Deficiency in Research and Cancer Therapy. Cell Chem Biol 24, 1101-1119, doi:10.1016/j.chembiol.2017.08.027 (2017).

Murata, S. et al. Predictors and Modulators of Synthetic Lethality: An Update on PARP Inhibitors and Personalized Medicine. Biomed Res Int 2016, 2346585, doi:10.1155/2016/2346585 (2016).

80 Nakao, M. et al. Internal tandem duplication of the flt3 gene found in acute myeloid leukemia. Leukemia 10, 1911-1918 (1996).

81 Cortes J, K. S., Martinelli G, et al. in 23rd Congress of the European Hematology Association (Stockholm, Sweden., June 16, 2018).

82 Perl, A. E. et al. Selective inhibition of FLT3 by gilteritinib in relapsed or refractory acute myeloid leukaemia: a multicentre, first-in-human, openlabel, phase 1-2 study. Lancet Oncol 18, 1061-1075, doi:10.1016/S14702045(17)30416-3 (2017).

83 Wang E, S. R., Collins R, et al. in 2017 EHA Congress (Madrid, Spain. , 2017).

84 Jorge E. Cortes, H. M. K., Tapan M. Kadia, Gautam Borthakur, Marina Konopleva, Guillermo Garcia-Manero, Naval Guastad Daver, Naveen Pemmaraju, Elias Jabbour, Zeev Estrov, Abhijit Ramachandran, Jamil Paradela, Blake Pond, Farhad Ravandi, Madhuri Vusirikala, Prapti Arvind Patel, Mark J. Levis, Alexander E. Perl, Michael Andreeff, Robert Collins. Crenolanib besylate, a type I pan-FLT3 inhibitor, to demonstrate clinical activity in multiply relapsed FLT3-ITD and D835 AML. Journal of Clinical Oncology 34 (2016).

85 Tang, R., Dodd, A., Lai, D., McNabb, W. C. \& Love, D. R. Validation of zebrafish (Danio rerio) reference genes for quantitative real-time RT-PCR normalization. Acta Biochim Biophys Sin (Shanghai) 39, 384-390 (2007).

86 Gyori, B. M., Venkatachalam, G., Thiagarajan, P. S., Hsu, D. \& Clement, M. V. OpenComet: an automated tool for comet assay image analysis. Redox Biol 2, 457-465, doi:10.1016/j.redox.2013.12.020 (2014).

87 Certo, M. T. et al. Tracking genome engineering outcome at individual DNA breakpoints. Nat Methods 8, 671-676, doi:10.1038/nmeth.1648 (2011).

88 Fellmann, C. et al. An optimized microRNA backbone for effective single-copy RNAi. Cell Rep 5, 1704-1713, doi:10.1016/j.celrep.2013.11.020 (2013).

89 Milanowska, K. et al. REPAIRtoire--a database of DNA repair pathways. Nucleic Acids Res 39, D788-792, doi:10.1093/nar/gkq1087 (2011).

90 Kanehisa, M. \& Goto, S. KEGG: kyoto encyclopedia of genes and genomes. Nucleic Acids Res 28, 27-30 (2000).

91 Wunderlich, M. et al. AML cells are differentially sensitive to chemotherapy treatment in a human xenograft model. Blood 121, e90-97, doi:10.1182/blood-2012-10-464677 (2013).

92 Lee, B. H. et al. FLT3 mutations confer enhanced proliferation and survival properties to multipotent progenitors in a murine model of chronic myelomonocytic leukemia. Cancer Cell 12, 367-380, doi:10.1016/j.ccr.2007.08.031 (2007). 
Godfrey, R. et al. Cell transformation by FLT3 ITD in acute myeloid leukemia involves oxidative inactivation of the tumor suppressor protein-tyrosine phosphatase DEP-1/ PTPRJ. Blood 119, 4499-4511, doi:10.1182/blood-201102-336446 (2012).

94 Klein, H. U. et al. Quantitative comparison of microarray experiments with published leukemia related gene expression signatures. BMC Bioinformatics 10, 422, doi:10.1186/1471-2105-10-422 (2009).

95 Lam, S. S. et al. Homoharringtonine (omacetaxine mepesuccinate) as an adjunct for FLT3-ITD acute myeloid leukemia. Sci Transl Med 8, 359ra129, doi:10.1126/scitranslmed.aaf3735 (2016).

96 Xia, F. et al. Deficiency of human BRCA2 leads to impaired homologous recombination but maintains normal nonhomologous end joining. Proc Natl Acad Sci U S A 98, 8644-8649, doi:10.1073/pnas.151253498 (2001).

97 Moynahan, M. E., Pierce, A. J. \& Jasin, M. BRCA2 is required for homologydirected repair of chromosomal breaks. Mol Cell 7, 263-272 (2001).

98 Davies, A. A. et al. Role of BRCA2 in control of the RAD51 recombination and DNA repair protein. Mol Cell 7, 273-282 (2001).

99 Chen, P. L. et al. The BRC repeats in BRCA2 are critical for RAD51 binding and resistance to methyl methanesulfonate treatment. Proc Natl Acad Sci U S A 95, 5287-5292 (1998).

100 Chen, J. et al. Stable interaction between the products of the BRCA1 and BRCA2 tumor suppressor genes in mitotic and meiotic cells. Mol Cell 2, 317328 (1998).

101 Couch, F. J. et al. BRCA2 germline mutations in male breast cancer cases and breast cancer families. Nat Genet 13, 123-125, doi:10.1038/ng0596-123 (1996).

102 Wooster, R. et al. Identification of the breast cancer susceptibility gene BRCA2. Nature 378, 789-792, doi:10.1038/378789a0 (1995).

103 Gaymes, T. J., Mohamedali, A., Eiliazadeh, A. L., Darling, D. \& Mufti, G. J. FLT3 and JAK2 Mutations in Acute Myeloid Leukemia Promote Interchromosomal Homologous Recombination and the Potential for Copy Neutral Loss of Heterozygosity. Cancer Res 77, 1697-1708, doi:10.1158/0008-5472.CAN-161678 (2017).

104 Moloney, J. N., Stanicka, J. \& Cotter, T. G. Subcellular localization of the FLT3ITD oncogene plays a significant role in the production of NOX- and p22(phox)-derived reactive oxygen species in acute myeloid leukemia. Leuk Res 52, 34-42, doi:10.1016/j.leukres.2016.11.006 (2017).

105 Mupo, A. et al. A powerful molecular synergy between mutant Nucleophosmin and Flt3-ITD drives acute myeloid leukemia in mice. Leukemia 27, 1917-1920, doi:10.1038/leu.2013.77 (2013).

106 Dai, Z. et al. edgeR: a versatile tool for the analysis of shRNA-seq and CRISPRCas9 genetic screens. F1000Res 3, 95, doi:10.12688/f1000research.3928.2 (2014).

107 Loeb, L. A. \& Monnat, R. J., Jr. DNA polymerases and human disease. Nat Rev Genet 9, 594-604, doi:10.1038/nrg2345 (2008).

108 Lange, S. S., Takata, K. \& Wood, R. D. DNA polymerases and cancer. Nat Rev Cancer 11, 96-110, doi:10.1038/nrc2998 (2011). 
109 Hubscher, U., Maga, G. \& Spadari, S. Eukaryotic DNA polymerases. Annu Rev Biochem 71, 133-163, doi:10.1146/annurev.biochem.71.090501.150041 (2002).

110 Zeman, M. K. \& Cimprich, K. A. Causes and consequences of replication stress. Nat Cell Biol 16, 2-9, doi:10.1038/ncb2897 (2014).

111 Marechal, A. \& Zou, L. DNA damage sensing by the ATM and ATR kinases. Cold Spring Harb Perspect Biol 5, doi:10.1101/cshperspect.a012716 (2013).

112 Magdalou, I., Lopez, B. S., Pasero, P. \& Lambert, S. A. The causes of replication stress and their consequences on genome stability and cell fate. Semin Cell Dev Biol 30, 154-164, doi:10.1016/j.semcdb.2014.04.035 (2014).

113 Seedhouse, C. H. et al. DNA repair contributes to the drug-resistant phenotype of primary acute myeloid leukaemia cells with FLT3 internal tandem duplications and is reversed by the FLT3 inhibitor PKC412. Leukemia 20, 2130-2136, doi:10.1038/sj.leu.2404439 (2006).

114 Kang, M. A., So, E. Y., Simons, A. L., Spitz, D. R. \& Ouchi, T. DNA damage induces reactive oxygen species generation through the H2AX-Nox1/Rac1 pathway. Cell Death Dis 3, e249, doi:10.1038/cddis.2011.134 (2012).

115 Rundle, S., Bradbury, A., Drew, Y. \& Curtin, N. J. Targeting the ATR-CHK1 Axis in Cancer Therapy. Cancers (Basel) 9, doi:10.3390/cancers9050041 (2017).

116 Shih, A. H. et al. Mutational cooperativity linked to combinatorial epigenetic gain of function in acute myeloid leukemia. Cancer Cell 27, 502-515, doi:10.1016/j.ccell.2015.03.009 (2015).

117 Jayavelu, A. K., Moloney, J. N., Bohmer, F. D. \& Cotter, T. G. NOX-driven ROS formation in cell transformation of FLT3-ITD-positive AML. Exp Hematol 44, 1113-1122, doi:10.1016/j.exphem.2016.08.008 (2016).

118 Li, L. et al. Knock-in of an internal tandem duplication mutation into murine FLT3 confers myeloproliferative disease in a mouse model. Blood 111, 38493858, doi:10.1182/blood-2007-08-109942 (2008).

119 Mallardo, M. et al. NPMc+ and FLT3_ITD mutations cooperate in inducing acute leukaemia in a novel mouse model. Leukemia 27, 2248-2251, doi:10.1038/leu.2013.114 (2013).

120 Behrens, K. et al. RUNX1 cooperates with FLT3-ITD to induce leukemia. J Exp Med 214, 737-752, doi:10.1084/jem.20160927 (2017).

121 Meyer, S. E. et al. DNMT3A Haploinsufficiency Transforms FLT3ITD Myeloproliferative Disease into a Rapid, Spontaneous, and Fully Penetrant Acute Myeloid Leukemia. Cancer Discov 6, 501-515, doi:10.1158/21598290.CD-16-0008 (2016).

122 Yang, L. et al. DNMT3A Loss Drives Enhancer Hypomethylation in FLT3-ITDAssociated Leukemias. Cancer Cell 29, 922-934, doi:10.1016/j.ccell.2016.05.003 (2016). 